\title{
Interference of mobile phones with electrophysiology and emotions
}

Citation for published version (APA):

Roggeveen, S. (2018). Interference of mobile phones with electrophysiology and emotions: results from short-term experimental studies. [Doctoral Thesis, Maastricht University]. Maastricht University. https://doi.org/10.26481/dis.20180302sr

Document status and date:

Published: 01/01/2018

DOI:

10.26481/dis.20180302sr

Document Version:

Publisher's PDF, also known as Version of record

\section{Please check the document version of this publication:}

- A submitted manuscript is the version of the article upon submission and before peer-review. There can be important differences between the submitted version and the official published version of record.

People interested in the research are advised to contact the author for the final version of the publication, or visit the DOI to the publisher's website.

- The final author version and the galley proof are versions of the publication after peer review.

- The final published version features the final layout of the paper including the volume, issue and page numbers.

Link to publication

\footnotetext{
General rights rights.

- You may freely distribute the URL identifying the publication in the public portal. please follow below link for the End User Agreement:

www.umlib.nl/taverne-license

Take down policy

If you believe that this document breaches copyright please contact us at:

repository@maastrichtuniversity.nl

providing details and we will investigate your claim.
}

Copyright and moral rights for the publications made accessible in the public portal are retained by the authors and/or other copyright owners and it is a condition of accessing publications that users recognise and abide by the legal requirements associated with these

- Users may download and print one copy of any publication from the public portal for the purpose of private study or research.

- You may not further distribute the material or use it for any profit-making activity or commercial gain

If the publication is distributed under the terms of Article $25 \mathrm{fa}$ of the Dutch Copyright Act, indicated by the "Taverne" license above, 
INTERFERENCE OF MOBILE PHONES WITH ELECTROPHYSIOLOGY AND EMOTIONS Results from short-term experimental studies 
ISBN: 978-94-92679-32-1

NUR: 100

Illustration cover by Jenna Arts

Layout and printing: Print Service Ede

(C) Suzanne Roggeveen, Groningen 2017. All rights are reserved. No part of this thesis may be reproduced, distributed, or transmitted in any form or by any means without the prior written permission of the author. 


\section{Interference of mobile phones with electrophysiology and emotions}

Results from short-term experimental studies

\section{PROEFSCHRIFT}

Ter verkrijging van de graad van doctor aan de Universiteit Maastricht op gezag van de Rector Magnificus

Prof. dr. Rianne M. Letschert

volgens het besluit van het College van Decanen in het openbaar te verdedigen op vrijdag 2 maart 2018 om 10.00 uur

door

Suzanne Roggeveen

Geboren op 17 december 1987 te IJmuiden 


\section{Promotor}

Prof. dr. Jim van Os

\section{Copromotor}

Dr. Richel Lousberg

\section{Beoordelingscommissie}

Prof. dr. Philippe Delespaul (voorzitter)

Prof. dr. Jan van den Bout (Universiteit Utrecht)

Prof. dr. ir. Hermie Hermens (Universiteit Twente)

Dr. Ellen Jongen

\section{Paranimfen}

Karlijn Cornel

Susanne van Voorst Vader

The research presented in this thesis was performed at the School for Mental Health \& Neuroscience (MHeNS), department of Psychiatry \& Psychology, Maastricht University, the Netherlands. 
Voor Kees en Anke 



\section{Contents}

CHAPTER 1 General introduction

CHAPTER 2 Effects of mobile phone radiation on heart rate:

a radiation-detector controlled pilot study

CHAPTER 3 EEG changes due to experimentally induced 3G mobile phone radiation

CHAPTER 4 Does the brain detect $3 G$ mobile phone radiation peaks?

An explorative in-depth analysis of an experimental study

CHAPTER 5 The brain exposed to remote controlled alternating mobile phone conditions: what happens to EEG?

CHAPTER 6 Does mobile phone use impact mental state?

A pilot study using the experience sampling method

CHAPTER 7 General discussion

Valorization

Curriculum Vitae

List of publications

Dankwoord

References 

General introduction 



\section{Background of the mobile phone}

'We won!' shouted the Greek soldier Pheidippides in 490 BC after he had run nonstop from the battlefield of Marathon to Athens. According to legend, after delivering the message to the people of Athens, Pheidippides collapsed and died. In those days, quickly sending a message over a large distance was not easy, not without apparent danger to the messenger's health or life! Communication is an essential part of (human) life, and thus, many studies and experiments have been conducted to develop easier ways of sending a message from one place to another. After centuries of mainly direct verbal, nonverbal and written communication, Scottish inventor Alexander Graham Bell patented the telephone in 1876. It was the first device which enabled people to speak to each other across large distances. Appropriately enough, the word telephone originates from the Greek language:

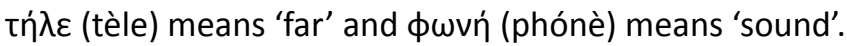

The traditional telephone was (and is) physically connected to the telephone network with the use of wires. Soon, the need for a portable phone arose so that people could talk to others from anywhere. The first mobile phone call with an apparatus which is comparable to what is now known as the mobile phone was made in 1973. Martin Cooper, a Motorola researcher and executive, walked down a New York street while talking on the phone. This device weighed about one kilogram and was given the nickname 'the brick' (1). Subsequently, mobile phones developed rapidly, and in 2015, there were more than seven billion mobile phone subscriptions worldwide (2). From 2001 to 2015, the proportion of the world population covered by the second generation (2G) mobile network grew from $58 \%$ to $95 \%$. Additionally, broadband networks (third generation [3G] or above) now reach $84 \%$ of the global population (3).

Parallel to this expansion, the application of radiofrequency electromagnetic fields (RFEMF) increased; this was necessary to make the increased mobile phone traffic possible. RF-EMF will be mentioned several times in this thesis. Some background information on this physical phenomenon by which mobile phones function is provided here.

In 1865, another Scot, James Clerk Maxwell, described the electromagnetic theory for the first time in 'A dynamical theory of the electromagnetic field' (4). He demonstrated that electric

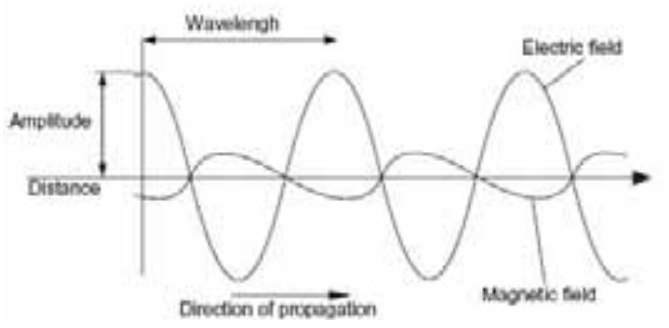
and magnetic fields travel through space in the form of waves at the constant speed of light in a vacuum. An electromagnetic field is a field in which electric current flows and is measured in amperes per meter $(A / m)$. It extends indefinitely throughout space and is one of the four fundamental forces of nature. A particular form of the more general electromagnetic field is electromagnetic radiation (EMR); it can be defined as a form of energy (photons) that is emitted and absorbed by charged particles and that travels 
through material or through space in a wave-like form. EMR is classified by the frequency of its waves. The wavelength varies from very short waves which are smaller than atom nuclei to long waves that are comparable to the size of buildings. The following types of EMR can be approximately distinguished in order of increasing frequency and decreasing wavelength: radio waves, microwaves, infrared radiation, visible light, ultraviolet radiation, $\mathrm{X}$-rays and gamma rays.

The frequency of EMR determines its behaviour. Lower frequencies have longer wavelengths and higher frequencies have shorter wavelengths. According to the formula (where = energy, = Planck's constant, = frequency of the wave, is wavelength and = the speed of light), high frequency/short wavelength types of radiation are associated with photons of higher energy. When EMR interacts with matter, its frequency changes and electric currents are spread out over the affected atoms. In electrical conductors, such as the antennas of a mobile phone, EMR is absorbed. These interactions produce electric currents, heat or both. At the high end of the ultraviolet range, the photon energy becomes large enough to part electrons from the atom ( $\mathrm{E}>10 \mathrm{eV}$ and $<124 \mathrm{~nm}, 33 \mathrm{eV}$ is needed to ionize a water molecule). This process is called photo-ionization. EMR with these and smaller wavelengths are called ionizing radiation. Note that there are also other kinds of ionizing radiation made from nonelectromagnetic particles.

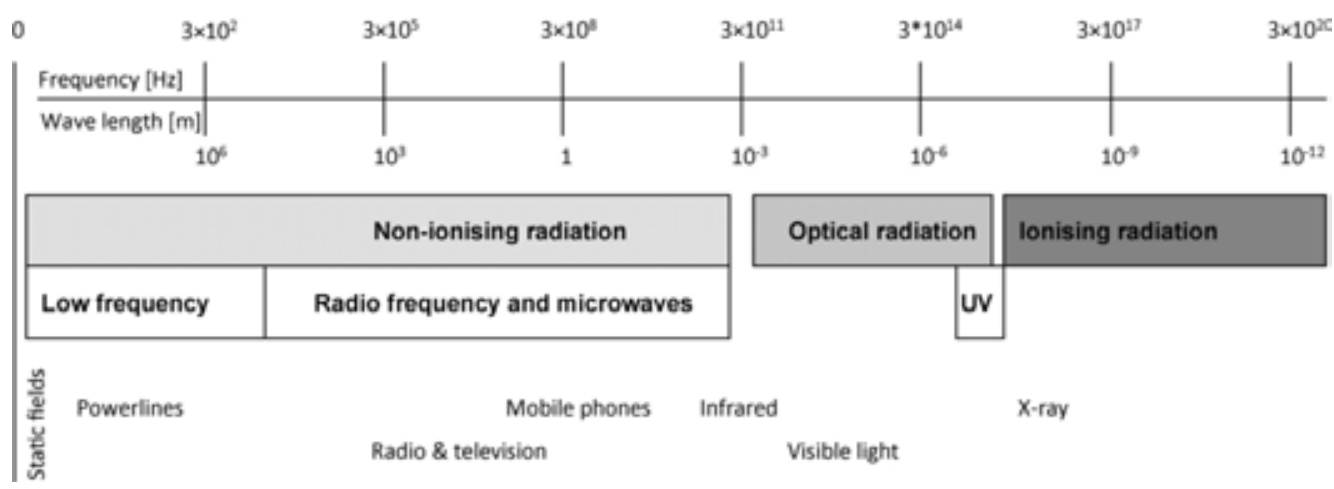

Figure 1. EMF spectrum (adapted from Schuz et al. (5))

In the mobile phone radiation literature, EMR is classified as RF-EMF, although mobile phones radiate both in the radio frequency as well as in the microwave range. At first, mobile phones used an analogue system for dialling. After generation zero (OG) and the first generation (1G) of mobile phone technology, the digital second generation (2G) technology, which worked more efficiently, came along. Most of these networks operated in the 900 or $1800 \mathrm{MHz}$ band. 
Next, 3G was developed. Unlike 2G, 3 G transmits data in megabytes per second instead of kilobytes per second, which makes it easier to use for multimedia purposes. Most $3 G$ networks in Europe operate in the $2100 \mathrm{MHz}$ frequency band. 4G is able to transmit more data compared to 3G. The frequency bands in which it operates are those of $800 \mathrm{MHz}$, $1800 \mathrm{MHz}$ and $2600 \mathrm{MHz}$. The fifth generation is being developed and used as well, but it is not being used by the general public yet. It is projected to be available by 2025 .

The energy of RF-EMF produced by mobile phones is absorbed by human tissue. The rate at which energy is absorbed per unit of biological tissue is denoted by the 'specific absorption rate' (SAR) in watts per kilogram $(\mathrm{W} / \mathrm{kg})$. The SAR value is different for every mobile phone. For EMR up to $10 \mathrm{GHz}$ and averaged over a six-minute period, the International Commission on Non-Ionizing Radiation Protection has recommended a SARlimit of $0.08 \mathrm{~W} / \mathrm{kg}$ average for the entire body and a SAR-limit of $2 \mathrm{~W} / \mathrm{kg}$ average for the head (6). These values are maintained by many European countries, but some countries, like the United States, maintain lower values. In some countries, like Germany and France, the government advises the public on how to use a mobile phone, whereas in other countries, the government does not. This advice most often contains the message that (young) children should not be exposed to mobile phones. There is no consent about whether or not preventive measures should be taken or what the best preventive measures are.

\section{Concerns about health}

After the invention of the mobile phone, which matched the need for a portable far distance communication tool, and the development of many applications for this device, critical voices have been raised about its possible side effects: Are there, like there was for Pheidippides in ancient times, health risks inherent to this modern method of communication?

The question is why critical voices arose regarding the seemingly innocent act of making a phone call. As mentioned before, several types of radiation exist. Natural background radiation is a phenomenon everybody is exposed to: cosmic rays are present everywhere, and there is natural radioactivity in food. In general, we cannot sense radiation: it cannot be seen, felt, heard, smelled or tasted. However, after 1945, when Little Boy and Fat Man, the atomic bombs which were dropped on Hiroshima and Nagasaki, the health effects of ionizing radiation became painfully visible. In the years after 26 April 1986, when the Chernobyl disaster - which was considered to be the worst nuclear power plant accident in history took place, the world was again confronted with the destructive power of extremely high doses of ionizing radiation. Unfortunately, a comparable accident (the only other disaster to measure level 7 on the International Nuclear Event Scale (7)) happened recently in 2011, when the nuclear power plant in Fukushima was affected after the Tohoku earthquake and tsunami. Ionizing radiation in these doses led to proven direct DNA interactions or to genetic lesions due to the formation of highly reactive free radicals. Ionizing radiation is 
most likely to induce DNA strand breaks. Because of these strand breaks, chromosomal rearrangements like deletions, additions, translocations and inversions can develop. Cell death or DNA repair can make these rearrangements disappear, but they can also lead to malignant transformations (8). The more common form of ionizing radiation, used in daily medical practice, is the X-ray. Nevertheless, this type of radiation also increases the risk of developmental problems and cancer. In particular, long-term exposure increases this risk (9). In conclusion, the harmful effect of ionizing radiation is generally acknowledged.

The exact point where nonionizing radiation (NIR) becomes ionizing is debated. The energy of radiation particles is said to be greater than the ionization energy (the amount of energy required to remove an electron from that atom or molecule) of the target material. The atom becomes ionized (or charged) when it collides with ionizing radiation. This sounds straightforward, but there are difficulties with this explanation. One difficulty is that targets are rarely composed of one type of atom. Another difficulty pertains to the fact that sometimes only part of the energy is transferred to the target. A third difficulty is that the probability of photo-ionization increases in a long exposure scenario. Therefore, the term ionizing radiation is elastic, and it cannot be definitively stated that the process of photo-ionizing starts from wavelengths of a certain length, because this depends on several factors. Once it was acknowledged that this explanation, which offered a more or less dichotomous distinction, was not so straightforward, doubts about the innocence of radiation characterized by lower wavelengths were expressed, and the line of investigation on this topic had to be broadened.

The expansion of radiation research resulted in experiments with ultraviolet light, the direct adjacent spectral region (between 180 and $400 \mathrm{~nm}$ ) to ionizing radiation. In the 1970s, it had already been shown that a certain dose of ultraviolet radiation is associated with painful eyes, skin burns, skin aging and even skin cancer (10).

Types of radiation that are clearly below the so-called 'ionizing threshold' are called NIR. NIR can originate from various sources, from natural sources (e.g. sunlight) to man-made (e.g. mobile phones) ones (11). NIR is roughly divided into four regions: static electric and magnetic fields $(0 \mathrm{~Hz}$ ); extremely low frequency fields (> $0 \mathrm{~Hz}$ to $300 \mathrm{~Hz}$ ); radiofrequency and microwave radiation ( $300 \mathrm{~Hz}$ to $300 \mathrm{GHz}$ ); and optical types of radiation, containing infrared (760 - $10 \mathrm{~nm})$, visible light $(400-760 \mathrm{~nm})$ and ultraviolet $(100-400 \mathrm{~nm})(6,11)$.

Like ionizing radiation, NIR is able to heat material. This heating causes electrons to move towards a higher energy state. This process, called excitation, brings the target material closer to its ionizing temperature. The heating effect of biological tissues by RF radiation is referred to as the 'thermal effect'. A temperature change is usually well regulated in the body. It is not clear to what extent RF radiation is tolerated without subsequent adverse health effects. In addition to thermal effects, 'nonthermal effects' might also exist. Nonthermal effects refer to the direct and indirect possible effects of absorbed energy 
inside biological tissue. However, there is no general understanding of the underlying mechanisms or processes that take place in the cells $(11,12)$.

In sum: ionizing radiation leads to the indisputable impairment of health. It is also clear that NIR is associated with biological effects (heating). However, it is still uncertain whether NIR (besides ultraviolet radiation) also causes adverse health effects.

The paragraph above mainly focused on the obvious adverse health effects of radiation. However, it should be noted that, despite these disturbing effects, the application of radiation can still be valuable in, for example, health care. Some examples of its use are the aforementioned X-rays as well as CT scans, laser utilities and radiotherapy (e.g. to bring carcinogenic processes to a halt).

\section{Research investigating the effects of mobile phone radiation}

The previous section ended with the unresolved issue of whether or not the broad spectrum of NIR may lead to adverse health effects. Research on the effects of mobile phones involves the more restricted range of RF radiation. As mentioned earlier, the biological effects of this type of radiation have been proven (13). It is important to note that biological effects do not necessarily lead to adverse health effects. RF radiation is produced by a large variety of sources, such as wireless networks, electricity pylons, radio and television broadcasting, pagers, satellite communication, radars, and microwaves. Additionally, the amount of RF radiation produced by mobile phones is increasing every day. It is important to find out how this constant, expanding exposure interacts with the human body and whether prolonged $\mathrm{RF}$ radiation exposure may result in (negative) health effects. Special interest in mobile phone research is justified, since a mobile phone is mostly carried on, and kept close, to the body, enabling optimal energy transfer. This probably explains the increasing number of publications on the effects of mobile phone radiation on several human systems.

To explore the research field, in the following section, a short overview will be given of the (hypothesized) general effects of mobile phone radiation on humans; the research conducted on carcinogenesis, infertility, electrophysiological research and behavioural and psychological research; and the effects of mobile phone radiation on children.

\section{General effects on human body}

Possible interactions between RF-EMF and molecules in biological systems are thought to take place once radiation is absorbed. This is why the above-mentioned SAR value was developed. However, the SAR value is difficult to determine when a diversity of factors is involved. The energy transfer, for example, depends on the composition of the human body and tissue, which is different for each individual. The SAR value of a certain mobile phone can best be interpreted as an indication of absorbed energy, and its value can be compared with other mobile phones. The well-known thermal effect is explained by dielectric heating. 
The dielectric material (i.e. human tissue) heats up as a result of polar molecule rotations induced by the electromagnetic field. The body is able to deal with this type of heating, but the eyes are an exception, since they do not have a temperature-regulating mechanism and can thus be damaged by very high doses of RF radiation. An illustrative example is the formation of cataracts in rabbits (14).

Besides this thermal effect, which is assumed to cause no harm, nonthermal effects are also suspected to exist $(12,15-23)$. In short, the nonthermal effects of NIR are thought to act as a trigger for cellular stress response and other protein changes due to reactive oxygen species, which could lead to DNA altering or change in tissue permeability. Further, other hypotheses exist for nonthermal effects, but this theory and several mechanisms within this theory have been described most frequently in the literature. To draw more definite conclusions about the nonthermal effects, however, more research is needed. It is important to note that thus far, no generally accepted mechanism for nonthermal effects exists.

\section{Carcinogenesis research}

A major concern is the possibility that RF-EMF is involved in the development of cancer. In addition to studies investigating the above-mentioned theories about how DNA damage can occur, a lot of epidemiological research has been conducted to investigate whether there is a causal relationship between the incidence of (brain) tumours and mobile phone use. The largest project to investigate this matter was carried out by the INTERPHONE Study Group. In this project, 13 countries used the same protocol to investigate whether glioma, meningioma and acoustic neuronoma were associated with mobile phone use (24, 25). An association could not be demonstrated when all exposure levels were included. However, there was an indication of an increased risk of glioma at the highest exposure levels. Other studies did not find evidence for increased brain tumour risk due to mobile phone use at all (26-29). At the same time, there have also been studies which reported an association between long-term mobile phone use and the development of brain tumours (30-33). An increased risk of acoustic neuroma (benign tumour) has been found for people using a mobile phone for more than 10 years (34). Another observation has been made that mobile phone users are more likely to develop a tumour on the 'dialling side' of the head (30).

Some critical notes with regard to the aforementioned studies are that their data do not give insight into long-lasting exposure (not longer than approximately 12 years). The patients in the studies were generally not exposed to mobile phones during childhood, and the mobile phone network and technology were different from the networks (3G and 4G) and technology currently in use. 


\section{Infertility and its effects on offspring - Research}

An important part of mobile phone research is the effect of mobile phones on the reproductive system. Infertility is a worldwide problem which is associated with several environmental factors (35). Since many people tend to keep their standby mobile phone in their pocket, relatively close to the reproductive organs, the hypothetical link is plausible. Several animal studies using similar designs have been conducted with rats, mice and rabbits. A recent review has shown that sperm count and mobility decreased and oxidative stress increased in exposed rodents compared to control rodents (36). Human studies have focused on RFEMF's effects directly on spermatozoa and on sperm parameters for men by contrasting mobile phone users and nonusers. The effects on spermatozoa were decreased motility, morphometric abnormalities and increased oxidative stress (20, 36-40). These outcomes are robust, and a meta-analysis has confirmed the effects (40). These abnormalities seem directly related to the duration of mobile phone usage. Another important concern is the issue of whether or not mobile phone usage can have prenatal (and postnatal) influences. There have been some indications that exposure leads to an increase in behavioural difficulties in children, although these associations might be due to confounding variables (41).

\section{Electrophysiological research}

To gain further knowledge of the possible effects of mobile phone radiation on human health and to identify neurobiological mechanisms, the interference of radiation with brain activity (a complex electrophysiological network) is being studied.

Electroencephalography (EEG) has been studied under mobile phone exposure in mainly two ways: resting EEG and sleep EEG. When investigating resting EEG, most studies have found rather consistent enhanced alpha activity $(8-12 \mathrm{~Hz})$ due to mobile phone exposure (42-45). However, other studies have not reported such effects $(46,47)$.

Some studies have investigated whether event-related potentials (for example auditory) are processed differently under mobile phone exposure. No consistent findings exist (4850). One study investigated whether or not radiation itself can cause an event-related potential (51), and there were indications that this was indeed the case.

In 2011, a study showed that a 50-minute mobile phone exposure causes increased brain glucose metabolism in the region close to the antenna, which suggests excitability of the brain due to RF-EMF (52).

Furthermore, in studies on rat brains, a leakage of albumin into the brain via a permeated blood-brain barrier has been found, when the brain was exposed to EMR with a SAR value of $0.12 \mathrm{~W} / \mathrm{kg}(53,54)$.

Finally, other electrophysiological measures like heart rate, heart rate variability and skin resistance have shown trends towards change when a subject is exposed to mobile phones. However, no consistently significant changes due to mobile phone exposure were demonstrated in a review (55). 


\section{Behavioural and psychological research}

A lot of studies have been conducted in this, more psychological, area of research. The majority of studies focused on the question of whether or not mobile phone use leads to addiction/abuse. The problem with this type of research is the lack of clear concepts of abuse and addiction in relation to mobile phones. There are numerous instruments for the assessment of these concepts. As a result, there is a large variability in estimated prevalence, ranging from 0-38\% according to a recent review of the literature (56-58). Low self-esteem is the personality trait most associated with addiction (56). Extraversion is associated with more extensive usage. The most commonly associated psychopathological symptom with mobile phone use is depression, and the other symptoms are stress and sleep disturbances $(56,59,60)$.

\section{Research on children}

Although rare, brain tumours are the second most common cancer type among children under the age of 15 (after leukaemia). Although no obvious increased risk of brain tumours have been found for users of mobile phones, most of these studies have been conducted with adults. A very important point is that the investigated adults were not exposed to mobile phones in childhood (when their brains and bodies were developing). Furthermore, because of, among other things, children's thinner skulls, the relative SAR value tends to be higher in children than in adult brain tissue. The age at which people start using a mobile phone is decreasing. Fisher-Price has even designed a 'drool-proof' rattle-iPhone case that allows toddlers to play apps that have been especially developed for this age group.

A recent review concluded that few studies on $\mathrm{RF}$ radiation exposure and its health effects on children have been conducted and that there are methodological limitations to the available studies. This prevents conclusions from being drawn about the causal effects of $\mathrm{RF}$ radiation exposure on health outcomes in children and adolescents (61). It is important to conduct further studies to obtain a more definite conclusion on the possible effects of RF radiation on children. Currently, a major study called MOBI-Kids is investigating the potential effects of childhood and adolescent exposure to EMF from mobile communication on brain tumour risk (62).

\section{Current state of the literature}

Remarkably, many of the research fields mentioned above contain proof of indeed an effect of mobile phones on health and proof of no effect on human health. Why is there no clear evidence yet? The variability in the results probably indicates that there are no large, overt, and evident effects in the short term. Negative health effects like brain tumours do not seem to appear in people after 10 years of intensive usage. Therefore, if there are health effects, they probably become apparent in the long term. Although 20 years sounds like a long period, the omnipresent existence of the mobile phone is a new phenomenon; 
in fact, it is hardly a generation old. During the last 20 years, mobile phone technology has been continuously developing, making it difficult to compare a modern phone to a phone from, for example, 2000. Furthermore, not much longitudinal research on the topic exists. The longitudinal research that has been conducted hitherto has, as test subjects, used adults who did not use a mobile phone when they were children. The generation that use a mobile phone in their first years is yet to grow up. Another methodological, problematic issue is the lack of a good control group/condition in which subjects are not at all exposed to radiation. The final point that needs to be made here, because it can influence research outcomes, is the large percentage of sponsored research by the telecom industry in this field. In a systematic review conducted in 2007, it was found that studies (researching the effects of low-level radiofrequency radiation) funded exclusively by the industry were substantially less likely to report statistically significant effects on a range of end points that may be relevant to health compared to research without any such conflicts of interest (63).

\section{Aims and outline of this thesis}

The ultimate aim of the studies examined in this thesis and of this thesis itself is to gain more insight into the hypothesized effects of a mobile phone in the short term. Many research groups have focused on manifesting undisputed negative health effects such as brain tumours and addictive behaviour. Since these issues remain unresolved thus far, it has been considered opportune to investigate the existence of mobile phone use effects on human physiology and psychology on a more basic level. ECG and EEG are representatives of direct electrical human physiology and are considered to be adequate parameters to subject to mobile phone radiation. To overcome the controversies in mobile phone studies investigating electrophysiological parameters, it is considered worthwhile to contribute to this part of mobile phone research. To investigate an even more precise area of the EEG, this thesis focuses on whether or not a radiation peak can be detected in brain activity in the form of event-related potentials. On a psychological level, the experience sampling method (ESM) is a powerful tool to investigate subtle changes in affect (emotions) in the context of daily life. To our knowledge, the use of this structured diary method in which participants are asked to rate their feelings and circumstances in real time has not been attempted before to evaluate the influence of a mobile phone.

Below, the research question for each chapter is described, and some information on the methodology is given.

Chapter 2 describes the outcome of a pilot study in which one test subject was tested during four sessions. The research question was whether dialling a mobile phone would cause a change in heart rate. Heart rate was measured using an electrode placed on the fifth intercostal space at the mid-clavicular line (V4). Setting up this first experiment involved trial and error. First, a radiation detector was deemed necessary to get insight into the radiation produced by an active mobile phone. Then, a connection between the 
radiation detector and measurement equipment had to be established. Second, it was tested whether mobile phone radiation influenced the test set-up. A test experiment showed that mobile phone radiation did not have a direct effect on the analogue/digital converter of the amplifier. Third, the try-out phase continued with the search for an answer to a series of methodological questions such as the following: Which type of mobile phone should be used? What is the best location for a mobile phone? How to control radiation sources in one's direct surroundings? How long should the exposure last? How to analyse the obtained data?

After the pilot study, the line of research was expanded and continued. In chapters $\mathbf{3}$ and 4, the outcomes of the subsequent study are presented. EEG was added in this study. EEG implies a measurement of cortical electrical activity due to neuronal activity through electrodes placed on the skull. A comparable experimental design to the pilot study was used, but with the following important modifications: a sample size of 31 subjects, two sessions per subject instead of four and placement of the mobile phone on the chest and ear instead of the chest only. Data analysis showed that the detection of ECG characteristics (e.g. R-peaks) with the processing program was not accurate for some subjects. Additionally, a script for a more reliable detection did not result in a satisfactory detection rate. Therefore, only brain activity was used as the effect parameter. In addition to being used to study frequency bands, EEG can also be used to investigate so called 'event-related potentials' (ERP), in which cortical stimulus-processing is investigated. It was hypothesized in the study that a radiation peak (as detected by the radiation detector) can be considered as a stimulus. The question of whether a radiation peak results in a measurable ERP is described in chapter 4.

Since repeatedly measured physiological data are highly correlated, this interrelationship should be corrected. Consequently, an autoregressive covariance structure, modelled within multilevel regression analysis, was applied. Multilevel techniques also took the nested structure of the data into account (physiological data were nested within sessions, days and subjects).

The following questions were investigated:

1 Is EEG activity influenced by the presence of a dialling mobile phone? Based on the literature, an increase in alpha activity $(8-13 \mathrm{~Hz}$, associated with relaxed wakefulness) during exposure was expected.

2 Does the distance from the mobile phone to the brain (placement on the chest compared to placement on the ear) make a difference in the effect on EEG?

3 Does a radiation peak cause an ERP?

In Chapter 5, a third experiment and its outcomes are described. Analyses of the previous experiment showed that entering the experimental room in between mobile phone 
conditions had an effect on the electrophysiological activity of the subject. Entering the experimenting room was found undesirable. After discussing the methodology with others (physicians, technicians and the department's statistician), a 'definite' third experiment was conducted. Exposure to a dialling phone and the control condition was remote controlled and was frequently and randomly alternated. A stronger proof of effect could thus be obtained. The main research question was as follows: Does the power of EEG frequency bands change because of a dialling mobile phone compared to a standby condition?

Chapter 6 addresses a very different area of mobile phone research. First, the relationship between smartphone use and positive/negative affect in daily life situations is addressed. The connection between this study and the previous one is the assessment of short-term and subtle, not directly visible, effects. In the three months during which the experiment was conducted, two healthy test subjects who did not consider their phone use to be problematic participated. In this study, ESM was applied: the subjects were asked 10 times per day to record their present emotional and behavioural state using a mobile phone application. The central research question was whether increased phone usage is accompanied by higher scores on negative affect, lower levels of positive affect, and lower levels of concentration.

Chapter 7 contains a general critical retrospect on the studies mentioned above. Additionally, notes on how these studies should be placed within the research field and future directions with respect to mobile phone research will be explored. 



\section{Effects of mobile phone radiation on heart rate: a radiation-detector controlled pilot study}

Suzanne Roggeveen

Jim van Os

Johan Gielissen

Ron Mengelers

Klaus Golombeck

Richel Lousberg

PeerJ PrePrints 2 (2014): e485v1. 


\section{ABSTRACT}

Objectives: To investigate to what degree radiofrequency electromagnetic radiation, induced by a mobile phone placed on the chest, impacts cardiac rhythm.

Design: $n=1$, single blinded pilot study.

Setting: Academic hospital, Maastricht, the Netherlands.

Participants: One healthy female 24 years old participant.

Interventions: The participant underwent four experimental sessions, spread over four days. A session consisted of four consecutive minute conditions, three with a sham phone and one with a dialing mobile phone. The participant was blind for the condition. During each condition, per-millisecond electrocardiac activity (lead V4) and radiofrequency radiation was recorded jointly.

Primary outcome measures: Heart rate. The association with radiation was analysed at two levels, (i) at macrolevel, based on averaged condition effects, and (ii) at microlevel, focusing on radiation peak-related effects within the exposure condition.

Results: The macrolevel analysis clearly indicated that heart rate was lowered during the radiation exposure condition. The heart rate during the preceding and subsequent sham phone condition was respectively 1.014 beats/minute $(p<0.001)$ and 1.009 beats/minute ( $p<0.001$ ) higher compared to the radiation exposure condition. In order to conduct radiation-detector controlled microlevel analyses, 142 critical segments were identified, in which a radiation-free period was followed by a radiation peak. The heart rate during the radiation-free period showed a mean increase, whereas the radiation peak period was associated with a mean decrease in heart rate (time*period interaction: $p=0.001$ ). Thus, the macrolevel finding was confirmed at microlevel.

Conclusions: Mobile phone radiation may impact heart rate, suggesting urgent further study to assess physiological safety parameters. 


\section{INTRODUCTION}

The number of mobile phones and the amount of mobile phone usage has expanded massively in the last decennium. In 2011 there were 5.9 billion mobile phone subscriptions, whilst about 16.7 billion text messages were sent each day in 2010 (64). In addition to the basic phone function, many other functions have been developed, transforming mobile phones into multimedia devices. For young people, mobile phones have become an integrated part of everyday behavioural interactions. A less conspicuous statistic, showing a parallel increase, is the level of exposure to radiofrequency electromagnetic fields (RFEMF), necessary for mobile phone connections, particularly in densely populated countries. The electromagnetic field is classified according to wavelengths. It contains the following varieties of radiation: ionizing radiation, ultraviolet, visible light, infrared, radiofrequency (10 kHz-300 GHz, mobile phones are within this range) and extremely low frequencies. For ionizing radiation, the photon energy is large enough to knock out electrons from atoms and molecules. It is acknowledged that ionizing radiation leads to cellular damage in biological tissue. Lower frequencies of the electromagnetic spectrum are called 'nonionizing radiation'. There is debate to what degree non-ionizing radiation may also induce biological changes. It has been demonstrated that electromagnetic fields from $100 \mathrm{kHz}$ and higher cause a thermal, heating effect (13). Apart from thermal effects, mobile phone use may also induce non-thermal effects. Non-thermal effects refer to the possible direct and indirect effects of absorbed energy inside biological tissue. However, how these may be mediated at cellular level remains unclear (12).

For thermal effects, the rate at which energy is absorbed per unit of biological tissue is known as the 'specific absorption rate' (SAR), expressed in watts per kilogram (W/kg). The International Commission on Non-Ionizing Radiation Protection has recommended a SAR-limit of $0.08 \mathrm{~W} / \mathrm{kg}$ average for the entire body and a SAR-limit of $2 \mathrm{~W} / \mathrm{kg}$ average for the head. For electromagnetic radiation up to $10 \mathrm{GHz}$, the localized SAR averaging mass is any 10 grams of contiguous tissue, averaged over a 6 minute period (6). These values are maintained by several countries, but substantial differences exist between countries in public recommendations in relation to mobile phone use.

As opposed to RF-EMF producing devices such as televisions and microwaves, the radiation caused by a mobile phone may be more invasive, as direct body contact with a mobile phone is the norm and the radiation the device emits is practically inescapable. In recent years, intense use of mobile phones has raised concerns about possible adverse health effects. The number of studies on this topic is increasing rapidly, with a primary focus on pathological effects, such as hypothesized carcinogenesis and infertility. However, despite the large body of work, results remain largely inconclusive due to contradictory findings. A possible explanation is that mobile phone radiation may not produce harmful health effects in the short term. However, possible adverse health effects, particularly 
in the long-term, cannot be entirely discarded. In addition, the field is rife with possible conflicting interests (63).

Within the broad spectrum of mobile phone radiation research, effects on electrophysiological functioning have also been examined. Although a large number of studies exist on the effects on electroencephalography, relatively few studies have been performed to investigate the possible cardiovascular effects of RF-EMF. Given that the heart is a vital organ, the functions of which are subserved by electrically excitable tissue, more research is required to unequivocally assess its susceptibility to RF-EMF, particularly given the fact that phones often are carried in proximity to the heart. The hypothesis that RF-EMF has systemic effects on the autonomic nervous system has been voiced frequently (65-69), however the majority of studies investigating RF-EMF effects on heart rate (HR) showed non-significant results $(66,68-78)$. Nevertheless, an animal study as well as experiments on human subjects show a strong tendency towards lowering of the HR under RF-EMF exposure $(55,79,80)$.

An important source of variability between studies concerns the use of different exposure methods. Whereas some studies use a continuously radiating module or a computercontrolled cellular phone $(68-70,74-76,78,80)$, other studies use a regular mobile phone. Although a module may be preferred to exactly control the radiation exposure, it may not represent an accurate simulation of reality. To our knowledge, no studies have investigated a direct relationship between a radiation peak and the immediate subsequent change in cardiac function. In addition, effect analyses are regularly based on averaged radiation (condition) effects, whereas it may be argued that a more fundamental and important question is to what degree radiation peaks (caused by a mobile phone) impact on subsequent electrocardiac activity. A further issue is that consecutive heart rate values are strongly interdependent. In the analysis, this interdependency should be taken into account.

A pilot study was set up to test the hypothesis whether radiation, induced by a mobile phone, causes a decrease in heart rate. In addition to the standard 'macrolevel' analysis (based on averaged condition effects), analyses were also carried out at 'microlevel' (i.e. radiation peak-related effects), taking into account interdependency among observations. This study was also intended to trial a new procedure for a larger programme of research.

\section{MATERIALS AND METHODS}

\section{Participant}

The participant was a 24-year old healthy female, non-smoking, with a BMI of 21.7. The ECG was regular and there was no history of cardiac or nervous system disorders.

The participant had used a mobile phone in the previous 9 years and had been using a 
smart-phone over the last 10 months, with approximately 1 hour of mobile phone usage per day.

On experimental days, no caffeine-containing beverages were used 3 hours before the start of the session. No alcohol was used during the 12 previous hours. At least 8 hours of sleep were ensured and care was taken that the participant's private mobile phone was switched off the night before each experimental session.

\section{Experimental procedures}

The pilot study consisted of four sessions, each session taking place on a separate day. At each session, an ECG was administered using three electrodes: the first, lead V4, was placed in the fifth intercostal space at the mid-clavicular line, the second electrode was placed on the manubrium as a reference and the third ground-electrode was placed in the abdominal region on the right hand side. The electrodes were connected to a BrainAmp ExG amplifier (Brain Products). Both ECG- and radiation data were sampled with $1000 \mathrm{~Hz}$ using Brain Vision Recorder software. As per the schedule shown in table 1, the participant was exposed to four consecutive conditions during each session: three with a sham phone, and one with a dialing mobile phone. In order to ensure blinding, the order of the conditions was variable and unknown to the participant, with two days during which the 'dialing' condition was second, and two days during which the 'dialing' condition was third. The experimenter changed the telephone every 15 minutes as per the schedule in table 1 . At the end of each 15 minute condition, the experimenter entered the experimenting room to change the telephone according to the schedule in table 1 . In the case of two consecutive sham phone conditions, the same procedure was followed.

The telephone characteristics were as follows:

- A 'smartphone' was used. During exposure conditions, the phone was dialled from a fixed line in another room. No sound was exchanged (mute settings), in order to ensure that the participant could not identify the dialing condition.

- The frequency band was a combination of GPRS (general packet radio service, including the Global System for Mobile communication GSM) and UMTS (Universal Mobile Telecommunications System) - the default setting the phone. These bands operate in the following frequencies: GSM: $800-900 \mathrm{MHz}$ and 1.8-1.9 GHz and UMTS: $1.9-2.2 \mathrm{GHz}$.

- The SAR level was $0.353 \mathrm{~W} / \mathrm{kg}(81)$.

- The sham phone was a non-functioning replica, of the same weight and the same characteristics as the smartphone.

As described in the introduction, a real mobile phone was used as inductor of RF-EMF. The timing of radiation-peaks was detected with a radiation detector (type: HF59B, Gigahertz Solutions), connected to an omnidirectional antenna. This detector was connected from 
the DC output with an auxiliary plug to the ExG-amplifier. The detector was placed in the upright position, $30 \mathrm{~cm}$ above the table (at which the participant was sitting) and $20 \mathrm{~cm}$ left from the participant. The phone was placed adjacent to the left side of the sternum, bordering the sternoclavicular joint at the caudal side, thus ensuring that there was no contact between the phone and the V4 lead. Previous testing experiments showed that there was no direct disturbing interference of the mobile phone impacting on either the V4 electrode or the amplifier (tested with a shielded and non-shielded electrode). The backside of the phone was placed on the skin. The phone was fixed using an elastic band. In order to maintain the participant's alertness and to guarantee a relatively stable mood, she read affectively neutral sections of a book during the experiment. All experimental sessions were carried out in the afternoon.

\begin{tabular}{lllll}
\hline & $\mathbf{1 5}$ minutes & $\mathbf{1 5}$ minutes & $\mathbf{1 5}$ minutes & $\mathbf{1 5}$ minutes \\
\hline Day $\mathbf{1}$ and $\mathbf{4}$ & Pre-exposure & Exposure & Post-exposure & Not used \\
Day 2 and 3 & Not used & Pre-exposure & Exposure & Post-exposure \\
\hline
\end{tabular}

Table 1 Experimental design. The sequence was randomly defined by the experimenter to ensure blinding of the participant. In conditions labelled as 'not used', an identical sham telephone was placed in the same way as in the preand post-exposure conditions.

\section{ECG analysis}

ECG data were analysed offline with the software program Brain Vision Analyser 2.0. Data were filtered using a high cut-off filter of $40 \mathrm{~Hz}$ and a low cut-off filter of $0.5 \mathrm{~Hz}$. R-peaks were detected by the program and manually checked. The SPSS dataset was constructed in such a way that each record contained one heartbeat (amplitude measured in microvolts and time measured in milliseconds), including the following related variables: (i) heart rate, estimated as the difference in milliseconds with the previous heartbeat and (ii) radiation intensity, calculated as the sum of radiation values over the previous thousand milliseconds.

\section{Statistical analysis}

Analyses were split into macro- and microlevel analyses, in which 'macro' refers to averaged condition effects (comparing pre-exposure (PRE), exposure (EXP) and post-exposure (POST)), and 'micro' refers to radiation peak-related electrophysiological effects.

\section{Macrolevel analysis}

A linear regression was used to compare the averaged condition effects. The dependent variable was the log10-transformed heart rate (log-HR). This transformation was performed 
because of a positively skewed distribution. The categorical condition variable (PRE, EXP and POST) was recoded into two dummy variables which were used as predictor variables. As mentioned in the introduction, consecutive heart rate values are strongly interdependent. A time series analysis was performed to adjust for autocorrelation and to check whether the macrolevel effect of the linear regression would remain significant. Thus, a time series model, using an ARIMA structure with 10 lags of autocorrelation, with the two condition predictor variables, was carried out.

\section{Microlevel analyses}

Case-control radiation peak finding within EXP: For this analysis, radiation information was used. A mobile telephone does not produce and receive radiation continuously. In this analysis, radiation peaks within EXP were detected. In order to achieve this goal, a dichotomous radiation-peak-variable was computed. Within the exposure condition the radiation level of all records were recoded into a ' 0 ' or a ' 1 '. A value of ' 0 ' represented a relatively low radiation level, a value of ' 1 ' a radiation peak. The cut-off point for ' 0 ' was a value lower than the mean radiation level (of all records) plus half a standard deviation. Higher radiation levels were recoded into a ' 1 '. Identification of case-control elements was based on the finding of '0011' patterns, in which'00' stands for two consecutive 'nonradiated' records, immediately followed by two '11' peak-radiated records (see Figure. 1). This pattern was found 142 times over the four exposure sessions.

For the statistical analysis, a within-subject ANOVA model for repeated measures was used. There were two within-subject factors, as depicted in Figure. 1: (i) 'case-control', contrasting the ' 00 ' non-radiated records with the ' 11 ' peak-radiated records and (ii) 'timeeffect': testing the time effect within the ' 00 ' and ' 11 ' (i.e. the effect from the first 0 to the second 0 and the first 1 to the second 1 , respectively). The dependent variable was log-HR. The critical interaction to be tested was 'case-control*time-effect'.

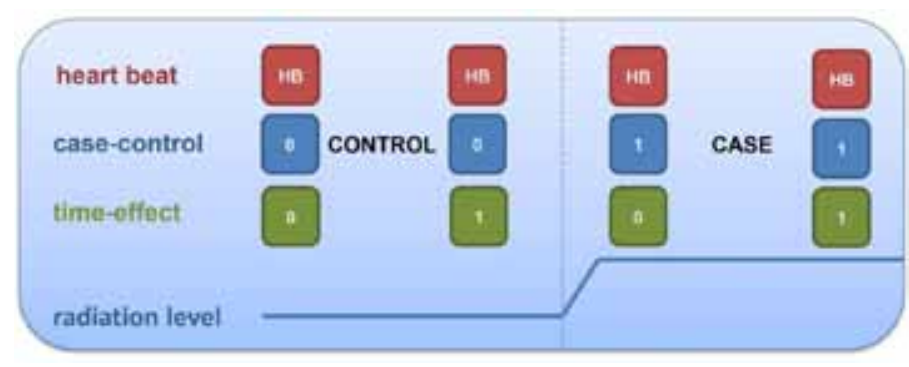

Figure 1. '0011' pattern. Horizontally, time passes by per heartbeat; the blue line represents an emerging radiation peak after a relatively low radiation level. The interaction of interest is the 'case-control*time-effect' (blue $0011^{*}$ green $0101)$. 
Control finding within PRE: In order to obtain control heartbeats for the '0011' patterns in EXP '0000', patterns were identified only in PRE (given that POST may be biased by EXP). The goal was to compare the '0011' patterns from EXP with the radiation free '0000' pattern, derived from PRE. A '0000' pattern represents a radiation level lower than the median radiation value in four consecutive records in the PRE condition. In order to balance the amount of controls with the cases (defined as '0011' found in EXP), a random sample of 142 '0000' patterns were used for the analysis. A comparable within-subject ANOVA model was used, but with the inclusion of a between-subjects-factor ('condition'), contrasting EXP with PRE. The critical interaction to be tested was the 'case-control*time-effect*condition'.

\section{RESULTS}

\section{Validity of radiation}

During the four sessions, level of radiation in the experimenting room was collected with the aid of the radiation detector. Figure 2 shows an overview of the level of radiation during the four experimental sessions. Radiation activity was relatively high during the EXP conditions. Low levels of radiation peaks in PRE and POST are likely associated with unknown background radiation processes including the elevator near the experimenting room and/or other mobile telephone users in the building.

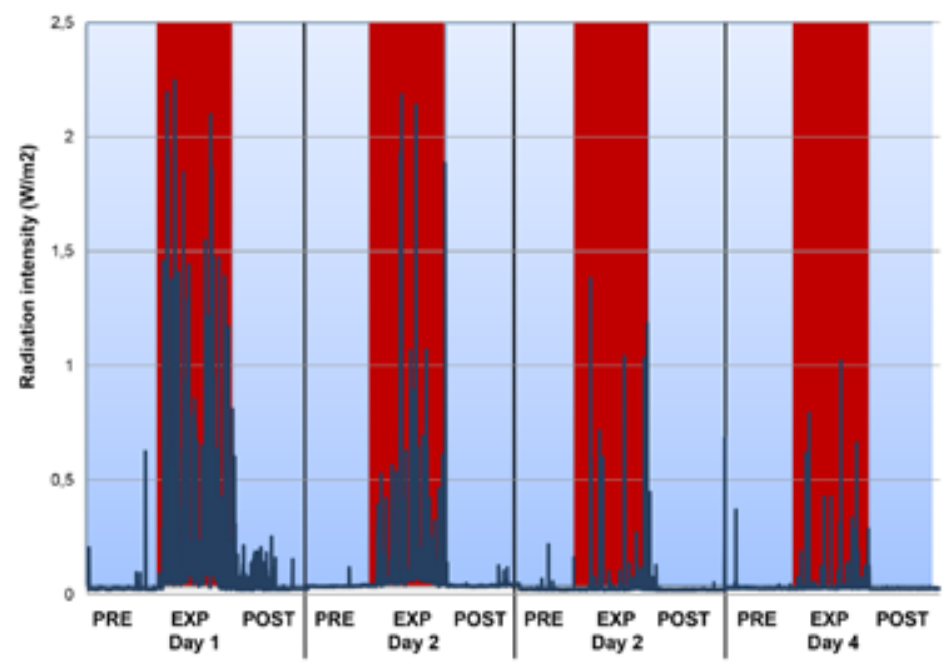

Figure 2. Overview of radiation levels over four days of testing.

Over the four sessions, the mean time distance between radiation peaks was 25.6 seconds (SD = 23.6 sec). The mean duration of a radiation peak was 2.5 seconds $(S D=3.1)$. 


\section{Macrolevel analysis}

Compared to EXP, the mean HR in PRE was 1.014 beats per minute higher $(95 \% \mathrm{Cl} 1.009$ 1.019). POST displayed an almost identical inversed effect: a higher mean HR of 1.009 beats per minute (95\% Cl 1.007-1.014), compared to EXP. The regression model with the two dummy variables was significant $(F=27.5, p<0.001$; $R$ Square $=0.004)$. The dummy variable contrasting PRE vs. EXP had a t-value of $7.1(p<0.001)$ and the dummy variable contrasting POST vs. EXP had a t-value of $5.2(p<0.001)$. Figure 3 shows the mean estimated HR for each of the three conditions.

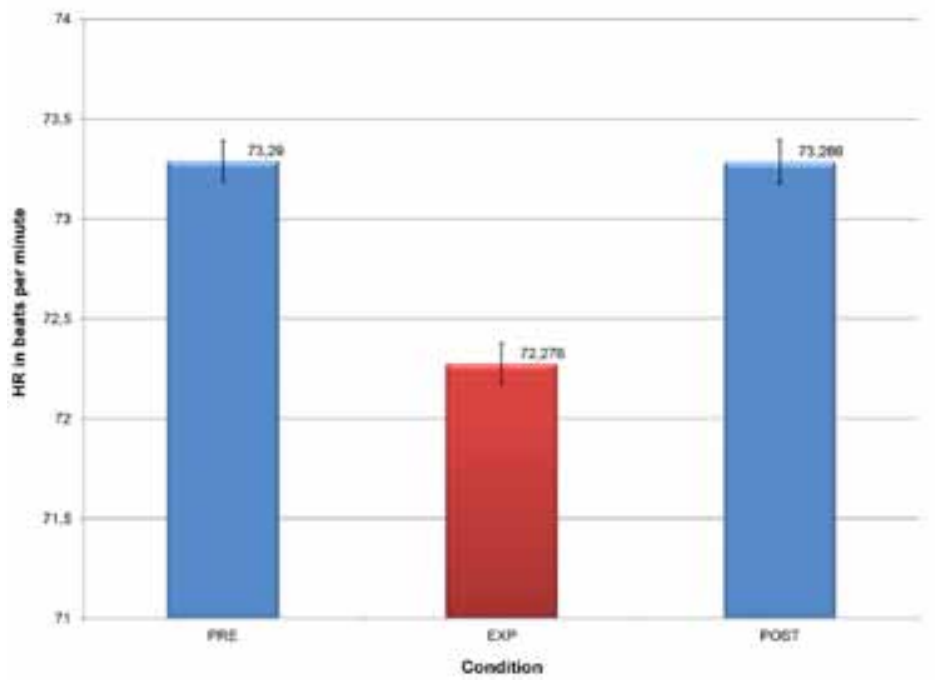

Figure 3. Estimated heart rate values for the three conditions

A strong interdependency between heart beats was apparent; for example, the correlation with lag1 heart rate was $>0.9$. Therefore, the regression assumption of independence of observations was not fulfilled. A time series model, using an ARIMA structure with 10 lags of autocorrelation and the two condition predictor variables was carried out. The results of this analysis indicated that the condition effects obtained by the linear regression analysis remained significant: the estimated HR in PRE was 1.0 beats per minute higher compared to EXP (t-value $=3.7 ; p<0.001$ ) and POST was 1.0 beats per minute higher than EXP (t-value = 4.7; $\mathrm{p}<0.001$ ).

The residuals of two models, as provided by the SPSS output, with and without the 10 lags of autocorrelation, are depicted in Figure. 4. It is evident that the residuals deviate less from zero in the corrected model compared to the original model, thus demonstrating the surplus value of the autoregressive model. 

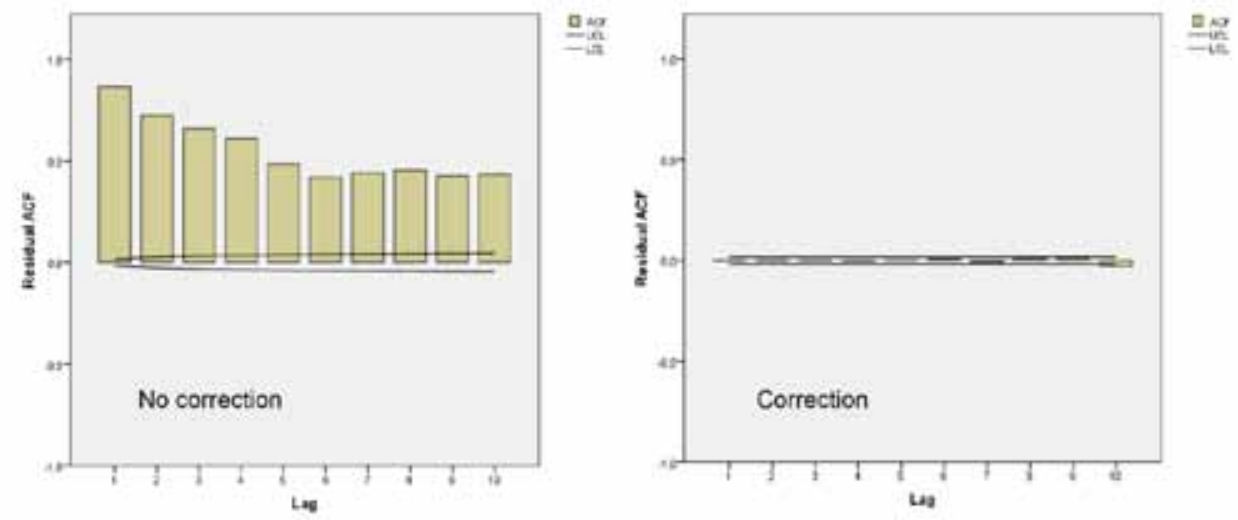

Figure 4. Residual plots without and with correction for autocorrelation. ACF: autocorrelation function, UCL: upper confidence limits, LCL: lower confidence limits for the values (95\%).

\section{Microlevel analyses}

Case-control radiation peak finding within EXP: The mean values for the 0011 pattern are displayed in Figure. 5, indicating that the no-radiation period ('00') showed an increase in heart rate, whereas the radiation period ('11') demonstrated a decrease. The hypothesized time-effect* case-control interaction (as explained earlier), differed significantly (F(Hotelling's Trace) $=10.5 ; p=0.001$ ), between case and control observations.

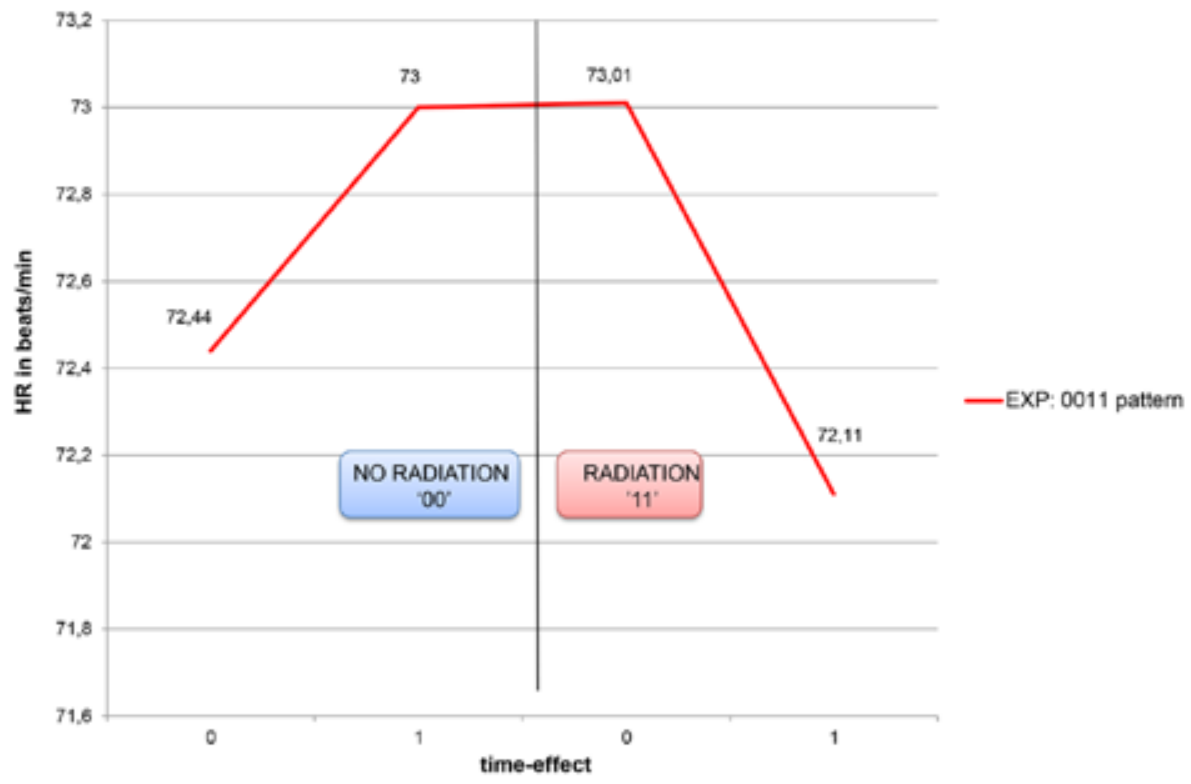

Figure 5. Microlevel analysis in EXP: mean heart rates in a 0011 pattern. 


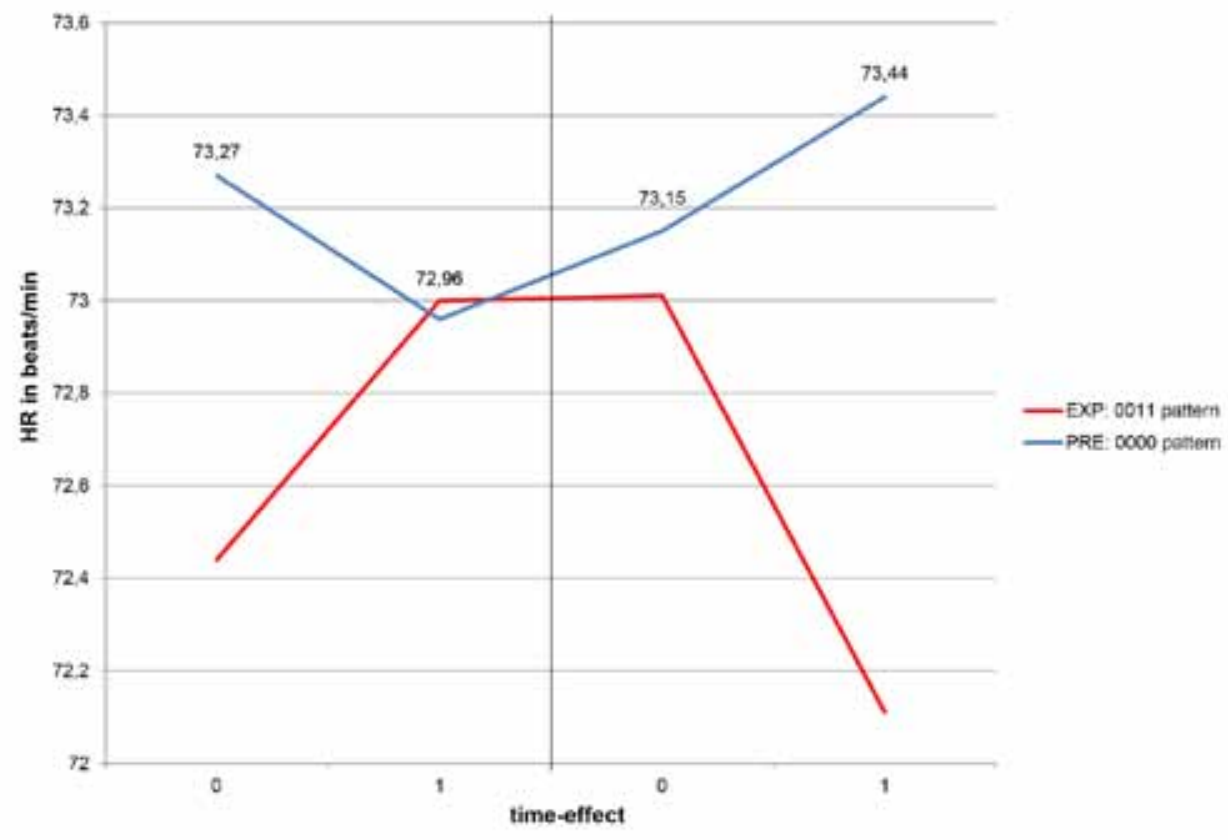

Figure 6. Microlevel analysis contrasting PRE and EXP. Mean heart rates in a 0011 vs. 0000 pattern.

Control finding within PRE: Figure 6 displays the mean values for the 0011 pattern in EXP (red line), compared to the '0000' pattern in PRE (blue line). The time course of the four radiation-free moments in PRE was different from the '0011' pattern. The critical timeeffect*case-control*condition interaction indicated significant differences between case and control observations ( $F($ Hotelling's Trace $)=8.5 ; p=0.004$ ).

\section{DISCUSSION}

In this pilot study a significant drop in heart rate, due to the placement of a dialling mobile phone on the chest, was found, thus confirming the hypothesis. Compared to the sham phone condition in the preceding 15 minutes, heart rate was lowered with approximately one beat per minute during the radiation condition. Heart rate returned to approximately the same level as before the radiation exposure in the subsequent sham phone condition. The results of the microlevel analyses were in line with the macrolevel finding that heart rate drops after the onset of a radiation peak. The macrolevel effect remained significant after correction for the autoregressive nature of the heart rate data.

A significantly lowered heart rate under RF-EMF exposure has also been reported in a 
study on rats (79) and in a Finnish study on human subjects (using by a $900 \mathrm{MHz}$ mobile phone) (80). Although the authors of the latter study attributed the observed lowered heart rate to initial "mental strain and nervousness of the volunteers", their observed decrease might in fact be due to mobile phone radiation. This alternative explanation would then be in accordance with the results of the present study. However, the effect of a decrease in heart rate in this $n=1$ study, due to mobile phone radiation, needs to be placed into perspective since the majority of studies $(66,68-78)$ did not report large or significant effects. Nevertheless, in a recent meta-analysis on this topic, the direction of the effect, albeit statistically inconclusive, is towards lower heart rate in association with mobile phone radiation (55).

In order to compare the results of the present study with those from others, it should be noted that the methodology of the present study differs in several aspects. First, in the current study, the mobile phone was placed on the chest instead of the ear. This placement in the proximity to the heart may have increased the effect size (and thus the significance level). Second, in contrast to all other studies, this study was based on the data of a single participant. Although each of the four experimental days contained one exposure and two sham conditions, there was no between-subject factor. Third, the RF-EMF exposure condition in this study was always directly preceded and followed by a sham condition, whereas in other studies the sham-condition was regularly performed on a separate day. Fourth, with respect to data analysis, the current study also focused on immediate radiation peak (microlevel) effects, which may represent a more sensitive way to detect radiationrelated impact on heart rate.

A possible mechanism for the observed drop in heart rate has been proposed in the literature, suggesting that RF-EMF may activate the autonomic nerve system resulting in a slow diastolic depolarization $(65,66,68,69,82)$. The microlevel finding of an increase in heart rate directly preceded by radiation peaks (see Figure. 5) could be explained as a 'compensatory' effect for the decrease in heart rate caused by earlier radiation peaks. Both the direct radiation peak effect as well as the compensating effect were absent (Figure. 6 even suggests a trend in the opposite direction) in the PRE phase, thus providing more support for the notion of a genuine radiation peak effect in the EXP phase.

The observed heart rate effect needs to be interpreted in a clinical perspective. Although the effect is significant, the short reversible change of one beat per minute unlikely represents a large or clinically relevant change in healthy individuals in the short term. The goal of this pilot study was not to demonstrate risk, but to investigate whether there are electrocardiac changes at all. The results indicate that more research is required to examine long-term effects. It is also recommended to investigate the effects of mobile phone radiation in specific (vulnerable) subgroups, such as children(61).

Limitations Some critical limitations require consideration. First, the fact that the reported results are based on a $n=1$ sample restricts the generalisability of the findings. $A$ 
replication study with a larger sample size is necessary. Significant findings may be due to a (relatively) high susceptibility to RF-EMF of the participant $(74,75,78,80,83)$. Although the participant in the current study did not report RF-EMF sensitivity (headaches or other complaints) it cannot be ruled out that individual susceptibility played a role. Another critical issue is the fact that this study was single blinded. It is, however, unlikely that the non-blindness of the experimenter influenced the results. Third, as can be seen in Figure. 2 , radiation level decreased over the four days of testing. A post-hoc explanation may be that this effect was due to randomly different occupation of the telecom network over the four days. A final critical aspect pertains to the chosen setting of the frequency band GPRS/ UMTS. This setting was chosen because it mimics real phone usage. As a consequence, however, the exact frequency in which radiation took place was unknown (although the exact timing of radiation was).

Future studies are required to further explore the interference of RF-EMF with human physiology. Within the field of electrophysiology, heart rate variability, EEG and respiratory rate would be interesting parameters to explore RF-EMF influence on the autonomic nervous system. Another aspect to elaborate further is the microlevel technique of analysis. In order to unravel microlevel peak-related radiation effects, a radiation detector is indispensable. Finally, because of its potentially global relevance, it is important to set up longitudinal studies to examine whether there are also long-term effects of RF-EMF. 


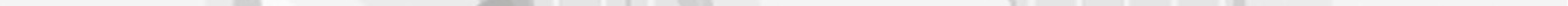




\section{EEG changes due to experimentally induced 3G mobile phone radiation}

Suzanne Roggeveen

Jim van Os

Wolfgang Viechtbauer

Richel Lousberg

PLoS ONE 10(6) (2015): e0129496. doi:10.1371/journal. pone.0129496 


\section{ABSTRACT}

The aim of this study was to investigate whether a 15-minute placement of a $3 \mathrm{G}$ dialing mobile phone causes direct changes in EEG activity compared to the placement of a sham phone. Furthermore, it was investigated whether placement of the mobile phone on the ear or the heart would result in different outcomes. Thirty-one healthy females participated. All subjects were measured twice: on one of the two days the mobile phone was attached to the ear, the other day to the chest. In this single-blind, cross-over design, assessments in the sham phone condition were conducted directly preceding and following the mobile phone exposure. During each assessment, EEG activity and radiofrequency radiation were recorded jointly. Delta, theta, alpha, slowbeta, fastbeta, and gamma activity was computed. The association between radiation exposure and the EEG was tested using multilevel random regression analyses with radiation as predictor of main interest. Significant radiation effects were found for the alpha, slowbeta, fastbeta, and gamma bands. When analyzed separately, ear location of the phone was associated with significant results, while chest placement was not. The results support the notion that EEG alterations are associated with mobile phone usage and that the effect is dependent on site of placement. Further studies are required to demonstrate the physiological relevance of these findings. 


\section{INTRODUCTION}

Mobile phone usage has become an integrated part of modern society. In recent years, number and level of usage of mobile phones has increased rapidly. In 2013, 6.8 billion mobile phone subscriptions were registered (84). In recent years, new technology of $3^{\text {rd }}$ generation (3G) or universal mobile telecommunication system (UMTS), using the 1.9 $2.1 \mathrm{GHz}$ frequency band has been introduced, followed by the $4^{\text {th }}$ generation. Although there are some worries (85) about the potential negative effects of RF-EMF on health, large sections of the population are avid customers. The number of studies investigating whether or not RF-EMF has adverse health effects has increased rapidly. The research field is broad since several areas are explored, ranging from carcinogenesis and infertility to basic effects on physiological parameters. In general, results are conflicting and inconclusive (86-89). While a number of studies demonstrate influence of radiation on health, others cannot replicate these findings. Nevertheless, the International Agency for Research on Cancer concluded that there is "limited evidence in humans" and in 2011 it was decided to classify mobile phone radiation in group 2B - possibly carcinogenic (85). In contrast, the 2012 overview report of the Mobile Telecommunications and Health Research (MTHR) Programme concluded that there is no evidence of carcinogenic effects due to exposure to mobile phone signals (90). However, examining possible effects due to long-term exposure and the effects on other outcomes were suggested as priority research areas. Also in the WHO Research Agenda for Radiofrequency Fields of 2011, "provocation studies to identify neurobiological mechanisms underlying possible effects of RF on brain function, including sleep and resting EEG" are considered to have a high priority (91).

The effects of mobile phone radiation on electroencephalography (EEG) have been studied since the mid-nineties (92). There are a number of studies which have investigated the effects of mobile phone radiation on resting EEG, on sleep EEG, on the performance of cognitive tasks, and on event related potentials (ERP) of conscious sensory stimuli. Apart from a relative consistent finding (42-44, 92-95) of an increased power in the alpha band, no consistent results have been reported. A possible contributing factor to these varying results may be found in the diversity of designs and in the statistical analyses. Some examples are: type of exposure (network $2 \mathrm{G} / 3 \mathrm{G}$ and a real mobile phone versus a radiating module), duration of exposure (ranging from minutes to several hours), and statistical tests (parametric versus non-parametric tests). Apart from these methodological aspects, it has been suggested that source of funding might influence the results (63). It has been shown that $87 \%$ of brain activity studies are sponsored by the mobile phone industry (87). Although this does not necessarily imply that the results of these articles are biased, the issue of conflict of interest cannot be neglected.

To shed further light on this topic, it was decided to set up a basic experiment to investigate whether EEG is influenced by mobile phone radiation. The focus on EEG as the dependent 
variable was deliberate since functioning of brain tissue is based on electrochemical processes (96) and interference by an electromagnetic device (mobile phone) placed directly against the head is, from a physical point of view, very likely to occur. Despite this plausible physical interference mechanism, adverse effects are rarely reported.

Before setting up the experiment, several methodological issues were considered. First, in most studies a control session was included on a separate day $(43,44,94,95,97)$. It is known, however, that resting EEGs can differ across days, even without any intervention (98). Therefore, it was decided to compare an exposure condition with two control measurements, directly preceding and following the exposure condition. In addition, a control-exposure-control session was conducted on two different days in order to test whether the location of placement of the mobile phone might be of influence. Apart from the obvious placement of the mobile phone on the ear, it was decided to also place the phone on the chest. Any differences in outcome between placement locations may be informative about a working mechanism. Third, an actual mobile phone was used instead of a GSM module or other method to simulate mobile phone radiation. This decision was made to represent reality as accurately as possible. In order to ensure that the radiation did not have a direct effect on the measurement equipment, shielded EEG electrodes were used. Finally, multilevel random regression analysis was used instead of ANOVA techniques. The main reason is that EEG data show hierarchical clustering in at least four levels: subjects, sessions, conditions and EEG segments. Multilevel regression analysis also allows modulation of random effects (regression coefficients may vary between subjects) as well as the incorporation of an autoregressive covariance structure (since consecutive EEG segments are highly correlated).

Two a priori hypotheses were tested. Based on existing literature, an increase in alpha activity during exposure was expected. Second, because of the smaller distance to the brain, the influence on the EEG of radiation was expected to be larger with ear placement as compared to chest placement.

\section{MATERIALS AND METHODS}

\section{Participants}

Thirty-one female participants (mean age of 26.7 years; SD=8.5), non-smoking, and without a medical history of cardiac or nervous system disorders were included. Four hours prior to the start of the session, no caffeine-containing beverages were used. No alcohol was used in the preceding 12 hours and sufficient night rest was ensured. After reading a document with detailed information about the study and having discussed any possible concerns with the researcher, subjects gave their verbal and written informed consent. Complete participation was compensated with $€ 50$,-. 


\section{Experimental procedures}

The study consisted of two sessions, each session taking place on a separate day, with a maximum of two days in between the two sessions. The experiments were conducted in an electrically non-shielded, room. The sequence of placement on the ear or heart was counterbalanced between the sessions. EEG was measured using shielded electrodes. Each shielded electrode had a separate ground plug, which was connected into a general ground-device. The following EEG electrodes were placed in accordance to the 10-20 system (99): Fz, F3, F4, Cz, C3, C4, Pz, P3, P4, Oz, O1, and O2. All electrodes were fixed using conductive paste (29). A reference was placed on each ear lobe. To check for possible eye movements, an electro-oculogram (EOG) electrode was placed 1 centimetre under the midline of both eyes. The electrodes were connected to a BrainAmp amplifier (Brain Products). Impedances were maintained below $5 \mathrm{k} \Omega$. Spike artefacts due to radiation, which are mentioned in other articles $(87,100)$, were not observed in the data. Both EEG and radiation data were sampled with $1000 \mathrm{~Hz}$ using Brain Vision Recorder software. Each participant was exposed to four consecutive conditions during each session, according to the schedule shown in Table 1. There were three conditions with a sham phone, and one condition with a dialling mobile phone. The experimenter entered the room at the end of each 15 minute condition to change the phone. During this exchange of phones, no electrophysiological measurements took place. In the case of two consecutive sham phone conditions, the same procedure was followed (a second sham phone was placed). In order to ensure blinding, the order of the conditions was unknown to the participant, thus achieving a single-blind experiment. In one session, the 'dialling' condition was in the second quarter of an hour and in the other session the 'dialling' condition was in the third quarter. This sequence order was balanced over the subjects. Subjects were not aware of the different phones used.

Table 1. Experimental design

\begin{tabular}{lllll}
\hline & $\mathbf{1 5}$ minutes & $\mathbf{1 5}$ minutes & $\mathbf{1 5}$ minutes & $\mathbf{1 5}$ minutes \\
\hline Day 1 or $\mathbf{2}$ & Pre-exposure & Exposure & Post-exposure & Not used \\
& $(\mathrm{PRE})$ & $(\mathrm{EXP})$ & $(\mathrm{POST})$ & \\
Day 1 or $\mathbf{2}$ & Not used & Pre-exposure & Exposure & Post-exposure \\
& & $(\mathrm{PRE})$ & $(\mathrm{EXP})$ & (POST) \\
\hline
\end{tabular}

The sequence was randomly determined in order to ensure blinding of the participant. In conditions labelled as 'not used', an identical sham phone was placed in the same way as in the pre- and post-exposure conditions. 


\section{Exposure}

- A 3 G smartphone was used. During exposure conditions, the phone was dialled from a fixed line in another room. No sound was exchanged (mute settings), and vibration mode was off, in order to ensure that the participant could not identify the dialling condition.

- The SAR level of the phone was reported as $0.69 \mathrm{~W} / \mathrm{kg}$ (head) in the manual.

- The sham phone was a non-functioning replica of the same weight and the same characteristics as the functioning smartphone. The sham phone contained the same type of battery as the real phone and care was taken that the battery was inactive in the sham condition. In a pilot study before the start of the actual experiment, no evidence was found that participants could detect differences between the actual mobile phone and the sham phone. As a check, subjects were asked whether they noticed any differences between phone placements after each session in the experiment.

Radiation activity was detected with a radiation detector (HF59B, Gigahertz Solutions), connected to an omnidirectional antenna. This detector was connected (from the DC output) to the BrainAmp headbox with an auxiliary plug. The detector was placed in the upright position, $30 \mathrm{~cm}$ above the table (at which the participant was sitting) and $20 \mathrm{~cm}$ left from the participant. In one of the two sessions, the phone/sham-phone was placed directly onto the left ear, ensuring that there was no contact between the phone and the EEG electrodes. The position of the phone was comparable to a typical dialling position, in an angle of approximately 45 degrees. During the other session, the phone was placed adjacent to the left side of the sternum, bordering the sternoclavicular joint. Previous tests showed that there was neither a direct interference of the mobile phone radiation on the shielded electrodes nor on the internal ADC converter of the amplifier. The rear side of the phone was placed on the skin in both sessions. The phone was fixed using an elastic band.

In order to investigate radiation exposure, a Network Analyzer, Agilent Technologies, E5061B ENA Series, $5 \mathrm{~Hz}$ - $3 \mathrm{GHz}$ was used. The frequency band operated in the following frequency: 1.9291 to $1.9397 \mathrm{GHz}$. A radiation peak as measured with the radiation detector, equalled a power of approximately $10 \mathrm{dbm}$ measured next to the ear with the Network Analyzer.

In order to maintain the participant's alertness and to guarantee a relatively stable mood, participants watched an affectively neutral documentary about the development of the earth. All experimental sessions were performed between 09.00 and 17.00 o'clock.

\section{Data reduction}

EEG data was analysed offline with the software program BrainVision Analyzer 2.0 (Brain Products, München, Germany). Data were filtered using a high cut-off filter of $50 \mathrm{~Hz}$ and a low cut-off filter of $0.5 \mathrm{~Hz}$. Each measurement was divided in epochs of $32768 \mathrm{~ms}$. Subsequently, a fast Fourier transformation (FFT) was executed for each epoch. The following frequency bands were computed: delta ranging from 0.5 to $4.0 \mathrm{~Hz}$, theta (4.0 to $7.5 \mathrm{~Hz}$ ), alpha (7.5 
to $13.0 \mathrm{~Hz}$ ), slow beta $(13.0$ to $20.0 \mathrm{~Hz}$ ), fast beta $(20.0$ to $30.0 \mathrm{~Hz}$ ), and gamma (30.0 to $47.0 \mathrm{~Hz}$ ). Data was exported to SPSS 21.0. The SPSS dataset was constructed in such a way that each record contained the unified information of the EEG bands per $32768 \mathrm{~ms}$. This means that each 15 minute condition was subdivided into 27 consecutive 'segments'. All EEG variables were $\log _{10}$-transformed because of a positively skewed distribution. In order to reduce the total number of 72 EEG dependent variables (12 locations $\times 6$ bands), the locations were bundled into brain regions per frequency band: left - midline - right and frontal - central - parietal - occipital. For example 'frontal-alpha' was computed as the average of the ( $\log _{10}$-transformed) Fz, F3, and F4 alpha activity.

EOG and radiation data were also divided into 32768 ms epochs, but no FFT was carried out in this data. The sum of EOG activity was computed for each segment. The same procedure was performed for radiation.

\section{Statistical analysis}

Statistical analyses were performed using SPSS 21.0. Multilevel random regression analyses were used to investigate the effect of radiation on the EEG outcome measures. The 27 consecutive segments within each condition were treated as the repeated measure variable. The multilevel regression analyses contained four levels: subject, session (every subject was measured on two separate days), condition (three conditions within each session), and segment ( 27 within each condition). As mentioned in the introduction, EEG activity of consecutive segments is strongly interdependent. An autoregressive (AR1) covariance structure was found to be most suitable, for the residuals at the fourth (segment) level. In order to find the optimal covariance structure, likelihood ratio tests were conducted to compare models with different covariance structures (independent, autoregressive and autoregressive moving average structures were compared). This is a well-established approach for selecting amongst various structures $[23,24]$. An SPSS syntax example of this model is shown below.

MIXED mean_delta_left WITH PRE POST radiation segment session age ear_heart timing of_exposure EOGleft EOGright /CRITERIA=CIN(95)MXITER(100)MXSTEP(10)SCORING(1) SINGULAR(0.000000000001) HCONVERGE(0, ABSOLUTE) LCONVERGE(0, ABSOLUTE) PCONVERGE(0.000001, ABSOLUTE)

$/ F I X E D=$ radiation session segment EOGleft EOGright ear_heart timing_of_exposure age PRE POST / SSTYPE(3)

$/ M E T H O D=R E M L$

/PRINT=SOLUTION TESTCOV

/RANDOM=INTERCEPT segment / SUBJECT(subject) COVTYPE(VC)

/RANDOM=INTERCEPT segment / SUBJECT(subject *session) COVTYPE(VC)

/RANDOM=INTERCEPT segment / SUBJECT(subject *session*condition) COVTYPE(VC)

/REPEATED=segment / SUBJECT(subject *session* condition) COVTYPE(AR1). 
All segments with outlying (above percentile 99) EOG activity were rejected from the analyses (2.3\% of all segments). Furthermore, all remaining EOG information (the summed activity per segment) was included in all statistical models as a covariate. The main predictor of interest was the summed radiation for each segment. Furthermore, five design factors were included in the analyses as covariates: condition (PRE, EXP, and POST recoded into two dummy variables), phone placement location (ear or heart), session (day 1 or day 2), segment (added as a quantitative covariate), and the timing of exposure (second or third 15 minute quarter of the experiment, see table 1). In addition, we controlled for the effects of age in all analyses by including age as an additional covariate. The statistical BenjaminiHochberg procedure controls the false discovery rate (FDR) and was used in retrospection to correct for multiple testing.

\section{RESULTS}

After each session, subjects were asked if they noticed any temperature change, or other difference between the conditions. None of the participants could identify noticeable differences.

Table 2 shows the mean spectral power densities of the mean midline (average of $\mathrm{Fz}, \mathrm{Cz}$, $\mathrm{Pz}$, and $\mathrm{Oz}$ ) activity per condition. As can be seen from the raw data in this table, there is a marginally elevated activity during EXP. Considering the standard errors, this elevation is clearly not significant.

Table 2. Mean values in the three conditions

\begin{tabular}{lccc|ccc|ccc}
\hline & \multicolumn{8}{c}{ Mean midline (Fz, Cz, Pz and Oz) } \\
\cline { 2 - 10 } & \multicolumn{3}{c}{ PRE (sham) } & \multicolumn{2}{c}{ EXP (dialing phone) } & \multicolumn{3}{c}{ POST (sham) } \\
\cline { 2 - 10 } & mean & SD & SE & mean & SD & SE & mean & SD & SE \\
\hline Delta (.5 - 4 Hz) & 1.93 & 0.18 & 0.03 & 1.94 & 0.18 & 0.03 & 1.93 & 0.18 & 0.03 \\
Theta (4 - 7.5 Hz) & 1.42 & 0.16 & 0.03 & 1.42 & 0.16 & 0.03 & 1.42 & 0.17 & 0.03 \\
Alpha (7.5 - 13 Hz) & 1.22 & 0.27 & 0.05 & 1.24 & 0.28 & 0.05 & 1.23 & 0.28 & 0.05 \\
Slow-beta (13 - 20 Hz) & 0.86 & 0.21 & 0.04 & 0.87 & 0.21 & 0.04 & 0.86 & 0.21 & 0.04 \\
Fast-beta $(20-30 ~ H z)$ & 0.65 & 0.18 & 0.03 & 0.67 & 0.18 & 0.03 & 0.67 & 0.19 & 0.03 \\
Gamma (30 - 47 Hz) & 0.42 & 0.18 & 0.03 & 0.44 & 0.20 & 0.04 & 0.43 & 0.20 & 0.04 \\
\hline
\end{tabular}

Mean spectral power densities $\left(\mu \mathrm{V}^{2}\right)$ in the six frequency bands for PRE, EXP and POST (standard deviation SD and standard error SE are given). 
Next, multilevel random regression analyses were performed to test whether an influence of radiation existed on EEG activity, while controlling for the abovementioned series of covariates.

Figure. 1 demonstrates the $p$-values of the predictor of main interest (radiation) in the eighteen (six EEG bands $\times$ three areas) analyses. The three areas refer to the left side of the brain (F3, C3, P3, O1), the midline ( $F z, C z, P z, O z)$, and the right side (F4, C4, P4, O2). All estimates were positive, indicating that an increase in radiation is associated with an increase of EEG band power. The alpha, slow-beta, fast-beta, and gamma bands have significant $p$-values and q-values. Post-hoc left-right contrasts were tested. Slow beta activity showed a significant left-right difference $(P=0.01)$, in which the estimates in the left hemisphere were more positive than right. With respect to the covariates, segment had significant $p$-values in sixteen of the eighteen analyses, especially in the slow beta band ( $p$-values <0.001, left and midline: $q$-values<0.01). There was an increasing trend within the conditions. In addition, EOG proved, as expected, to be a significantly related to EEG in all analyses ( $p$-values $<0.002$ ).

The AR1 covariance structure was justified since all AR1 estimates were highly significant (all Wald $Z$ values $>4$ for the rho estimates). Random intercepts were also significant for all models (Wald $Z>3$ ). The random slope for segment was significant (Wald $Z>2$ ) for all

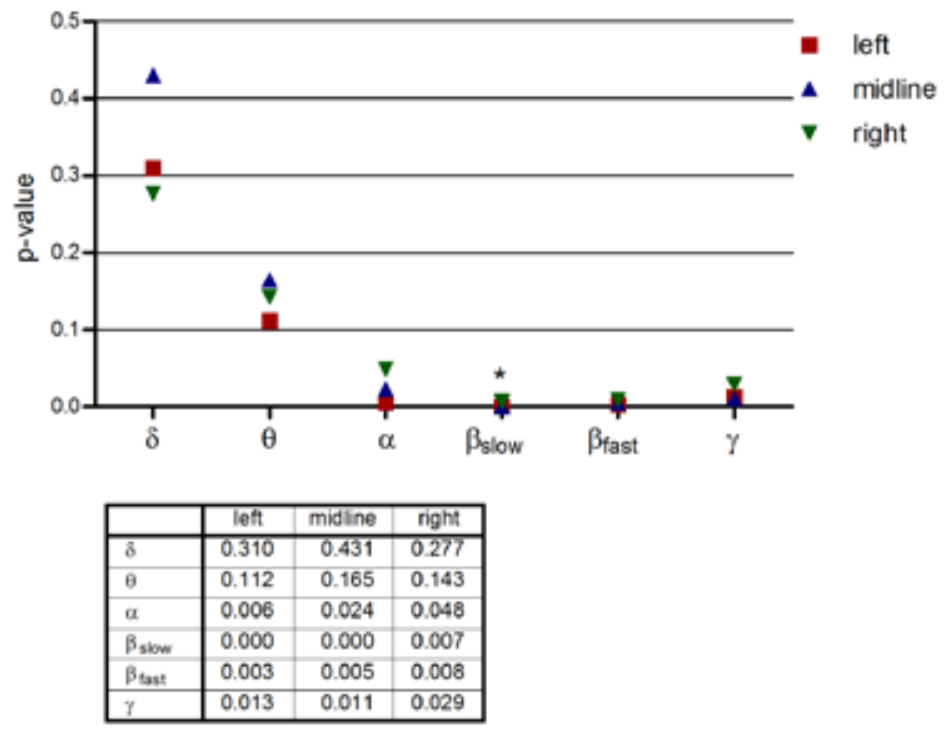

Figure. 1. Left midline right. Each symbol represents the p-value of the main predictor 'radiation' in the relevant area. ${ }^{*}$ in the graph indicates a significant left-right contrast. Below the graph a table depicts the $\mathrm{p}$-values. ${ }^{*}$ in the table represents a significant $q$-value $(q<0.05)$ after correction for multiple testing using the false discovery rate (FDR) method. ** significant $\mathrm{q}$-value $(\mathrm{q}<0.01)$ after correction for multiple testing. All values of this table were included for the FDR computation. 
frequency bands, except delta. The latter means that each person, in each session and condition has a significantly unique time course of EEG activity (segment representing time).

Similar analyses were performed, this time for the four cortical regions: frontal (Fz, $F 3, F 4)$, central $(C z, C 3, C 4)$, parietal $(P z, P 3, P 4)$, and occipital $(O z, O 1, O 2)$. Significant radiation effects were found in the alpha, slowbeta, fastbeta, and gamma bands (Figure. 2 ). With respect to the covariates and random effects, comparable results were obtained as reported in the previous set of analyses.

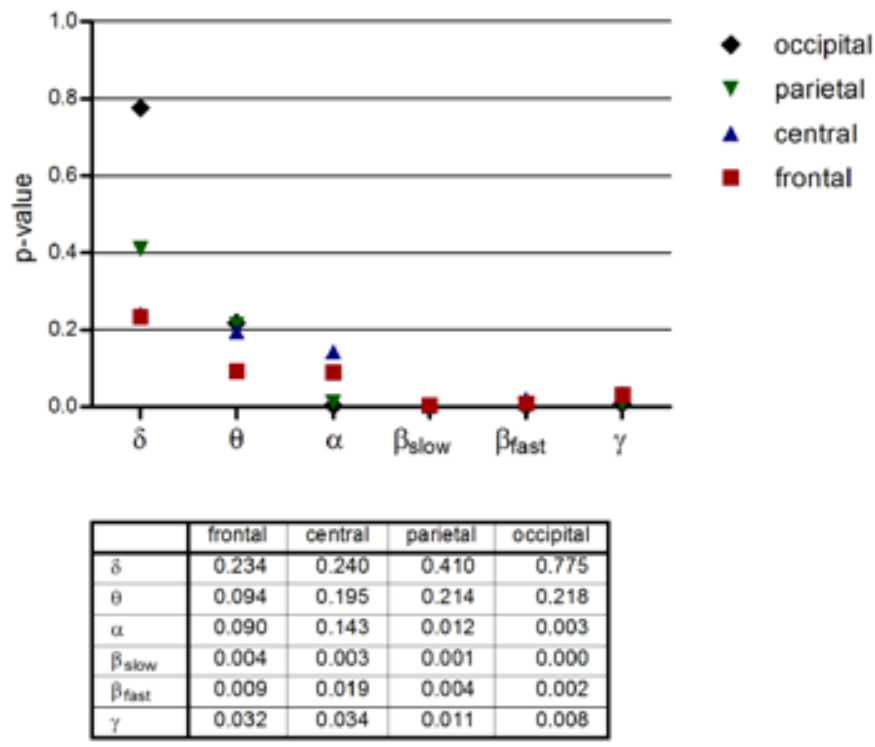

Figure. 2. Cortical regions. Each symbol represents the p-value of the main predictor 'radiation' in the relevant area. Below the graph a table depicts the $p$-values. ${ }^{*}$ significant $q$-value $(q<0.05)$ after correction for multiple testing using the false discovery rate (FDR) method. ** significant $q$-value $(q<0.01)$ after correction for multiple testing. All values of this table were included for the FDR computation.

In the analyses above, the radiation effect was controlled for a main (fixed) effect of location of placement. To further investigate the influence of placement, an interaction between radiation and location of placement was incorporated in the model of the left - midline right analyses. Figure. 3 depicts the $p$-values of this placement*radiation effect. The theta and alpha range show statistical significance of the interaction. All other interactions, except for fastbeta - left, were not significant. The estimates were negative, which has to be interpreted as a lower effect of radiation on EEG power for the chest placement compared to the ear. 


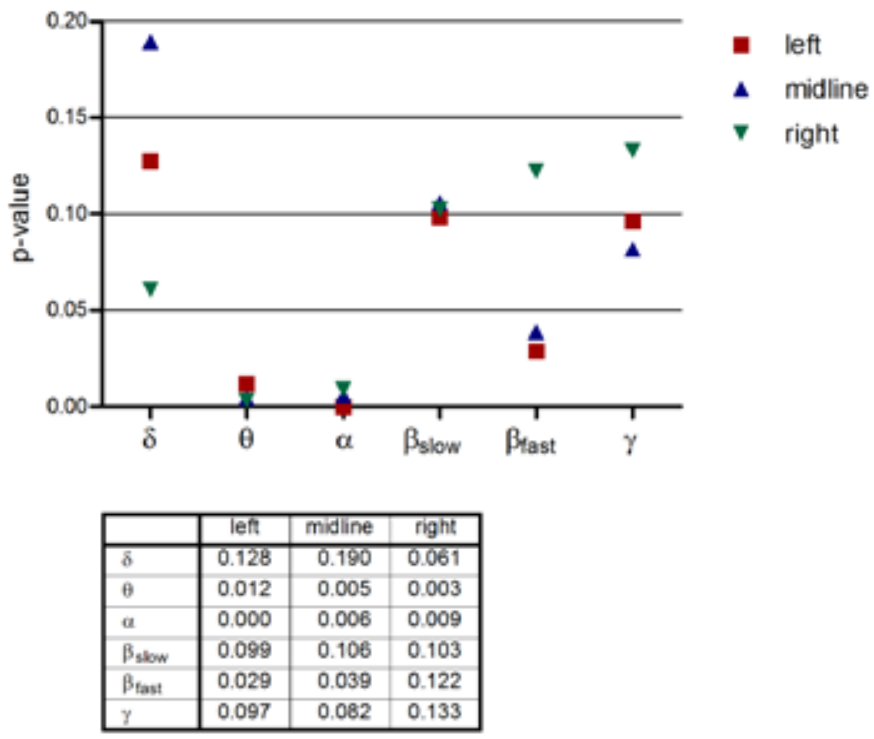

Figure. 3. Interaction variable placement*radiation. Each symbol represents the $p$-value of the interaction variable in the relevant area. Below the graph a table depicts the $p$-values. ${ }^{*}$ significant $q$-value $(q<0.05)$ after correction for multiple testing using the false discovery rate (FDR) method. ${ }^{* *}$ significant $q$-value $(q<0.01)$ after correction for multiple testing. All values of this table were included for the FDR computation.

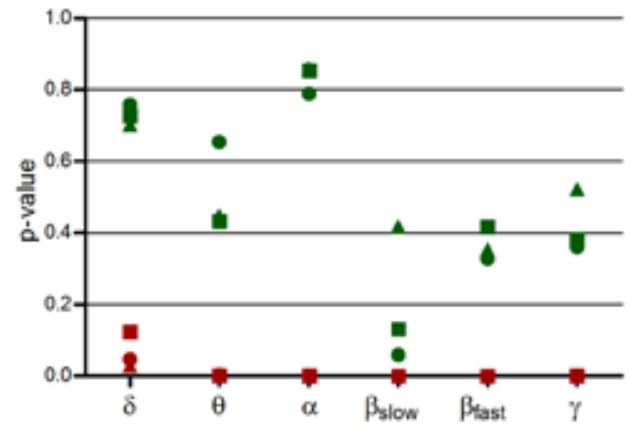

- EAR - left

- EAR - midline

A EAR - right

- hEART - left

- hEART = midline

A HEART - right

\begin{tabular}{|l|r|r|r|r|r|r|}
\hline & EAR - left & EAR - midline & EAR - right & HEART - left & HEART - midline & HEART - right \\
\hline 5 & 0.047 & 0.124 & 0.030 & 0.759 & 0.729 & 0.704 \\
\hline 0 & 0.004 & 0.002 & 0.001 & 0.655 & 0.433 & 0.450 \\
\hline$\alpha$ & 0.000 & 0.001 & 0.003 & 0.789 & 0.853 & 0.860 \\
\hline$\beta_{\text {slias }}$ & 0.000 & 0.000 & 0.001 & 0.059 & 0.131 & 0.419 \\
\hline$\beta_{\text {last }}$ & 0.000 & 0.000 & 0.001 & 0.328 & 0.418 & 0.355 \\
\hline$\gamma$ & 0.002 & 0.001 & 0.003 & 0.360 & 0.363 & 0.524 \\
\hline
\end{tabular}

Figure. 4. Radiation effects on EEG: ear and heart sessions analyzed separately. Each symbol represents the p-value of the main predictor 'radiation' in the relevant area. Below the graph a table depicts the p-values. * significant q-value $(q<0.05)$ after correction for multiple testing using the false discovery rate (FDR) method. ${ }^{* *}$ significant $q-$ value $(q<0.01)$ after correction for multiple testing. All values of this table were included for the FDR computation. 
The main radiation effect was analyzed again for ear and heart sessions separately (Figure. $4)$. None of the analyses which were performed on the heart placement data showed a significant outcome, while almost all (except for delta) analyses that were performed on the ear placement data were significant. The interaction effect on the theta and alpha band are evident in this graph.

\section{DISCUSSION}

In this placebo-controlled, single-blind, cross-over study, we investigated whether a 15 minute RF-EMF exposure by a $3 G$ mobile phone impacts EEG activity. It was demonstrated that the results (and conclusions) strongly depend on the method of analysis. Analysed in the traditional fashion, that is, not controlling for the nested structure of the data, no significant differences could be demonstrated (see table 2 ), a finding which is in accordance with several other studies $(97,101-104)$. However, when the data were analysed with an appropriate multilevel statistical model, 'radiation' proved to be a significant predictor of the alpha, slow beta, fast beta, and gamma frequency bands over almost all brain regions (Figure. 1 and 2). There is a trend for the radiation effect to be stronger on the ipsilateral side. The positive significant time effect (segment) within conditions, observed in all regions and frequency bands, was unexpected and an explanation is lacking at this moment. Guided by the significant placement*radiation interactions, separate analyses for the ear and heart placements made clear that the radiation effect was mainly present in sessions where the mobile phone was placed on the ear (Figure. 3 and 4). To our knowledge, this ear-heart contrast has not been studied before. The present data suggest that a greater distance to the brain in case of the chest placement results in less EEG effects.

Although there are some studies which found an increase in the alpha frequency band due to RF-EMF (42-44, 92-95), the extent to which the different EEG bands are affected in the present study has not been reported in literature to date. This discrepancy needs clarification and probably has to be sought in methodological differences with other studies. As mentioned above, the type of statistical approach is an important factor in this issue. The multilevel approach is the preferred approach given the present study design. As stated in the introduction, this approach allows for modelling clustered data, to correct for autocorrelation, and for modelling random effects. In addition, in this study radiation was used as the predictor of primary interest instead of a general condition (exposed vs. nonexposed conditions) effect. This was made possible by connecting the radiation detector to the amplifier. Another methodological difference may lie in the usage of shielded electrodes (most articles do not describe this specific information) which prevents a direct influence of RF-EMF on the wires. Yet another difference is that in the present study an actual mobile phone was used functioning within the UMTS bandwidth (instead of 2G). The studies which 
also used UMTS do not find EEG effects $(97,103,105)$. A final difference pertains to the control measurement. Whereas most studies had the control session on a separate day, the present study used a crossover moment in the same session, directly preceding and following the exposure session.

Some limitations have to be considered. First, the study was performed with adult female subjects only. The generalizability of the results to, for example, male subjects, children, and the elderly has to be demonstrated in future research. Second, a sample size of thirtyone is relatively small. Future studies with larger sample sizes are required. Two other critical points are exposure time and follow up measurements. In this study, only one exposure condition (15 minutes) was used and a (long term) follow up measurement was not included. It would be interesting to investigate what the effects are of other (shorter or longer) exposure periods to mobile phone radiation, as well as to find out what the effects are of frequent experimental exposure to radiation in the long term. Fifth, no inner ear temperature was measured. As there is evidence that mobile phones cause a thermal, heating effect [30], it could be argued that inner ear temperature fluctuations between the conditions may have confounded the findings. On the other hand, it has also been reported that any changes in cerebral blood flow due to mobile phone radiation, assessed by positron emission tomography, are unlikely to be temperature-related [31,32]. This issue needs further investigation. Sixth, the experiment was performed in a non-shielded room, thus including environmental background radiation. It would be ideal to carry out such experiments in a radiation-free environment. As a seventh point of concern, in retrospect it would have been preferable to not enter the experimenting room in-between conditions to change phones. Ideally the phone should be programmed from outside the room. Furthermore, a note should be made with respect to the number of tests performed. For example, Figure. 1 contains eighteen test results. When corrected with the Bonferroni procedure, only two p-values (slow-beta left and midline) would remain significant. However, at least some of the findings would hold up under such a correction and it should be noted that the Bonferroni method is actually overly conservative for multiple correlated tests. (106) Instead, the 'False discovery rate' (FDR) was used to correct for multiple testing. Most results were still significant after correction. Finally, information on other (psycho) physiological and biological measures may be included in future work.

The question is whether the (temporary) EEG changes, induced by mobile phone radiation, have clinical/adverse consequences. Answering this question is complex and beyond the scope of the present manuscript. First, it is unknown whether mobile phones change EEG activity in the long term. Second, EEG is a reflection of very complex cerebral processes. It is thought that the activity in the different frequency bands represents underlying cortical functions. An example is the thalamocortical network, which plays an important role in the generation of alpha activity (107). Beta activity, however, only plays a role in the cortex and can, for example, be related to active concentration (108). Since the functional role of the 
different frequency bands is still not fully understood, it is also hard to draw conclusions on the (clinical) implications of EEG changes.

In future studies other indicators of brain activity may be included. For example, transcranial magnetic stimulation is a method to test brain excitability. There are several indications that brain excitability is modified due to mobile phone radiation [36-38].

This study attempted to approach the question whether or not mobile phones cause (short-term) changes in EEG activity. There was evidence that mobile phone radiation is associated with increased activity of the alpha, beta, and gamma frequency bands in nearly every brain region. The distance of the mobile phone to the brain was relevant, a larger distance resulting in less or no EEG interference. Replication of the present findings and investigation of possible long term (clinically relevant) effects is urgently required. 


\section{Does the brain detect 3G mobile phone radiation peaks? An explorative in-depth analysis of an experimental study}

Suzanne Roggeveen

Jim van Os

Richel Lousberg

PLoS ONE 10(5) (2015): e0125390.doi:10.1371/journal. pone. 0125390 


\section{ABSTRACT}

This study aimed to investigate whether third generation mobile phone radiation peaks result in event related potentials. Thirty-one healthy females participated. In this singleblind, cross-over design, a 15 minutes mobile phone exposure was compared to two 15 minutes sham phone conditions, one preceding and one following the exposure condition. Each participant was measured on two separate days, where mobile phone placement was varied between the ear and heart. EEG activity and radiofrequency radiation were recorded jointly. Epochs of $1200 \mathrm{~ms}$, starting $200 \mathrm{~ms}$ before and lasting until 1000ms after the onset of a radiation peak, were extracted from the exposure condition. Control epochs were randomly selected from the two sham phone conditions. The main a-priori hypothesis to be tested concerned an increase of the area in the $240-500 \mathrm{~ms}$ post-stimulus interval, in the exposure session with ear-placement. Using multilevel regression analyses the placement*exposure interaction effect was significant for the frontal and central cortical regions, indicating that only in the mobile phone exposure with ear-placement, an enlarged cortical reactivity was found. Post-hoc analyses based on visual inspection of the ERPs, showed a second significantly increased area between $500-1000 \mathrm{~ms}$ post-stimulus for almost every EEG location measured. It was concluded that, when a dialing mobile phone is placed on the ear, its radiation, although unconsciously, is electrically detected by the brain. The question whether or not this cortical reactivity results in a negative health outcome has to be answered in future longitudinal experiments. 


\section{INTRODUCTION}

Whether or not mobile phone radiation has an influence on human physiology and especially on brain activity is a research topic of increasing interest. Typically, people do not report bodily effects due to mobile phone use. Considered from a physical point of view, however, it is conceivable that the complex, sensitive electrochemical network that encompasses the brain, detects the electromagnetic radiation emitted by a mobile phone held against the head. An already known effect is that of heat transfer from mobile phones to the body $(6,13,109)$, an effect which can be eliminated by the body. Next to this thermal process it is proposed that so called 'non-thermal effects' also take place while using a mobile phone. In short, it is thought that radio frequent electromagnetic fields (RFEMF) may act as a trigger for the cellular stress response. No working mechanisms have been proven, but it is hypothesized that protein changes take place, which in turn could ultimately lead to undesired alterations like DNA damage which in turn could lead to tumor promoting effects and increase in permeability of the Sertoli cell barrier which could lead to male infertility (12). In the mean while also studies are performed which focus on the measurement of direct electrophysiological effects of exposure to mobile phone radiation. Several studies with cortical activity as the dependent variable have been performed: experiments focusing on effects in waking and sleep EEG, as well as studies assessing event related potentials (ERP). In waking EEG studies, the most consistent finding is an increase in the alpha frequency band $(8-12 \mathrm{~Hz})$ activity during mobile phone radiation exposure $(43,93,105)$. In sleep EEG studies an increase of the sleep spindle frequency range (12-15 $\mathrm{Hz}$ ) in non-rapid-eye-movement sleep has been reported repeatedly $(89,110-112)$. ERP is another often applied method to study brain activity, in which cortical stimulus-processing is investigated. Most studies in the field of mobile phone research investigate whether auditory stimuli (cochlear and brainstem auditory processes) are processed differently by the brain in the presence of a mobile phone (113). The idea behind this hypothesized effect is that auditory organs absorb most of the radiation energy from the mobile phone in a dialing position (114). However, not enough evidence has been reported to conclude that the presence of an active mobile phone alters the processing of these auditory stimuli $(88,93)$. In 2010, Carrubba and collegues proposed that mobile phone radiation pulses (instead of auditory stimuli), can be considered as stimuli (115). Twenty participants were included and in $90 \%$ of the participants evoked potentials were observed at a latency of approximately $270 \mathrm{~ms}$ in response to mobile phone radiation pulses. Strictly speaking, this study investigated the ERP response of an unconscious/subliminal stimulus. Evidence has been reported that ERPs of subliminal stimuli have a comparable morphological structure to ERPs of supraliminal stimuli. However, the amplitudes produced by subliminal stimuli are smaller (116). 
Recently a study was set up by our research team to investigate whether waking EEG frequency bands are influenced by mobile phone radiation (117). In this study, significant radiation effects were found for the alpha, slowbeta, fastbeta, and gamma bands. Interestingly, it was found that the effects depended on placement location of the mobile phone (ear versus chest), the ear placement showing larger effects compared to the chest placement.

Considering a radiation pulse/peak as a stimulus, thereby following the idea proposed by Carrubba, is probably the most profound method to investigate whether radiation causes a direct change in the brain physiology. It was decided to re-analyse the above mentioned dataset of Roggeveen et al (117), to investigate whether a mobile phone radiation peak results in an event (radiation peak) related potential (ERP). Thus, instead of investigating change in the EEG frequency bands, in the present article the data of the same study was used to investigate the hypothesized presence of ERP in response to radiation peaks. In contrast to the study of Carrubba et al., the radiation source was a functioning mobile phone instead of a simulator and a $3 G$ mobile phone network was used instead of a $2 G$ network. As a consequence of the choice for a mobile phone as radiation source, a radiation detector was used to detect peaks (stimuli). Further, it was decided to apply a recently published technique to quantify ERP data: the so called 'Event Related Fixed Interval Area' (ERFIA) method. This method is appealing since it focuses on areas instead of specific peak amplitudes (118). Because in some ERP studies, investigating subliminal stimuli, a P300 is observed, it was decided to create one ERFIA, ranging from $240-500 \mathrm{~ms}$, as the outcome measure of main interest. As a final methodological difference with Carrubba's study, multilevel regression analysis was used, since EEG/ERP data contain a nested structure.

Since the results on Roggeveen's dataset (117) demonstrated that the EEG-effects of mobile phone exposure were especially pronounced during mobile phone placement on the ear (compared to the chest), an a-priori placement*exposure interaction effect was expected.

\section{MATERIALS AND METHODS}

\section{Participants}

Thirty-one female participants (mean age of 26.7; SD=8.5), non-smoking, and without a medical history of cardiac or nervous system disorders were included. Four hours prior to the start of the session, no caffeine-containing beverages were used. No alcohol was used in the preceding 12 hours and sufficient night rest was ensured. After reading a document with detailed information about the study and having discussed any possible concerns with the researcher, subjects gave their verbal and written informed consent. Complete participation was compensated with €50,-. 


\section{Experimental procedures}

The study consisted of two sessions, each session taking place on a separate day, with a maximum of two days in between the two sessions. The experiments were conducted in an electrically non-shielded, room. The sequence of placement on the ear or heart was counterbalanced between the sessions. EEG was measured using shielded electrodes. Each shielded electrode had a separate ground plug, which was connected into a general grounddevice. The following EEG electrodes were placed in accordance to the 10-20 system (99): $\mathrm{Fz}, \mathrm{F} 3, \mathrm{~F} 4, \mathrm{Cz}, \mathrm{C3}, \mathrm{C4}, \mathrm{Pz}, \mathrm{P3}, \mathrm{P} 4, \mathrm{Oz}, \mathrm{O} 1$, and $\mathrm{O} 2$. All electrodes were fixed using conductive paste (29). A reference was placed on each ear lobe. To check for possible eye movements, an electro-oculogram (EOG) electrode was placed 1 centimetre under the midline of both eyes. The electrodes were connected to a BrainAmp amplifier (Brain Products). Impedances were maintained below $5 \mathrm{k} \Omega$. Spike artefacts due to radiation, which are mentioned in other articles $(87,100)$, were not observed in the data. Both EEG and radiation data were sampled with $1000 \mathrm{~Hz}$ using Brain Vision Recorder software. Each participant was exposed to four consecutive 15 minute conditions during each session, according to the schedule shown in Table 1. There were three conditions with a sham phone, and one condition with a dialling mobile phone. The experimenter entered the room at the end of each 15 minute condition to change the phone. During this exchange of phones, no electrophysiological measurements took place. In the case of two consecutive sham phone conditions, the same procedure was followed (a second sham phone was placed). In order to ensure blinding, the order of the conditions was unknown to the participant, thus achieving a single-blind experiment. The experimenters were not blinded. In one session, the 'dialling' condition was in the second quarter of an hour and in the other session the 'dialling' condition was in the third quarter. This sequence order was balanced over the subjects. Subjects were not aware of the different phones used.

Table 1. Experimental design

\begin{tabular}{lllll}
\hline & 15 minutes & 15 minutes & 15 minutes & 15 minutes \\
\hline Day 1 or 2 & Pre-exposure & Exposure & Post-exposure & Not used \\
& (PRE) & (EXP) & (POST) & \\
Day 1 or 2 & Not used & Pre-exposure & $\begin{array}{l}\text { Exposure } \\
\text { (EXP) }\end{array}$ & $\begin{array}{l}\text { Post-exposure } \\
\text { (POST) }\end{array}$ \\
& & (PRE) & & \\
\hline
\end{tabular}

The sequence was randomly determined in order to ensure blinding of the participant. In conditions labelled as 'not used', an identical sham phone was placed in the same way as in the pre- and post-exposure conditions. 


\section{Exposure}

- A 3 G smartphone was used. During exposure conditions, the phone was dialled from a fixed line in another room. No sound was exchanged (mute settings), and vibration mode was off, in order to ensure that the participant could not identify the dialling condition.

- The SAR level of the phone was reported as $0.69 \mathrm{~W} / \mathrm{kg}$ (head) in the manual.

- The sham phone was a non-functioning replica of the same weight and with the same characteristics as the functioning smartphone. In a pilot study before the start of the actual experiment, no evidence was found that participants could detect differences between the actual mobile phone and the sham phone.

Radiation activity was detected with a radiation detector (HF59B, Gigahertz Solutions), connected to an omnidirectional antenna. This detector was connected (from the DC output) to the BrainAmp headbox with an auxiliary plug. The detector was placed in the upright position, $30 \mathrm{~cm}$ above the table (at which the participant was sitting) and $20 \mathrm{~cm}$ left from the participant. In one of the two sessions, the phone/sham-phone was placed directly onto the left ear, ensuring that there was no contact between the phone and the EEG electrodes. The position of the phone was comparable to a typical dialling position, in an angle of approximately 45 degrees in relation to the perpendicular, tilted to the back of the head. During the other session, the phone was placed adjacent to the left side of the sternum, bordering the sternoclavicular joint. Previous tests showed that there was neither a direct interference of the mobile phone radiation on the shielded electrodes nor on the internal ADC converter of the amplifier. The rear side of the phone was placed on the skin in both sessions. The phone was fixed using an elastic band.

In order to investigate radiation exposure, a Network Analyzer, Agilent Technologies, E5061B ENA Series, $5 \mathrm{~Hz}-3 \mathrm{GHz}$ was used. The frequency band operated in the following frequency: 1.9291 to $1.9397 \mathrm{GHz}$. A radiation peak as measured with the radiation detector, equalled a power of approximately $10 \mathrm{dbm}$ measured next to the ear with the Network Analyzer.

In order to maintain the participant's alertness and to guarantee a relatively stable mood, participants watched an affectively neutral documentary about the development of the earth. All experimental sessions were performed between 09.00 and 17.00 o'clock.

\section{Data reduction}

EEG data was analysed offline with the software program BrainVision Analyser 2.0, Brain Products, München, Germany. EEG data was filtered using a high cut-off filter of $50 \mathrm{~Hz}$ and a low cut-off filter of $0.5 \mathrm{~Hz}$, to remove noise from the data. In the exposure condition (EXP, 15 minute dialling exposure)mobile phone radiation peaks were identified and manually marked as such. Based on these markers time segments, further called epochs, of 1200 ms were created, starting $200 \mathrm{~ms}$ before and lasting until $1000 \mathrm{~ms}$ after the onset 
of a radiation peak. After segmentation a baseline correction (interval -200 to $0 \mathrm{~ms}$ ) was performed. EOG data and radiation data were also divided into $1200 \mathrm{~ms}$ epochs. In the PRE and POST condition for each individual the same amount of markers was placed randomly. Twenty-millisecond ERFIAs (118) were calculated from -200 to $1000 \mathrm{~ms}$, resulting in 60 ERFIAs per radiation peak per participant. For the analyses in this article, 4 aggregated ERFIAs were computed: -200 to $0 \mathrm{~ms}, 0$ to $240 \mathrm{~ms}, 240$ to $500 \mathrm{~ms}$ and $500-1000 \mathrm{~ms}$. On the average 40 radiation peaks were present during EXP. The same amount of epochs were randomly selected from PRE and POST. The three PRE-EXP-POST condition were reduced to one dichotomous variable, contrasting a dialing mobile phone (EXP) versus a sham phone condition (PRE and POST).

\section{Statistical analysis}

Multilevel random regression analyses were used to investigate the effect of the radiation on the raw EEG outcome measures. The consecutive number of radiation peaks within each condition was the repeated measure variable. The multilevel regression analyses contained four levels: subject, session (every subject was measured on two separate days), condition (three conditions within each session) and radiation peak number (or its controls in PRE and POST). An autoregressive (AR1) covariance structure was used on the fourth level of radiation peak number in order to correct for the interdependency of the data. In all models a random intercept was included. An example of this model is shown in S1.

\section{S1 Text. Example of SPSS syntax for multilevel regression analysis.}

The main outcome variable was computed as the area of 240-500 ms post stimulus. For the post-hoc analyses (see the results section) a second outcome variable was created: the area between 500 and 1000 ms post-stimulus. In order to demonstrate that there were no pre-stimulus effects a so called 'baseline' measure was computed, being the area from 200 ms pre-stimulus to zero.

To correct for eye blinking/movements, data with outlying electro-oculogram (EOG) activity were rejected from the analyses. Besides this rejection, the remaining EOG information was used as a covariate in the statistical models. In all regression models the outcome variable was predicted by the following main effects: exposure (dialling versus sham), placement of the phone (ear versus heart), EOG activity, session (day 1 or day 2) and radiation peak number. In addition, the interaction variable placement*exposure was included in all models.

P-values $<=0.05$ were considered to be significant. All statistical analyses were performed with SPSS 22.0. 


\section{RESULTS}

In order to visualize radiation intensity during the epochs, a graph was created with the mean radiation values in the two conditions (dialling/EXP versus sham) (figure 1). As can be seen, the sham epochs (consisting of the PRE and POST conditions) show a flat line of radiation at approximately $0.1 \mathrm{~W} / \mathrm{m}^{2}$. This baseline-level can be considered as the background radiation level within the experimenting room. The radiation level during EXP epochs is, on the average, clearly above SHAM epochs. Even the radiation level of the $-200 \mathrm{~ms}$ to $0 \mathrm{~ms}$ baseline period is significantly heightened. This is explained by a general raise in radiation level during phone calls. In EXP epochs an immediate increase of radiation from $0 \mathrm{~ms}$ onward can be observed. The maximum of $5.6 \mathrm{~W} / \mathrm{m}^{2}$ is reached at $260 \mathrm{~ms}$ after the onset of the peak. There was variability between radiation epochs during the EXP (SDs ranged from MIN/MAX), however the difference between SHAM and EXP was significant $(p<0.0001)$. Radiation mainly fluctuated between days, due to a different burden on the mobile phone network. It is worth noting, that after $1000 \mathrm{~ms}$ the radiation level has not yet returned to the level before the onset of the peak. The average amount of peaks during EXP per 15 minute session was 34.56 (2.30/minute) with a maximum of 100 peaks and a minimum of 14 peaks per 15 minutes. In total there were 2143 radiation peaks.

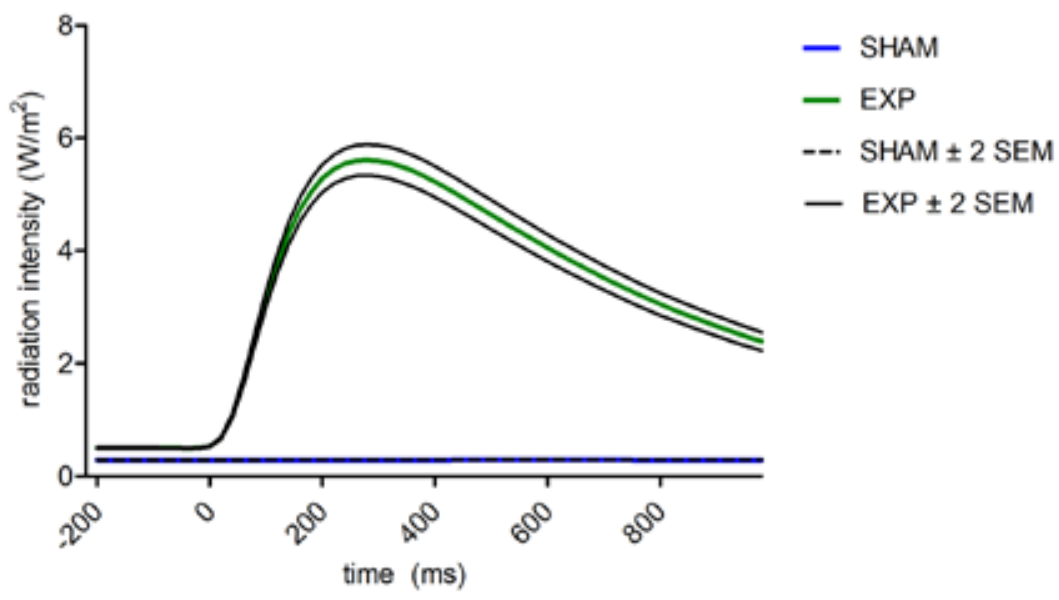

Figure 1. Mean radiation intensity of exposed and sham exposed epochs \pm 2 standard error of the mean.

The 4 grand averages of the non-conscious evoked related potentials of the twelve different locations are depicted in Figure 2. A visual inspection makes clear that the pre-stimulus baseline area $(-200-0 \mathrm{~ms})$ does not show remarkable differences between the four grand averages. In the post-stimulus area, the exposed ear session is the only condition which has 


\section{- Ear-sham - Ear-exp - Chest-sham - Chest-exp}

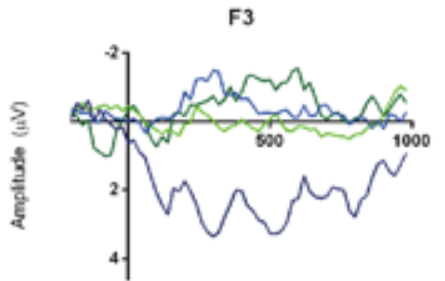

ERFLA iper 20 ms:

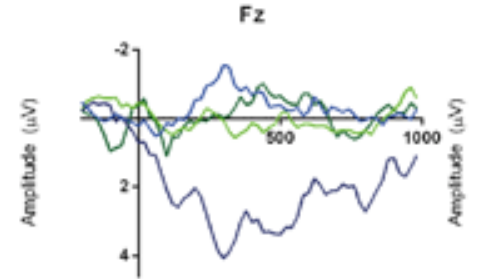

ERFIA (per $20 \mathrm{~ms}$ )

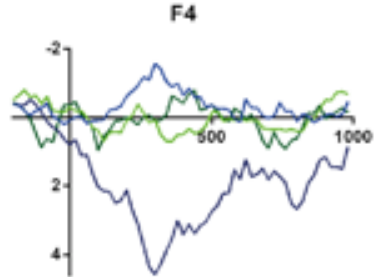

ERFIA (per $20 \mathrm{~ms})$ c3

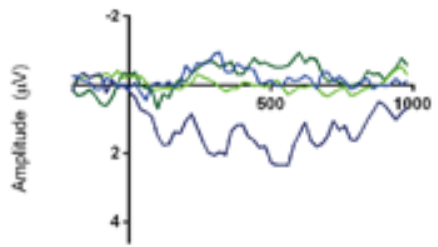

ERFIA iper $20 \mathrm{~ms}$ )

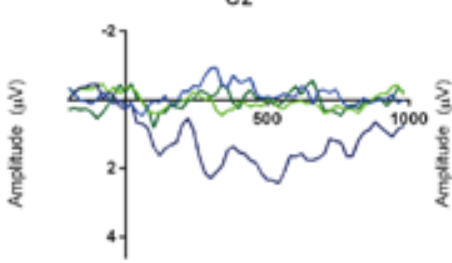

ERFIA (per $20 \mathrm{~ms}$ )

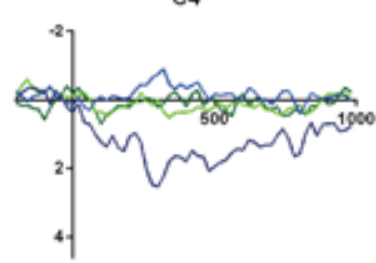

ERFIA (per $20 \mathrm{~ms}$ )

P3

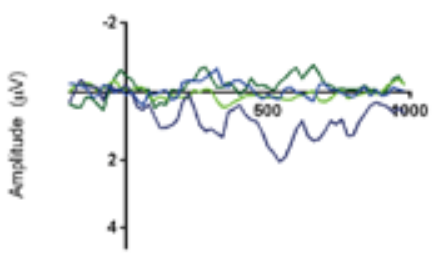

ERFLA (per $20 \mathrm{~ms}$ )

01

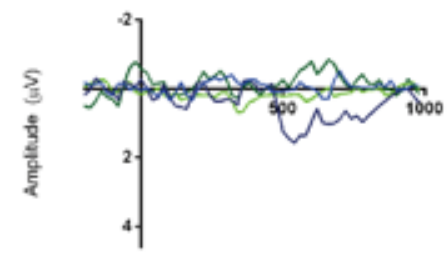

ERFIA (per $20 \mathrm{~ms}$ )

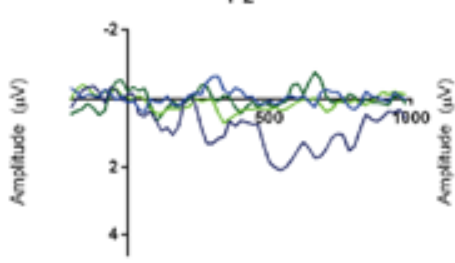

ERFIA (per $20 \mathrm{~ms}$ )

$\mathrm{Oz}$

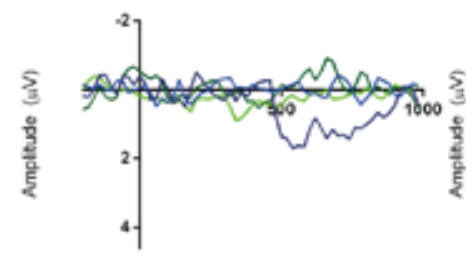

ERFIA (per $20 \mathrm{~ms}$ )

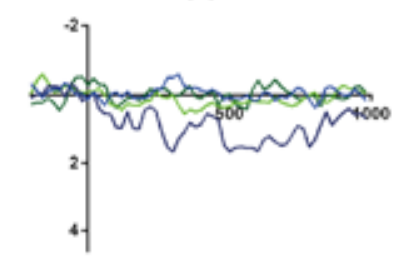

ERFIA (per $20 \mathrm{~ms}$ )

$\mathrm{O} 2$

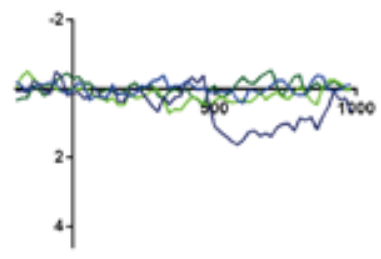

ERFIA (per $20 \mathrm{~ms}$ )

Figure 2. Event Related Fixed Interval Area (per 20ms) grand averages in twelve EEG locations 
a distinct course. This effect is especially prominent in the $240-500 \mathrm{~ms}$ frontal and central post-stimulus areas. Except Fz and F4, in which a P300-like peak can be detected, the morphology is not similar to that of most conscious ERP responses: a N200 is missing and the ERP has a smaller amplitude in general. Moving from frontal to occipital, the 'P300 peak' seems to diminish and a later effect, from 500-1000ms, becomes more noticeable. These are no obvious visual left-right hemispherical differences. Figure 3 shows the topography of the grand averages.

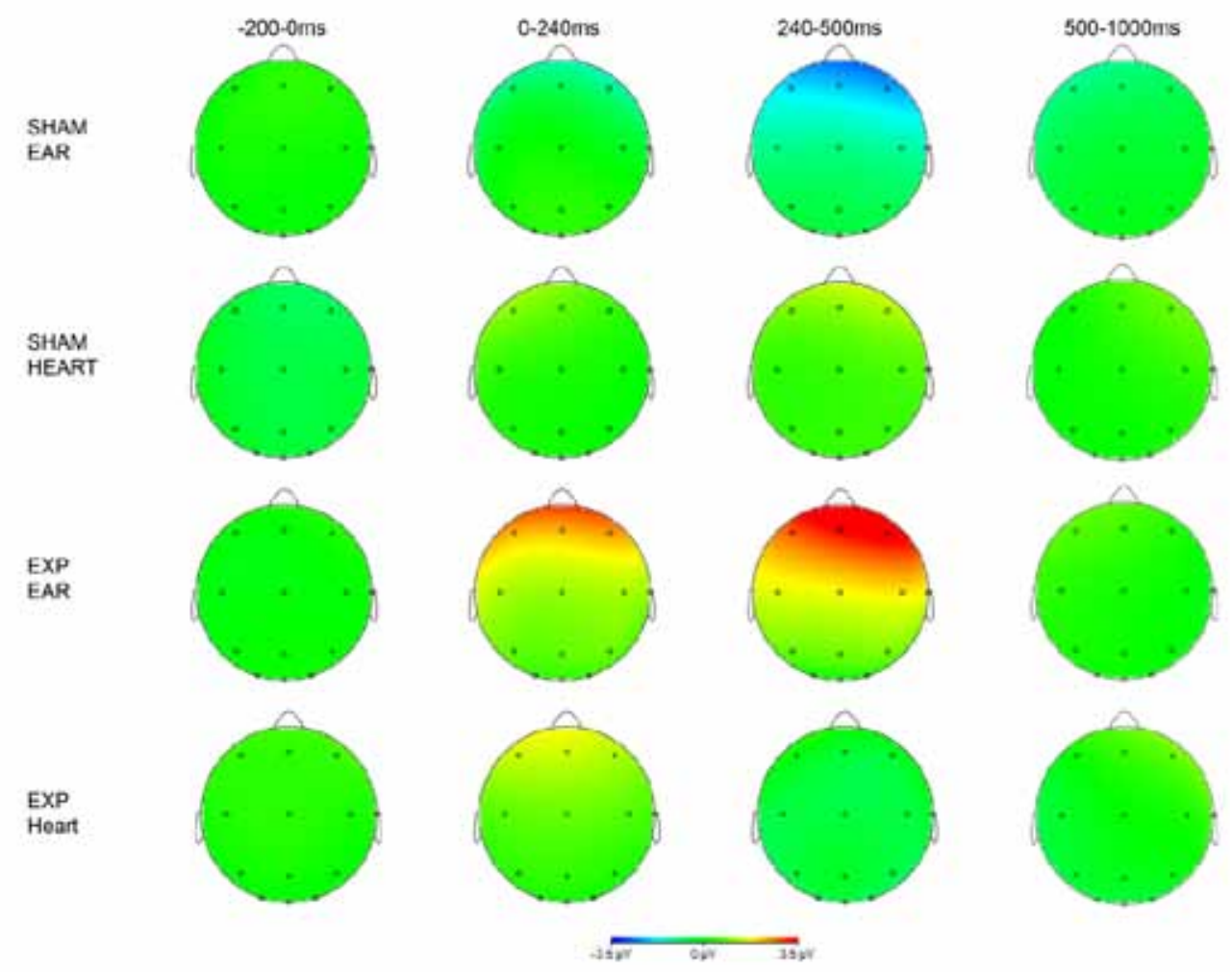

Figure 3. Topography of EEG activity

In table 2 the t-values (and their corresponding $p$-values) of the main outcome variable are presented: the interaction effect between placement and exposure. As expected, the baseline (-200-0ms) never reaches significance. The same applies for the first post-stimulus period ranging from 0 to $240 \mathrm{~ms}$. In the critical range from $240-500 \mathrm{~ms}$ the frontal and central regions show a significant elevation for the ear exposed condition compared to the other conditions. Based on the visual inspection of the grand averages, it was decided 


\begin{tabular}{|c|c|c|c|c|c|c|c|c|}
\hline & \multicolumn{2}{|c|}{-200 to $0 \mathrm{~ms}$} & \multicolumn{2}{|c|}{0 to $240 \mathrm{~ms}$} & \multicolumn{2}{|c|}{240 to $500 \mathrm{~ms}$} & \multicolumn{2}{|c|}{500 to $1000 \mathrm{~ms}$} \\
\hline & t-value & p-value & t-value & p-value & t-value & p-value & t-value & $p$-value \\
\hline Fz & 1.889 & 0.059 & -0.047 & 0.963 & -3.030 & $0.002^{*}$ & -2.123 & 0.034 \\
\hline F3 & 1.243 & 0.214 & -0.543 & 0.588 & -2.532 & 0.011 & -2.648 & 0.008 \\
\hline F4 & 1.106 & 0.269 & -0.477 & 0.634 & -3.121 & $0.002^{*}$ & -1.033 & 0.302 \\
\hline Cz & 1.880 & 0.060 & 0.163 & 0.871 & -2.152 & 0.031 & -2.436 & 0.015 \\
\hline C3 & 1.379 & 0.168 & -0.537 & 0.592 & -2.567 & 0.010 & -2.990 & $0.003^{*}$ \\
\hline C4 & 1.360 & 0.174 & -0.344 & 0.731 & -2.442 & 0.015 & -1.750 & 0.080 \\
\hline $\mathbf{P z}$ & .891 & 0.373 & 0.246 & 0.805 & -0.721 & 0.471 & -2.814 & 0.005 \\
\hline P3 & .841 & 0.400 & -0.060 & 0.952 & -1.360 & 0.174 & -2.855 & $0.004 *$ \\
\hline P4 & .736 & 0.462 & -0.328 & 0.743 & -1.171 & 0.242 & -2.379 & 0.017 \\
\hline $\mathrm{Oz}$ & .540 & 0.589 & 0.372 & 0.710 & 0.583 & 0.560 & -3.291 & $0.001^{*}$ \\
\hline 01 & .388 & 0.698 & 0.030 & 0.976 & -0.008 & 0.994 & -3.265 & $0.001 *$ \\
\hline 02 & .417 & 0.676 & 0.230 & 0.818 & 0.580 & 0.562 & -2.956 & $0.003 *$ \\
\hline
\end{tabular}

T-values and p-values of the predictor; the interaction variable placement*exposure. The area in the first row is the dependent variable. An example of the statistical model used can be seen in S1. * significant after Bonferroni correction.

to perform a series of post hoc analyses on the ERFIA range of 500-1000ms post-stimulus. A significant elevation for the exposed ear condition was found for all electrodes except for F4 and C4. Finally, when correcting for multiple testing (12 locations) by means of the Bonferroni procedure $\left(p_{\text {critical-corrected }}(0.05 / 12)=0.004\right)$, an asterisk is placed in column ' $C$ ' when the $p$-value remains significant.

\section{DISCUSSION}

Several studies have demonstrated altered EEG frequency bands due to the presence of an active mobile phone (7-9). However, the causal mechanisms for this effect are, to our knowledge, not yet uncovered. Supposed electromagnetic radiation causes changes in EEG activity, a dose-response relationship should be demonstrable. In the present study it was hypothesized that $3 \mathrm{G}$ radiation peaks, short-term elevations of electromagnetic radiation, produce an immediate change in EEG activity, compared to a 'non-radiation' sham phone control condition. Radiation peaks were conceptualized as non-conscious stimuli which may produce event related potentials (ERPs). In other words, the key question to be answered was whether or not a $3 G$ radiation peak (being a subliminal stimulus) can be 
detected by the brain, without assuming a response typical for a supraliminal stimulus. In the experimental design subjects were both exposed to a mobile phone placed on the ear, and to a mobile phone placed on the chest. These measurements took place on two separate days. The a-priori expected effect on the post-stimulus ERFIA range of $240-500 \mathrm{~ms}$, was evident: Not only a clear visual effect was observed, also the placement times exposure interaction was statistically significant, meaning an increase of cortical activity, only during the ear exposure condition and only in the frontal and central regions. Although this effect is not as large, regarding the amplitude, as observed in studies investigating supraliminal stimuli, it is comparable to effects of subliminal stimuli (116).

The non-significant interaction effects during the $200 \mathrm{~ms}$ baseline may be considered as a validation of the just mentioned post-stimulus effects. Although the ERFIA grand averages of the exposed ear condition visually started from zero onwards, non-significant effects of the $0-240$ ms region were found. This might be due to a lack of power or may be the result of a non-optimal chosen ERFIA range.

By means of a visual inspection of the grand average ERFIA plots (figure 2), it was noted that a second region (or to be considered as an extension of the first), from $500-1000 \mathrm{~ms}$, is affected during the ear-placement condition in all cortical regions. The placement times exposure interaction in this late region turned out to be significant in almost every EEG location. Although a profound interpretation of this late effect is lacking, it has to be noted that, in contrast to most ERP studies, the experimental stimulus (in this study a radiation peak) is active during the entire post-stimulus interval. Typically, the duration of a stimulus in an ERP study is relatively short ( $<100 \mathrm{~ms})$. The mean radiation peak (figure 1$)$, however, did not return to baseline after $1000 \mathrm{~ms}$. It therefore might be that EEG effects are more extended in time, compared to regular ERP studies. A post hoc explanation for the late (500-1000ms) effect might be that the maximum radiation intensity is reached after $260 \mathrm{~ms}$. Interestingly, this late effect turned out to be statistically greater compared to the 240-500ms effect.

To our knowledge, only the study of Carrubba et al (115) tested a comparable hypothesis to that of the present study. Although there are important methodological differences between these two studies (see introduction), it is worthwhile to compare the results. The timeframe in which an evoked potential was found in Carruba et al. was from 267 to $529 \mathrm{~ms}$ post-stimulus. The largest ERFIA amplitudes of the present study were found in almost the same range. This resemblance might indicate a certain robustness of the radiation effect on cortical activity, quantified with ERP / ERFIA.

Several limitations of this study have to be mentioned. First, a relatively small and homogeneous population of 31 healthy females was included. A larger sample size, selected from the general population is needed to investigate the replicability and generalizability of the results. A second limitation concerns the, strictly speaking, non-experimental control of the radiation peaks. Although the exposure condition contained a lot of radiation peaks, 
there was no active control on both the size and the timing of these peaks. In addition, by using an active mobile phone, the brain is exposed to both electromagnetic and thermal processes. The usage of a device which experimentally simulates controlled radiation peaks comparable to that of a mobile phone might be preferred. On the other hand and this was the main reason choosing a mobile phone in this study - a mobile phone provides the best representation of reality. Moreover, the finding of an immediate change in cortical activity after a radiation peak makes an explanation in terms of only thermal effects unlikely. Third, the design compared a 15 minutes dialling condition with a PRE and POST 15 minute sham phone condition. It could be argued that a more frequent alternating dialling schedule would be a more preferred method than the chosen ABA design. Fourth, since the duration of a mean radiation peak is longer than $1000 \mathrm{~ms}$, it would be interesting to experiment with a segment extending $1000 \mathrm{~ms}$. Fifth, the experimenter was not blinded. However, it is implausible that this lack of blinding has influenced the results. Finally, it seems unlikely that, executing the experiment in a non-shielded room (thereby allowing background radiation), has had a substantial effect on the EEG measured around radiation peaks.

In sum, this study demonstrates that non-consciously sensed radiation peaks, produced by a dialing $3 \mathrm{G}$ mobile phone, are detected by the brain in terms of short-term increased cortical activity. In addition, the ear placement specificity (compared to the chest) of the radiation effect on the cortex is striking. The crucial question whether or not the immediate effect of radiation on cortical activity may have an (negative) influence on health, cannot be answered yet. It would be ideal, but challenging, to perform longitudinal prospective research with differentially RF-EMF exposed groups in relation to several health outcomes. Next to EEG, transcranial magnetic stimulation might be used to test brain excitability, which has also shown changes in brain excitability due to mobile phone usage [25]. In addition, there is scope for investigation of effects at the cellular level, especially DNA change due to radiation, which will probably become more practical with the advent of novel imaging techniques. 


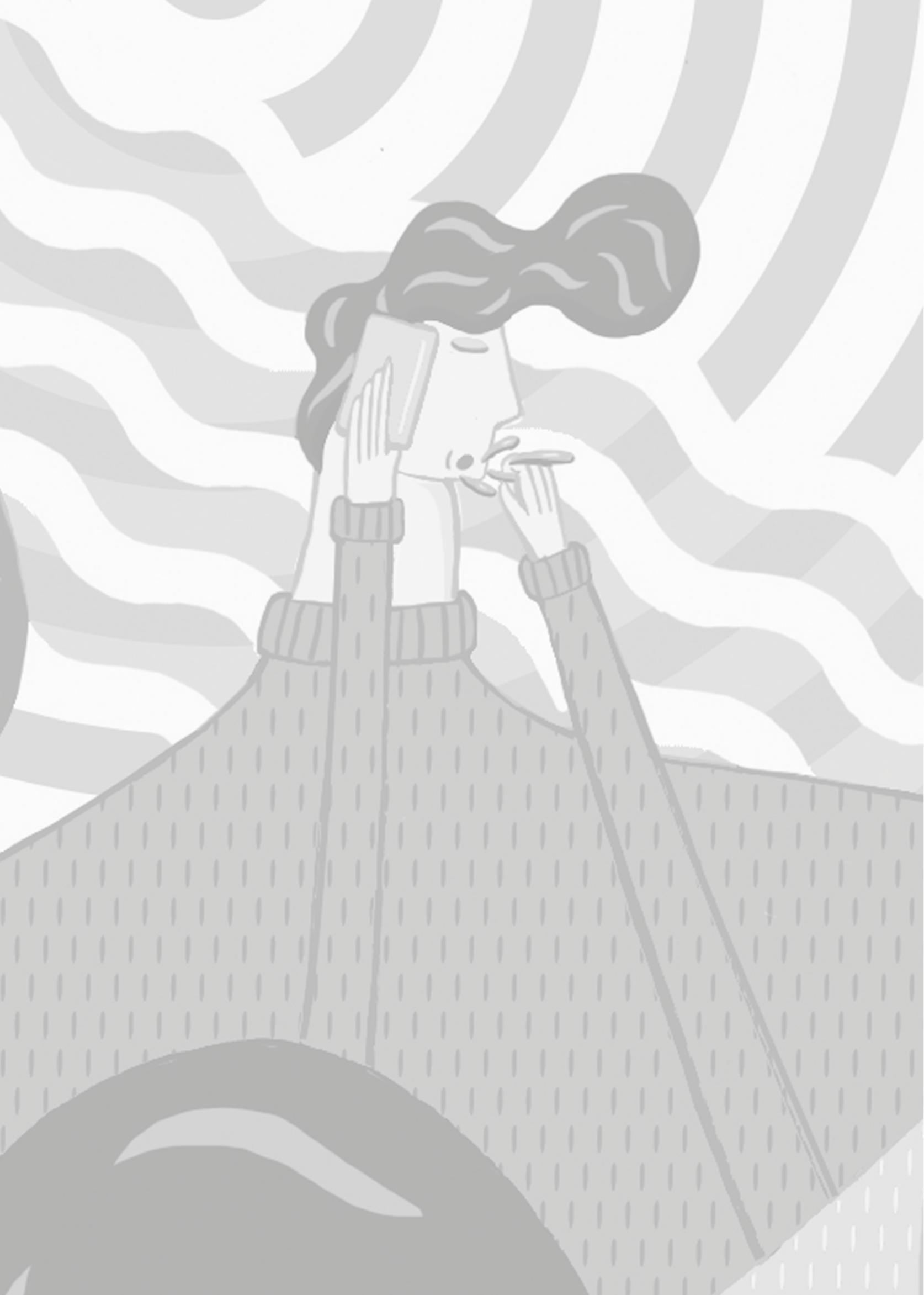




\section{The brain exposed to remote controlled alternating mobile phone conditions: what happens to EEG?}

Suzanne Roggeveen

Jim van Os

Wolfgang Viechtbauer

Anouk van Alphen

Johan Gielissen

Rosan Luijcks

Richel Lousberg 


\section{ABSTRACT}

This study investigated whether an active, dialing $3 G$ mobile phone, in comparison with a standby mobile phone, causes a change in EEG. Fifty subjects underwent a protocol in which a mobile phone was placed next to the ear. The condition of the mobile phone was remotely alternated between standby and dialing. Each 30-second period, during a one-hour measurement, was individually, randomly allocated to either dialing or standby. A twelve-lead EEG and radiofrequency radiation were recorded simultaneously. Six EEG frequency bands (delta, theta, alpha, slowbeta, fastbeta and gamma) were computed. Guided by previous work, it was hypothesized that a dialing mobile phone would be associated with increased EEG activity. Using multilevel random regression analyses, no significant differences between the standby and dialing condition were apparent, although a trend towards increased EEG activity was present during the dialing condition across all bands. The contrast with standby as a control condition, rather than a dummy state, may represent a post-hoc explanation for the inconclusive results. Follow-up work is required to test the hypothesis of a possible 'standby' effect on EEG, contrasting standby versus dummy versus dialing. 


\section{INTRODUCTION}

Two-thirds of the world population owns a mobile phone, whilst twenty years ago this was only $3 \%$ (119). Growth is still expanding and it is expected that 1 trillion objects will be connected to the Internet in 2025 (119). Every sector of the economy will be, or is already, digital, which makes it a necessity to be an active digital user in a large part of the world. Most digital products involve a degree of exposure to electromagnetic radiation. The spectrum of radiation is broad. The bands of $1885-2025 \mathrm{MHz}$ and $2110-2200 \mathrm{MHz}$ were intended for use of the $3 \mathrm{G}$ network on a worldwide basis (120).

The possible impact of mobile phone radiation on physical, psychological and ecological measures remains an important topic of research, since the technology is changing constantly and the phenomenon is relatively new. There are, for instance, indications that the usage of mobile phones can lead to an increased risk of stress, altered sleep and symptoms of depression (59). However, contrasting results have been found, ranging from findings that mobile phone usage causes an increased risk of brain tumors (30-33) to findings in which mobile phone use is not found to be harmful $(26,27,29)$. Currently, no clear conclusions about (health) effects of mobile phone usage can be drawn.

One area of research focusses on the question whether or not mobile phone radiation causes any physiological change at all. This research mostly involves the brain, since a dialing mobile phone is normally held against the ear. The brain represents a complex electrophysiological network which may be influenced by electromagnetic radiation of mobile phones. It remains uncertain to what degree mobile phone radiation impacts brain activity. Several conflicting results have been published $(121,122)$, and an increase in power of the alpha frequency band in response to an active mobile phone was reported recurrently $(42-45,92,94,105,113)$. We recently investigated possible direct effects of mobile phone radiation on electrocortical activity $(123,124)$. In one experiment, it was investigated whether radiation peaks, as measured during a dialing mobile phone condition, could cause an event related potential (ERP). Evidence suggested that radiation peaks may cause a so-called subliminal (unconscious) ERP. In a second report, an increase in EEG activity in the alpha, but also slowbeta, fastbeta and gamma frequency bands under exposure of a $3 \mathrm{G}$ dialing mobile phone compared to a dummy phone was described (123). An ABA design was applied, in which the 15-minute exposure duration was preceded and followed by a 15 -minute dummy phone condition.

In the present study, we wished to test more frequent randomly alternating mobile phone conditions for superior replication and proof of principle of earlier findings. A remote controlled system was created to change mobile phone settings from a distance, including up to approximately 30 switches in condition per session. As a mobile phone was used, instead of a radiation simulation device, it was not possible to turn off the emission of radiation of the mobile phone completely during the control condition. Therefore, the 
control condition in this study was the mobile phone standby state. To have standby as control condition, rather than a dummy telephone, has the advantage that it closely mimics reality since people often carry their mobile phone in standby condition. The difference in radiation level between the conditions was measured by the presence of a radiation detector. In the double-blind, randomized paradigm, subjects attended a single session. During the course of the protocol, electroencephalography and radiation activity were measured simultaneously with a $1000 \mathrm{~Hz}$ sampling rate.

The experiment was set up to investigate the following research question. We wished to examine whether the power of EEG frequency bands is altered due to a mobile phone dialing condition as compared to a standby condition. The hypothesis, guided by previous experiments, was that the power of the alpha and higher frequency bands would increase during the dialing condition.

\section{MATERIALS AND METHODS}

\section{Participants}

Fifty healthy participants, 20 men and 30 women, aged $18-29$ years, participated in the experiment (age: $\mu=21.8 \sigma=2.6, \sigma^{\top}: \mu=22.2 \sigma=2.9, q: \mu=21.6 \sigma=2.3$ ). All participants were in the possession of a smartphone (inclusion criterion) and had no medical history of cardiac or nervous system disorders (exclusion criteria). On the day the experiment took place, no caffeine-containing beverages were used. No alcohol was used during the 12 previous hours and sufficient night rest was ensured. Subjects were asked to provide an overview of their mobile phone usage (dialing minutes and MB usage) of the past 3 months as charged by their phone provider. After reading a document with detailed information about the study and having discussed any possible concerns with the researcher, subjects provided written informed consent. Participation was compensated with €20,--

\section{Experimental procedures}

Each participant underwent a single session, lasting about two hours and taking place between 9 am and 5 pm. The experiments were performed in an academic mental health care institute at the outskirts of the city; the experimental room (which was not electrically shielded) was located on the second floor. EEG was measured using shielded electrodes. Each shielded electrode had a separate ground plug, which was connected to the amplifier ground. The following EEG electrodes were placed in accordance to the 10-20 system (125): Fz, F3, F4, Cz, C3, C4, Pz, P3, P4, Oz, O1 and O2. All electrodes were fixed using 1020 conductive paste (126). A reference was placed on each ear lobe. To check for possible eye movements, an electro-oculogram (EOG) shielded electrode was placed 1 centimeter under the midline of both eyes. The electrodes were connected to a BrainAmp amplifier 
(Brain Products). Impedances were maintained below $5 \mathrm{k} \Omega$. Spike artefacts due to radiation, described in other articles (121), were not observed. Both EEG- and radiation data were sampled with $1000 \mathrm{~Hz}$ using Brain Vision Recorder software. A mobile phone was placed with the rear side to the participant's left ear with an elastic band avoiding direct contact between the phone and the electrodes. The position was in an angle of approximately 45 degrees (Fig. 1).

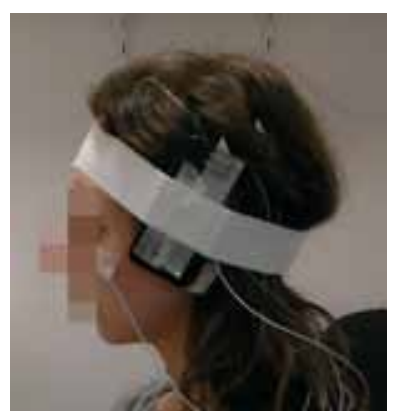

Fig. 1. Test set-up

The randomized, remote-controlled system to control the mobile phone conditions was constructed as follows. The desired contrast was between alternating standby and dialing conditions. The whole experiment lasted 70 minutes. A baseline phase was created based on standby state during the first 10 minutes. The following 60 minutes were divided in 120 segments of 30 seconds. In each participant, each 30 second segment was randomly allocated to the standby or dialing condition. Consequently, each participant had a different, random dialing schedule. This is illustrated in Fig. 2. This allocation implicated that several successive dialing or standby segments could be formed. The mean length of a dialing segment was 59.81s ( $S D \pm 42.20 \mathrm{~s}$ ) and $58.89 \mathrm{~s}(\mathrm{SD} \pm 43.21 \mathrm{~s}$ ) for a standby segment. In order to execute participant-specific dialing schedules from a distance, a free application, which allowed for answering a call automatically, was installed on the mobile phone. Second, an executive program with commands for the 60 distinct dialing schedules was installed on a PC. Using this program, each schedule could be activated separately. When activated,

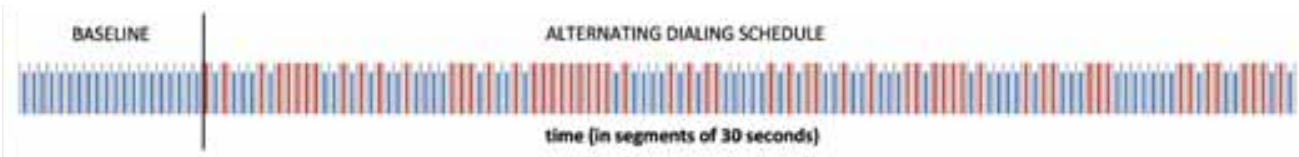

Fig. 2. Dialing schedule. The first 10 minutes were always in standby condition. After this baseline, each participant was exposed to an individual dialing schedule in which each half-minute period was randomly assigned to either the dialing or the standby condition. Blue represents a 30 second standby segment, red a 30 second dialing segment. 
an online connection was made to a (paid) dialing account. Simultaneously, a connection was made to a cloud where the commands for the several dialing/standby durations was encoded, allowing execution of the activated dialing schedule.

\section{Exposure}

- A 3 G smartphone, identical to the phone used in the previous study (127) was used. No sound was exchanged (mute settings), in order to ensure that the participant could not identify the dialing condition.

- The SAR level of the phone is reported as $0.69 \mathrm{~W} / \mathrm{kg}$ (head) in the manual.

Radiation activity was detected throughout the experiment with a radiation detector (HF59B, Gigahertz Solutions), connected to an omnidirectional antenna. This detector was connected (from the DC output) to the BrainAmp headbox with an auxiliary plug. The detector was placed in the upright position, $30 \mathrm{~cm}$ above the table at which the participant was sitting and $20 \mathrm{~cm}$ left from the participant. Previous tests showed that there was no direct interference of the mobile phone radiation with either the shielded electrodes or the internal $A D C$ converter of the amplifier.

In order to investigate the administered radiation, a Network Analyzer, Agilent Technologies, E5061B ENA Series, $5 \mathrm{~Hz}-3 \mathrm{GHz}$ was used. The frequency band operated at the following frequency: 1.9291 to $1.9397 \mathrm{GHz}$. Second, a radiation peak as measured next to the ear with the radiation detector was approximately $10 \mathrm{dbm}$. In order to maintain the participant's alertness and to guarantee a relatively stable mood, participants watched an affectively neutral documentary about mammals. Before the start of the experiment, participants were encouraged to pay close attention to the video and they were told that they would be tested afterwards with regard to the content of the documentary. A small financial recompense was promised for the participant with the best test performance.

\section{Data reduction}

Brainvision Analyzer 2.0 (Brain Products, München, Germany) was used to analyse the data offline. In order to create EEG frequency bands, the data were filtered using a high cut-off filter of $50 \mathrm{~Hz}$ and a low cut-off filter of $0.5 \mathrm{~Hz}$, as customary for EEG data. The start of each dialing/control condition was marked. After each marker, a MatLab script created consecutive segments of 1024 ms. A fast Fourier transformation (FFT) was performed for each epoch. The following frequency bands were computed: delta (from 0.5 to $4.0 \mathrm{~Hz}$ ), theta (from 4.0 to $7.5 \mathrm{~Hz}$ ), alpha (from 7.5 to $13.0 \mathrm{~Hz}$ ) slow beta (from 13.0 to $20.0 \mathrm{~Hz}$ ), fast beta (from 20.0 to $30.0 \mathrm{~Hz}$ ) and gamma (from 30.0 to $47.0 \mathrm{~Hz}$ ). After, EEG-data were exported to SPSS 21.0. The dataset was set up in such a way that each record contained the information of approximately a half-minute period; each record consisted of an FFT average of 29 consecutive epochs $(29 * 1024 \mathrm{~ms}=29696 \mathrm{~ms})$. A variable called 'half_minute_ 
block' was created to use as time variable in the models. This was necessary as dialing/ control segments were always a multitude of 30 seconds. All EEG variables were log10transformed because of a positively skewed distribution. EOG and radiation data were also divided in $1024 \mathrm{~ms}$ epochs, but were exported to SPSS without FFT transformation.

\section{Statistical analysis}

To investigate the effect of the two different conditions (dialing and standby) on the EEG variables, multilevel random regression analyses were used. The 'half_minute_block' variable was used as the repeated measure variable. The model contained two levels, in which consecutive half-minute-blocks were nested within subjects. There were 72 (12 electrodes * 6 EEG frequency bands) dependent variables. In total $12 * 6=72$ analyses were performed. Since EEG activity of consecutive EEG segments is interdependent, an autoregressive (AR1) covariance structure was used to correct for this interdependency.

To correct for EOG activity, outlying EOG activity was rejected from the analyses $(0.5 \%$ of the data rejected). The remaining EOG activity was included in all models as a covariate. The main predictor was the dichotomous condition variable (dialing or standby). Age, sex, and half_minute_block were included as covariates in all models. Next to the fixed effects, for the following variables random effects were included: intercept, the condition variable and half_minute_block.

For all the models, $p$-values $<=0.05$ were considered significant. All statistical analyses were performed with SPSS 21.0.

\section{RESULTS}

After the experiment, participants were asked whether they had noticed changes in the state of the mobile phone during the session. None of the subjects reported impression of changes in condition.

\section{Condition}

Multilevel random regression analyses were performed to test whether EEG data was impacted by condition of the mobile phone (dialing or standby). Fig. 3 shows the t-values of the condition variable, which reached significance in only three instances (delta P4, delta C4 and slowbeta C4). Taking into account multiple testing (72 tests, each performed at 0.05 level), findings were not significant. The EOG covariates were very significant, with p-values $<0.001$ across models. Time was not a significant covariate, as was age. Sex was a significant covariate in most models. 


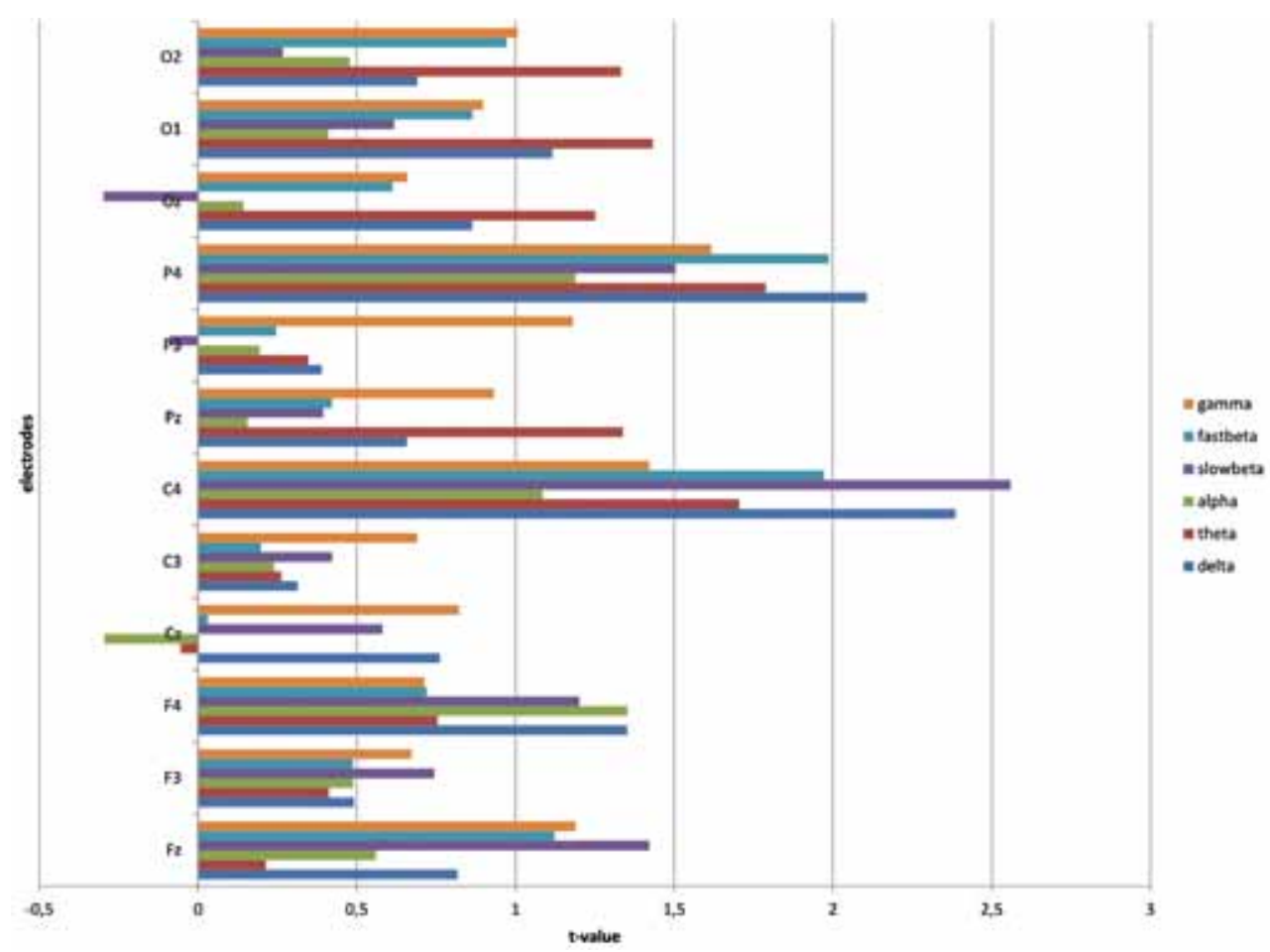

Fig. 3. Condition effects (t-values) of the 12 lead EEG. A value $>=2$ represents a significant association.

\section{Post-hoc}

Few condition effects were present in the data. Post-hoc analyses were performed to further investigate the non-hypothesized result, comparing the intensity of radiation across the standby condition with a dummy condition as recorded in a previous study (127). The first 10 minutes of both studies were investigated. This confirmed that the radiation intensity in the standby condition was significantly higher compared to the dummy condition.

Next, all models testing the condition effects were run again with all covariates omitted. More specifically, only condition remained as predictor and EOG, time, sex and age were removed as covariates. This simplified model resulted in more (13 versus 3 ) significant effects (Fig. 4). Almost all frequency bands at $\mathrm{C} 4$ and P4 had positive, significant estimates in the hypothesized direction: more EEG power was observed during the dialing condition compared to the standby condition. Stepwise removal techniques of the covariates, demonstrated that EOG was the covariate that acted most strongly as a confounding variable. 


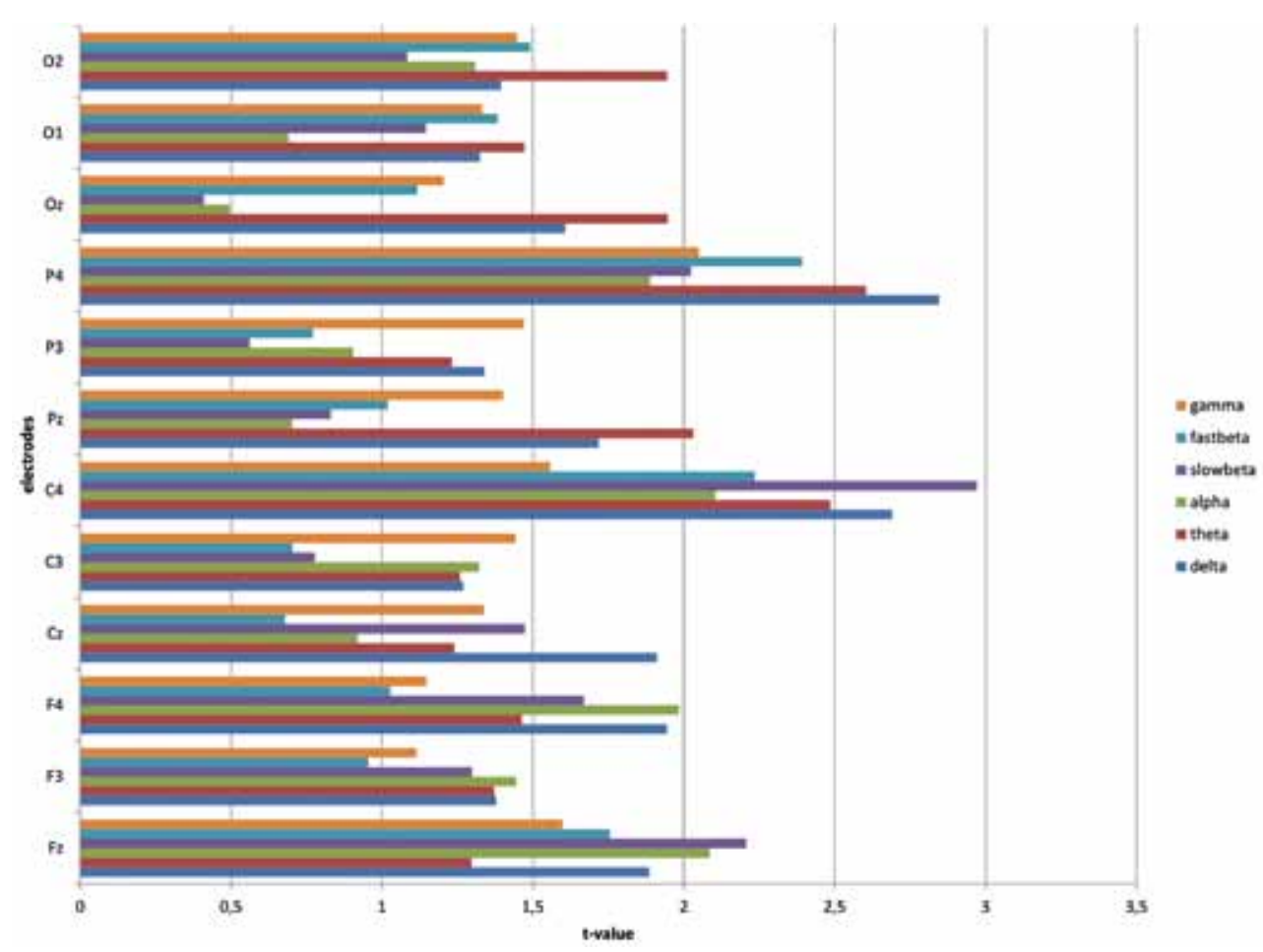

Fig. 4. T-values of main predictor condition when analyzed in a simplified model. A value $>=2$ represents a significant outcome.

\section{DISCUSSION}

A relatively large number of subjects $(\mathrm{N}=50)$ took part in this experimental study to investigate whether or not a dialing mobile phone impacts brain activity. The dependent variable was the power of EEG frequency bands. The key issue was to investigate whether condition effects could be identified.

\section{Condition effects}

The hypothesis was that the effects of dialing found in the previous study (127) would be replicated. Thus, increased power of all EEG frequency bands in the dialing condition was hypothesized. However, the analyses revealed a null finding. This discrepancy between the results of the two studies requires an explanation.

Three explanations can be considered. i) The outcome of the first experiment was false-positive, ii) the results of the present experiment are false-negative and iii) both 
studies are true but not comparable. Based on a critical methodological evaluation of the studies, the first two explanations, but maybe not the latter, are implausible. Although the methodology of the present experiment was correct, it may not sufficiently match the research question. The methodological decision to include a standby state as the control condition may represent a mismatch. It was expected that the standby condition would be neutral and comparable to a dummy state. In retrospect, this assumption may not be correct. Some of the electrical components in a mobile phone are active in the standby mode, as all electronic devices cause interference when switched on. For this reason, a dummy phone may yield different results compared to a phone in standby mode. A low dose of radiation (as in the standby condition) may already affect brain activity. Post-hoc testing revealed that the standby condition was associated with a significantly higher level of radiation compared to the dummy condition. Therefore, in setting up a study design aimed at providing 'proof of principle' of EEG effects of a dialing mobile phone, the control (standby) condition as used in the present study may represent insufficient contrast. A dummy condition is required as well.

Other issues may be relevant. First, in the previous study a consecutive 15-minute dialing exposure condition was used, whereas dialing in the current study varied between 30 and 300 seconds and was repeatedly interrupted by the standby control condition. An EEG effect may require a minimal uninterrupted time of exposure (e.g. $>10$ minutes). It was not possible to test this post-hoc explanation, since the number of uninterrupted, long-lasting exposures (300 seconds) was tiny ( $\mathrm{N}=2$ ).

A second issue is related to statistical modelling. Ideally, only variables which are under direct experimental control should be included in the statistical models. In the present experiment, the dichotomous variable condition (contrasting the dialing with the standby condition) is the predictor of main interest and was under experimental control. The actual models also contained other covariates which may confound associations and are often controlled for in EEG analyses. Of these, EOG acted as a confounder for the condition effect, as removing EOG from the model revealed a trend towards increased EEG activity in the dialing condition. It is possible that EOG itself is also influenced by mobile phone radiation (there are suggestions in the literature $(14,128)$ that for example eye fluids can be influenced by mobile phone radiation). In accordance with this post hoc hypothesis, it has to be noted that the present study contains 70 minutes of exposure (standby cannot be considered radiation free) compared to 15 minutes of exposure in the previous study. 


\section{CONCLUSION}

The design of the present study is adequate to answer the question whether a dialing mobile phone has a different effect on brain activity compared to a standby mobile phone. No significantly different brain activity was observed. For future research it is recommended to carry out an experiment contrasting a standby mode versus a dummy state, taking into account the methodological considerations of this study. As a final statement, standby is often considered a relatively 'innocent/inactive' phone condition, but the outcomes of this study raise the possibility that standby could also affect EEG. 


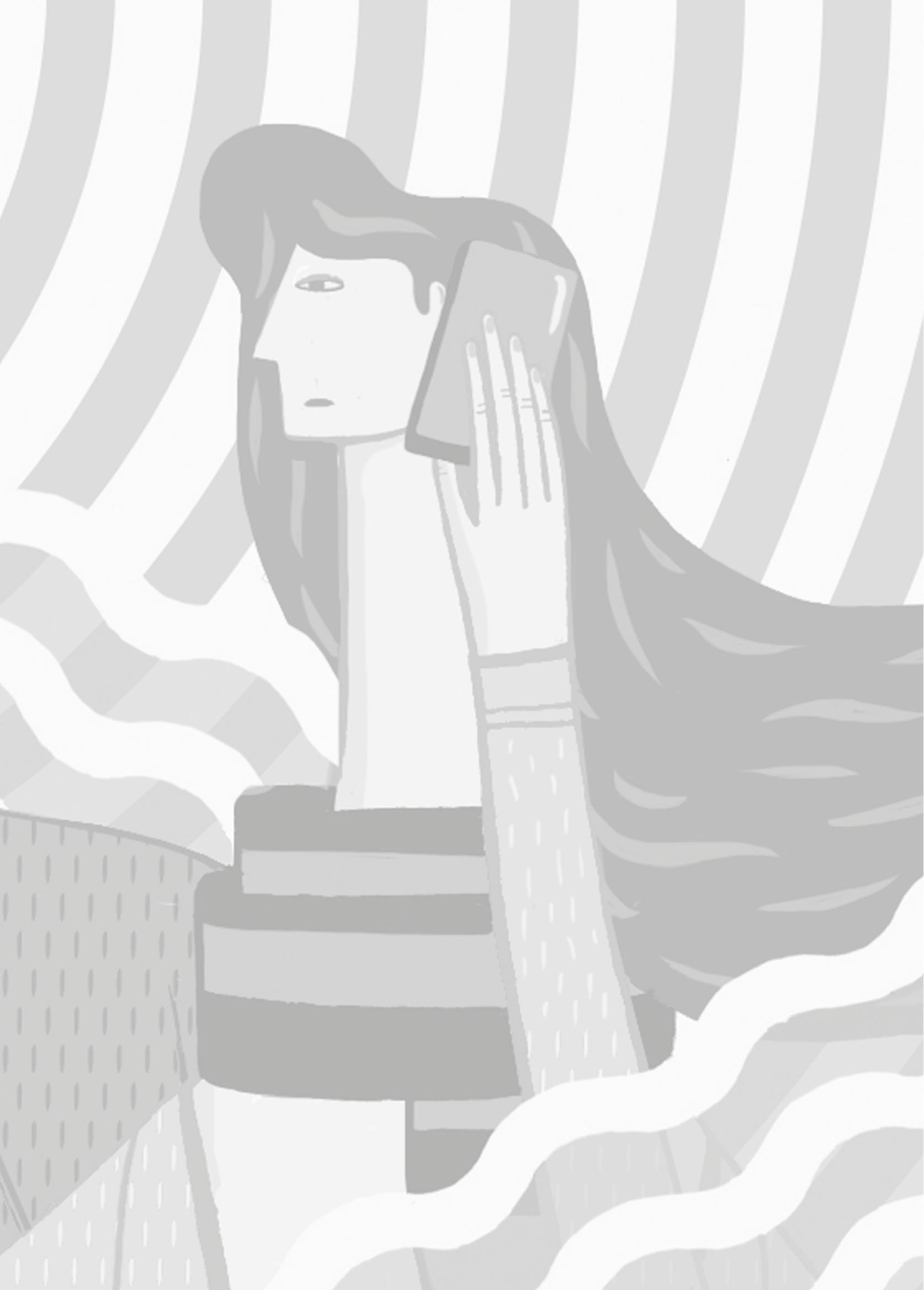




\section{Does mobile phone use impact mental state? A pilot study using the experience sampling method}

Suzanne Roggeveen

Jim van Os

Kelly Bemelmans

Mikal van Poll

Richel Lousberg 


\section{ABSTRACT}

In an $n=2$ pilot study, the possible impact of mobile phone usage on mental state was investigated with the experience sampling method. The ESM-based PsyMate ${ }^{\mathrm{TM}}$ application was installed on the mobile phones of two healthy 20-year old participants. Over a period of three months, participants rated their mental states at 10 semi-random moments in the flow of daily life. Each assessment included present state emotions, environmental circumstances and phone usage. Multilevel regression analyses indicated that an increase in mobile phone use was associated with a small increase in negative affect (particularly feeling bored and feeling lonely), and small decreases in positive affect and concentration. Treating the data as two separate $n=1$ studies revealed that the association with negative affect was present in both participants, whereas the associations with positive affect and concentration were evident in only one of the two participants. This pilot study suggests that mobile phone usage may be associated with person-specific and group-level changes in emotional state. A larger study is required to study these associations, possible causality and factors driving underlying heterogeneity in the pattern of associations. 


\section{INTRODUCTION}

Given widespread use of mobile phones, research has been conducted to investigate possible side effects. For example, mobile phone use is associated with slower response whilst driving (129) and cyber bullying (130). Furthermore, mobile phone use may be excessive or even compulsive, which was coined as 'problematic mobile phone use' (131). At least eleven different questionnaires have been used to test the construct of mobile phone use addiction (131-141), mostly based on criteria for dependence as described in the DSM-IV-TR (142). The term 'nomophobia' (the fear of being out of mobile phone contact) was proposed in 2014 (143). The related fear of missing out (FoMO) was defined as 'a pervasive apprehension that others might be having rewarding experiences from which one is absent'(144). In addition to a possible addictive component, associations have been reported between mobile phone use and depression, anxiety, stress and sleep problems $(58,59,135,139,145-147)$. Estimates of problematic mobile phone use, across these different outcomes, differ widely, ranging from 0-38\% (148).

Associations between mobile phone use and mental health may be mediated by personality traits such as self-esteem and extraversion. Lower levels of self-esteem were consistently associated with problematic mobile phone use across different studies (131, $145,149,150)$; higher levels of extraversion were associated with more frequent mobile phone usage $(131,151)$.

Although mobile phone use is a highly dynamic process, varying from moment to moment in daily life, studies in this area majorly use traditional retrospective questionnaires that are associated with several well-known forms of bias and cannot capture dynamic variation of mental states associated with daily life phone use (152). A data acquisition method which is relatively free of these kinds of bias is the Experience Sampling Method (ESM)(153). ESM is a valid and reliable method which is able to contribute to the understanding of the relationship between environmental phenomena and mental experience (154). Another advantage of this method is the ability to detect possible subtle (unconscious) changes in affect in the context of daily life in relation to mobile phone use. ESM has, to our knowledge, never before been applied in this research area.

In order to pilot the use of ESM in the context of mobile phone use, an $n=2$ ESM pilot study was conducted in order to examine associations between mobile phone use and subtle changes in mental states. In ESM studies, participants are 'beeped' at semi-random moments to record their in-the-moment emotional and behavioural states several times during the day (usually 6-10 times) (154). In addition, the actual circumstances (where and with whom a participant is) are also rated. This dynamic repeated measure design allows for prospective modelling of behavioural and affective dynamic patterns during the day as well as for examining associations with context (154).

Guided by previous literature, the following hypotheses were postulated: (i) A general 
increase of phone usage will be associated with higher scores on negative affect, lower levels of positive affect and lower levels of concentration $(59,155)$; (ii) whenever a person cannot engage in mobile phone use, increased levels of negative affect will ensue.

\section{MATERIALS AND METHODS}

\section{Participants}

Recruitment took place in September 2016, using posters distributed at Maastricht University Medical Centre in Maastricht, The Netherlands. Inclusion criteria were: age 20-25 years, healthy, good understanding of the Dutch language and smartphone usage. Exclusion criteria were a psychiatric diagnosis and pregnancy. Two healthy, female volunteers, both 20 years of age and students at Maastricht University, were thus enrolled. Participants were frequent smartphone users, used to carry a smartphone with them at all times, who did not experience their phone usage as problematic. Participation was compensated with $€ 150$, - per participant.

\section{Procedures}

\section{Briefing}

During the briefing, participants were helped to download the ESM PsyMate ${ }^{\mathrm{TM}}$ application on their smartphone (using the App store/Google play store). They were instructed on how to use the application. It was stressed that participants should not change their daily life routines; they were asked to carry their smartphone with them at all times in order to miss as few beeps as possible. In addition to the ESM scheme, participants filled in a separate morning and an evening questionnaire. In the morning questionnaire, before the first beep of the day, participants were asked to answer some questions about the quality of sleep and the location of the mobile phone in the past night (Appendix 1). In the evening, after the last beep, some additional questions were asked about the use of the PsyMate ${ }^{\mathrm{TM}}$ app and its possible impact on the participant (Appendix 1). At all times during the study, a researcher (SR) was available for questions. After the briefing session, the study period of three months started.

\section{Data collection}

In order to collect ESM data, the PsyMate ${ }^{\mathrm{TM}}$ application (www.psymate.eu) was installed on the personal smartphone of participants. Data collection took place over a period of three months. The PsyMate ${ }^{\mathrm{TM}}$ app emitted ten beeps per day at semi-random intervals in each of ten 90-minutes time blocks between 7:30 AM and 10:00 PM. The application worked independently of internet connectivity. After each beep, participants were asked 
to answer the ESM items as soon as possible (thus capturing information about the in-themoment state). Items should be answered within 15 minutes in order to safeguard realtime assessment (156). There were four positive affect ESM items (cheerful, mentally fit, relaxed and globally feeling well). Six items indexed negative affect (irritated, bored, lonely, gloomy, stressed and worried). Next, current context and activities (physical activity, daily life activities, persons present) as well as physical items (tired, level of concentration and pain) were rated. Finally, mobile phone use since the last beep (frequency, frustration when not able to use the mobile phone) was measured. An overview of ESM items is presented in appendix 1 . The affect items were rated on a 7-point Likert scale, ranging from 'not at all' to 'very much'. Mobile phone use was rated as follows. At each beep, the participant was asked to give an estimate of the frequency of mobile phone usage between the last beep and the present beep. Zero represents no usage, one represents once, two represents 2-5 times, three 5-10 times and four more than 10 times. Over the total period, participant 1 had a mean between-beep mobile phone usage of 1.72 (SD 1.06) and participant 2 a mean of 0.81 (SD 0.975).

After the three month ESM period, a debriefing session was held with both participants. Participants were asked to what degree the past three months were representative for their daily life and to what extent PsyMate ${ }^{\mathrm{TM}}$ had interfered with their normal routines.

\section{Data reduction}

App-data were directly transferred to an internet cloud, when internet connectivity was available. When there was no connection to the internet, data were temporarily stored on the mobile phone. The data of both participants was directly extracted from the cloud and imported in an SPSS datafile.

PsyMate $^{\mathrm{TM}}$ studies have shown that positive and negative affect (PA and NA, respectively) items can be reliably (Cronbach alpha>0.7) and consistently (154) scaled into two factors: a PA and an NA factor.

\section{Analyses}

Data on momentary mental state at beep moment $t$ and level of phone usage between the last beep ( $t-1)$ and the present $(t)$ was retrieved, in order to model affect parameters as the dependent and phone usage as the independent variable in the analyses.

Statistical analyses were conducted with SPSS 24.0 (157). The data were hierarchically structured, since multiple assessments were performed and clustered within days that in turn were clustered within participants. Multilevel random regression analyses were used to test the relationship between mobile phone usage and affect, taking the hierarchical structure into account. In order to model time effects, beep number and beep time interval were incorporated as covariates in all analyses. In order to correct for interdependence of the data over successive beeps, an autoregressive (AR1) covariance structure was selected. 
Since there were two participants, allowing for investigation of person-specific patterns, data was also analysed as two $n=1$ studies. To this end, linear regression analyses, using affect as dependent parameter and mobile phone usage as predictor were performed separately for participant 1 and 2 . In these regression analyses, beep number and beep time interval were also incorporated as covariates.

A two-sided $p$-value $<0.05$ was considered statistically significant.

\section{Ethics statement}

Approval was obtained from the medical ethics committee of the Academic Hospital Maastricht, on May, 19th, 2016. All participants provided written informed consent.

\section{RESULTS}

Participant 1 used the PsyMate ${ }^{\mathrm{TM}}$ application during 96 days and responded to 399/960 beeps (42\%). Thus, on average 4.2 out of 10 beeps each day were completed. Participant 2 completed $506 / 930$ beeps (54\%) or 5.4 beeps out of 10 each day. Guided by previous work

\begin{tabular}{|c|c|c|c|c|c|c|}
\hline & $\begin{array}{l}\text { Mean } \\
\text { participant } 1 \\
\text { (min-max) } \\
\text { (scale 1-7) }\end{array}$ & SD & N (days) & $\begin{array}{l}\text { Mean } \\
\text { participant } 2 \\
\text { (min-max) } \\
\text { (scale 1-7) }\end{array}$ & SD & $\mathbf{N}$ (days) \\
\hline $\begin{array}{l}\text { Responding to Pymate } \\
\text { beeps has influenced my } \\
\text { mood }\end{array}$ & $1.54(1-6)$ & 1.24 & 52 & $1.82(1-5)$ & 0.88 & 84 \\
\hline $\begin{array}{l}\text { Without PsyMate }{ }^{\mathrm{TM}} \text {, I would } \\
\text { have done other things } \\
\text { today }\end{array}$ & $1.12(1-7)$ & 0.83 & 52 & $1.02(1-2)$ & 0.153 & 84 \\
\hline $\begin{array}{l}\text { After responding to Pysmate } \\
\text { beeps, I used my mobile } \\
\text { phone }\end{array}$ & $2.98(1-6)$ & 1.85 & 52 & $4.11(1-7)$ & 1.73 & 84 \\
\hline $\begin{array}{l}\text { The PsyMate }{ }^{\mathrm{TM}} \text { has } \\
\text { influenced my normal } \\
\text { phone usage today }\end{array}$ & $2.17(1-5)$ & 1.32 & 52 & $1.44(1-6)$ & 0.91 & 84 \\
\hline $\begin{array}{l}\text { Today, I experienced fear of } \\
\text { missing out }\end{array}$ & $3.62(1-7)$ & 1.57 & 52 & $1.39(1-4)$ & 0.70 & 84 \\
\hline
\end{tabular}

Table 1. Results from 'evening questionnaire' in both participants. 
with this ESM scheme, a response of $30 \%$ to the ESM beeps was considered the minimum for inclusion in the analysis (158).

In order to model change in affect from beep to beep in relation to mobile phone use, an a priori limit was set on days with at least 4 completed beeps. In participant 1, 62 of 96 days met this requirement (65\% of all the days), with an average of 5.2 completed beeps per day. In participant 2,78 days ( $84 \%$ of all days) met the requirement, with an average of 6.0 beeps per day. Setting the a priori limit caused an ESM data reduction of $19 \%$ in participant 1 and $8 \%$ in participant 2 .

\begin{tabular}{|c|c|c|c|c|c|c|}
\hline & $\begin{array}{l}\text { Estimate } \\
\text { mobile } \\
\text { phone } \\
\text { usage } \\
n=2\end{array}$ & t-value & $\begin{array}{l}\text { Estimate } \\
\text { mobile } \\
\text { phone } \\
\text { usage } \\
\text { participant } \\
1\end{array}$ & t-value & $\begin{array}{l}\text { Estimate } \\
\text { mobile } \\
\text { phone } \\
\text { usage } \\
\text { participant } \\
2\end{array}$ & t-value \\
\hline Negative affect & 0.47 & $4.07 * * *$ & 0.67 & $2.54^{*}$ & 0.33 & $2.62 * *$ \\
\hline Irritated & 0.07 & 1.71 & 0.06 & 0.72 & 0.08 & 1.94 \\
\hline Bored & 0.22 & $5.37 * * *$ & 0.31 & $3.87^{* * *}$ & 0.14 & $3.30 * *$ \\
\hline Lonely & 0.12 & $4.60 * * *$ & 0.22 & $3.89 * * *$ & 0.05 & 1.76 \\
\hline Sadness & 0.05 & 1.44 & 0.05 & 0.62 & 0.03 & 0.66 \\
\hline Stressed & 0.04 & 1.19 & 0.01 & 0.09 & 0.01 & 0.15 \\
\hline Worried & 0.03 & 0.88 & 0.03 & 0.43 & 0.04 & 0.76 \\
\hline Positive affect & -0.29 & $-3.09 * *$ & -0.41 & -1.90 & -0.08 & -0.69 \\
\hline Mentally fit & 0.00 & 0.14 & 0.04 & 0.67 & 0.024 & 0.74 \\
\hline Cheerful & -0.10 & $-2.72 * *$ & -0.16 & $-2.16^{*}$ & -0.04 & -0.85 \\
\hline Relaxed & -0.09 & $-2.39 *$ & -0.19 & $-2.58^{*}$ & -0.01 & -0.27 \\
\hline Globally well & -0.11 & $-3.37 * *$ & -0.09 & -1.38 & -0.06 & -1.67 \\
\hline \multicolumn{7}{|l|}{ Other } \\
\hline Tired & 0.05 & 1.18 & -0.06 & -0.69 & 0.06 & 0.89 \\
\hline Concentrated & -0.13 & $-3.26 * *$ & -0.26 & $-3.54 * * *$ & -0.05 & -0.97 \\
\hline
\end{tabular}

Table 2. Estimates of 'mobile phone usage'. Vertical columns represent dependent variables. In the first two columns, the association with phone use in the combined dataset with both participants is shown, using multilevel analyses. The remaining columns show the outcomes per participant, obtained using linear regression analyses. ${ }^{*} p<0.05 * * p<0.01$ $* * * p<0.001$ 
Both participants remarked during the debriefing session that responding to the PsyMate ${ }^{\mathrm{TM}}$ beeps over the three-month period was feasible and not annoying. Table 1 shows that responding to PsyMate beeps generally was not rated as impacting mood or normal phone usage. One change was that normally participants would not carry their phones with them at all times, but because of the study they now did do so. Furthermore, participants noted that it was tempting to take a look at their phone after a PsyMate ${ }^{\mathrm{TM}}$ beep some of the time. A difference in response between the two participants can be noted in 'fear of missing out': participant 1 experienced this feeling more often than participant 2.

In table 2, an overview of the results of multilevel (results of the two participants together) and linear (results per participant) regression analyses is provided. The frequency of mobile phone usage between the previous and the current beep was modelled as predictor of current affect variables. In the combined dataset, higher levels of mobile phone use was associated with more NA and less PA. Decomposing NA and PA into their separate constituents revealed that 'bored' and 'lonely' stood out in strength of association among the NA items, whereas 'cheerful', 'relaxed' and 'globally feeling well' stood out among the PA items. The item 'concentration' was also negatively associated with higher levels of phone use. Analysing the participants separately revealed that the association between frequency of phone use and NA was consistent across participants. The association with PA was consistent across the two participants, although only significant in participant 1.

Cohen's $d$ for negative affect was 0.14 and 0.11 for positive affect.

The second hypothesis, that when a participant was not allowed/capable to use a mobile phone, he/she would report more negative affect parameters, could not be tested, due to a lack of data. For example, participant 1 only reported 'no phone usage' in 56 beeps, of which only 8 could be attributed to being not allowed/capable to use a mobile phone.

\section{DISCUSSION}

In this $n=2$ pilot study, participants answered questions in the PsyMate ${ }^{\mathrm{TM}}$ application about their mental state and mobile phone use over a three-month period. The goal was to investigate whether an association between the two could be demonstrated as a prelude to a larger study. Guided by previous work, it was hypothesized that a general increase of phone usage would be associated with higher scores on negative affect, lower levels of positive affect and lower levels of concentration $(59,155)$. The results show that these hypotheses were confirmed. Although all the negative affect items showed a positive association, the NA items 'lonely' and 'bored' stood out. Based on the literature, it was also expected that other components of NA such as 'sadness' would be significantly associated 
with mobile phone use. This item was directionally associated with mobile phone us but below the conventional limit of significance. The significant decrease of positive affect after an increase of phone use was seen in 3 out of 4 components of PA. While the association with NA affect was replicated across the two participants, the association with PA and concentration appeared to be person-specific. Person-specific moderators may play a role, such as level of self-esteem and extraversion that have been linked to problematic phone use, as well as other personality traits (159). In the current analysis, participant 1 reported more 'fear-of-missing-out' (FoMO). The experience of FoMO may also underlie personspecific results in the association between mental state and mobile phone use.

It was not possible to investigate the hypothesis that not being allowed/capable to use a mobile phone would result in higher levels of negative affect. This was due to a lack of data resulting in lack of variability.

This study indicates that in-the-moment associations between mobile phone use and affect may be subtle and difficult to report using retrospective reports from crosssectional questionnaires. Participants in this study appeared to differ in their global and in-the-moment reports. If the outcomes of this study can be replicated in a larger study population, combining group-level and person-specific approaches of analysis, it may be easier to develop person-specific and evidence-based approaches for 'problematic mobile phone use'.

\section{Limitations and recommendations}

This was a pilot study and results must be considered preliminary. A larger study is required to further study the associations described in this analysis. Second, based on the results from table 1, it may be hypothesized that the use of a mobile phone ESM app to collect the data may have influenced mobile phone use to some extent, with a potential for bias. To what degree this may impact the results has to be investigated in future studies. Third, in this pilot the level of mobile phone use (in minutes) was estimated at each beep by the participants themselves. It would have been more accurate to (also) measure phone usage digitally in duration and type (distinguishing between e.g. e-mail and social media).

In future research, the above considerations need to be taken into account. In addition, there are some other recommendations for future research. First, it would be instructive to investigate the effects of mobile phone use on the quality of sleep, as an association was suggested in previous studies $(59,155)$. In this study, the questionnaire was embodied but analyses could not be performed due to lack of variability in the data. Second, as observed in the 'evening questionnaire' of this ESM pilot, FoMO can vary greatly between individuals and it would be desirable to add this question to the beeps. 


\section{Appendix 1 PsyMate $^{\mathrm{TM}}$ questionnaire}

\begin{tabular}{|c|c|c|}
\hline Domain & Description & Scale \\
\hline \multirow[t]{10}{*}{ affect } & I feel cheerful & $1=$ not $4=$ moderate $7=$ very \\
\hline & I feel irritated & $1=$ not $4=$ moderate $7=$ very \\
\hline & I feel mentally fit & $1=$ not $4=$ moderate $7=$ very \\
\hline & I feel bored & $1=$ not $4=$ moderate $7=$ very \\
\hline & I feel relaxed & $1=$ not $4=$ moderate $7=$ very \\
\hline & I feel lonely & $1=$ not $4=$ moderate $7=$ very \\
\hline & I feel sad & $1=$ not $4=$ moderate $7=$ very \\
\hline & I feel stressed & $1=$ not $4=$ moderate $7=$ very \\
\hline & I am worried & $1=$ not $4=$ moderate $7=$ very \\
\hline & Overall I feel well & $1=$ not $4=$ moderate $7=$ very \\
\hline \multirow[t]{8}{*}{ context } & Activity, I am ... & $\begin{array}{l}\text { 1=lying } 2=\text { sitting } 3=\text { walking } 4=\text { =biking } 5=\text { sports } \\
6=\text { other }\end{array}$ \\
\hline & At the moment I am ... & $\begin{array}{l}1=\text { eating/drinking } 2=\text { hygiene } 3=\text { work } / \text { school } \\
\begin{array}{l}4=\text { resting } 5=P C / \text { tablet } 6=\text { phone } 7=\text { household } \\
8=T V ~ 9=\text { face to face conversation } 10=\text { going out } \\
11=\text { other }\end{array}\end{array}$ \\
\hline & I am doing this because ... & $\begin{array}{l}1=\text { general health } 2=\text { fun } 3=\text { distraction } 4=\text { obligatory } \\
5=\text { other }\end{array}$ \\
\hline & This costs effort & $1=$ not $4=$ moderate $7=$ very \\
\hline & I would rather do something else & $1=$ not $4=$ moderate $7=$ very \\
\hline & At the moment I am at... & $\begin{array}{l}1=\text { home } 2=\text { someone else's home } 3=\text { at work } / \text { school } \\
4=\text { public space } 5=\text { on the road }\end{array}$ \\
\hline & $\begin{array}{l}\text { At the moment I am in the } \\
\text { company of... }\end{array}$ & $\begin{array}{l}1=\text { nobody } 2=\text { partner } 3=\text { family } 4=\text { friends } \\
5=\text { colleagues } 6=\text { acquaintances } 7=\text { strangers }\end{array}$ \\
\hline & This is agreeable & $1=$ not $4=$ moderate $7=$ very \\
\hline \multirow[t]{5}{*}{ other } & I am tired & $1=$ not $4=$ moderate $7=$ very \\
\hline & I am concentrated & $1=$ not $4=$ moderate $7=$ very \\
\hline & I have physical complaints & $1=$ not $4=$ moderate $7=$ very \\
\hline & Location of pain & $\begin{array}{l}\text { 1=head } 2=\text { neck } 3 \text { =back } 4=\text { =abdomen } 5=\text { hands } \\
6=\text { other }\end{array}$ \\
\hline & $\begin{array}{l}\text { These complaints have ... since } \\
\text { the last beep }\end{array}$ & $1=$ reduced $2=$ stayed the same $3=$ increased \\
\hline \multirow[t]{4}{*}{ dependency } & $\begin{array}{l}\text { I have used my phone since the } \\
\text { last beep }\end{array}$ & $0=$ not $1=$ once $2=2-5 \times 3=5-10 \times 4=>10$, when 0 \\
\hline & $\begin{array}{l}\text { I have not used my phone } \\
\text { because... }\end{array}$ & $1=$ forbidden $2=$ not possible $3=$ no need \\
\hline & $\begin{array}{l}\text { It was frustrating to not be able to } \\
\text { use my phone }\end{array}$ & $1=$ not $4=$ moderate $7=$ very \\
\hline & $\begin{array}{l}\text { The last time I used my phone } \\
\text { was ... }\end{array}$ & $\begin{array}{l}1=<5 \mathrm{~min} \text { ago } 2=5-15 \mathrm{~min} \text { ago } 3=15-45 \mathrm{~min} \text { ago } \\
4=>45 \mathrm{~min} \text { ago }\end{array}$ \\
\hline evaluation & This beep disturbed me & $1=$ not $4=$ moderate $7=$ very \\
\hline
\end{tabular}




\section{Appendix 2 Morning questionnaire}

\begin{tabular}{|c|c|c|}
\hline & Item & Scale \\
\hline 1 & $\begin{array}{l}\text { How long did it take to fall } \\
\text { asleep yesterday evening? }\end{array}$ & $\begin{array}{l}1=0-5 \min 2=5-15 \min 3=15-30 \min 4=30-60 \min \\
5=1-2 \text { hours } 6=2-4 \text { hours } 7=>4 \text { hours }\end{array}$ \\
\hline 2 & $\begin{array}{l}\text { How often did you wake up } \\
\text { during the night? }\end{array}$ & $0->5$ \\
\hline 3 & I slept well & $1=$ not $4=$ average $7=$ very \\
\hline 4 & How many hours did you sleep? & $\begin{array}{l}1=<3 \text { hours } 2=4-5 \text { hours } 3=6 \text { hours } 4=7 \text { hours } \\
5=8 \text { hours } 6=9 \text { hours } 7=>10 \text { hours }\end{array}$ \\
\hline 5 & $\begin{array}{l}\text { How many alcoholic bevarages } \\
\text { did you drink yesterday evening? }\end{array}$ & $1=0 \quad 2=1-2 \quad 3=3-5 \quad 4=6-10 \quad 5=>10$ \\
\hline
\end{tabular}

\section{Appendix 3 Evening questionnaire}

\begin{tabular}{lll}
\hline \multicolumn{2}{l}{ Item } & Scale \\
\hline $\begin{array}{l}\text { Answering the PyMate } \\
\text { influenced my mood }\end{array}$ & 1=not 4=average 7=very \\
\hline 2 & $\begin{array}{l}\text { Without PsyMate }{ }^{\mathrm{TM}} \text { I would have } \\
\text { done other things today }\end{array}$ & 1=not 4=average 7=very \\
\hline 3 & $\begin{array}{l}\text { After answering the Pysmate beeps } \\
\text { I have used my mobile phone }\end{array}$ & 1=not 4=average 7=very \\
\hline 4 & $\begin{array}{l}\text { The PsyMate } \\
\text { normal has influenced my }\end{array}$ & 1=not 4=average 7=very \\
\hline 5 & $\begin{array}{l}\text { Today I experienced fear of missing } \\
\text { out }\end{array}$ & 1=not 4=average 7=very \\
\hline 6 & $\begin{array}{l}\text { Where was my phone mostly today } \\
\text { 1=on/against my body } 2=\text { bag 3=elsewhere whithin }\end{array}$ \\
\hline
\end{tabular}




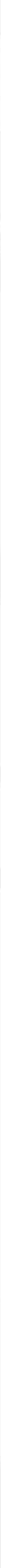


General discussion 

This thesis does not primarily investigate the question to what degree of mobile phone usage may be harmful to human health. Rather, we develop proof of principle to investigate potential effects on aspects of central nervous system functioning. To date, mobile phone usage has not been associated with noticeable immediate health effects and/or a shortened life span. Since (intensive) mobile phone usage is a phenomenon that has only become common in the past twenty years, long-term effect studies are relatively scarce. It is therefore reasonable to assume that the effects, when scientifically demonstrated, are small, at least in the short term. In fact, this assumption formed the basis for our line of investigation. Short term, direct influences of mobile phones on electrophysiology and emotions were studied in detail to build a more stable basis for the mobile phone literature and to conduct long-term longitudinal research in the future. Overviewing the scientific literature so far, it was concluded that short-term mobile phone effects are a relatively underexplored research area. Although this thesis only gives answer to some aspects of short-term mobile phone effects on electrophysiology and emotions, it represents an independent and novel effort in this complex area of research.

The early chapters (2-5) focused on the effects of mobile phones (radiation) on electrophysiology. Chapter 2 contained a pilot study on a single test person and had to be considered as an experiment for gaining knowledge of the design and execution of this type of experiment. However, it was considered relevant to add this chapter to the thesis, since it provided important insights into the methodological aspects of this type of research and was the basis for developing subsequent experiments. In the pilot study, it was found that a radiation detector could be used to gain control over the administered dose of radiation. The detector was acquired and connected to the amplifier to register radiation levels per millisecond. The presence of this radiation detector made 'microlevel' analyses possible, in which heart rate directly followed by a radiation peak was analysed. These 'microlevel' analyses, which conceptually resembled the event-related potential (in chapter 4), provided additional support for the findings at the 'macrolevel', encompassing the comparison of 15-minute conditions of dialling with dummy. The smaller details of what happens directly after a radiation peak were examined to arrive at the central theme of the investigation: short-term, direct effects. Of course, the outcome of lowered heart rate due to mobile phone exposure could not be generalized because of the sample size of $n=1$.

Using a larger experiment - described in chapters 3 and 4 - the effect of a 3G, dialling mobile phone compared to a dummy telephone was investigated in relation to electric brain activity. At the so-called macrolevel - that is, the entire condition of a mobile phone compared to that of a dummy telephone - an increase in alpha, beta and gamma EEG frequency bands was found in relation to mobile phone exposure. At the microlevel, it was hypothesized that the radiation peak can be interpreted as a stimulus. It turned out that radiation peaks, caused by dialling a $3 G$ mobile phone, resulted in subconscious event- 
related potentials. To our knowledge, this finding has been reported only once before.

A third experiment was set up to create a 'proof of principle' experiment for the examination of EEG effects. In this study, dialling and standby were alternated frequently. Contrary to the hypothesis, no significant changes in EEG frequency bands could be demonstrated between the conditions.

The final chapter described an $n=2$ pilot study investigating the influence of mobile phone usage on emotions using the ESM, a frequently used research method for studying daily-life contextual effects $(160,161)$. The results of this study were in line with our a priori hypotheses: an increase of phone use was associated with an increase in negative affect and decrease in positive affect and concentration.

The remaining portion of this discussion involves a critical re-evaluation of the methodological choices made in the studies. Furthermore, the EEG results of the experiment presented in chapter 3 are compared with the most recent literature. Next, the conflicting EEG results of the two electrophysiological studies within this thesis (chapters 3 and 5) are discussed. Further, the relation between mobile phone usage and affect is examined, the actual literature is put into perspective, and an attempt is made to integrate the electrophysiological and psychological lines of research. Finally, general conclusions and recommendations for future research are given.

\section{A re-evaluation of the chosen electrophysiological methodology}

In the literature, there is no standard investigation format for measuring the possible effects of mobile phone radiation on electrophysiological outcomes. Basically, each research group has its own ideas about 'the best way' to tackle the issue of how possible effects on brain functioning due to mobile phone radiation should be measured. We were no different, and with the wisdom of hindsight, we came to consider the first year of experimentation as a series of trial-and-error procedures. Even when setting up a so-called 'proof of principle' experiment (chapter 5), post-hoc methodological limitations were detected. Looking back in the course of writing this thesis, it should be noted that more electro technical knowledge and expertise about the physics of radiation would have been beneficial. Additionally, setting up the methodology of an experiment should, theoretically, be straightforward, but it actually proved to be very complex, since choices between many compatible possibilities had to be made. Nevertheless, 'mistakes' are never really mistakes, but should be seen as opportunities to achieve new insights, especially in a relatively young research field like mobile phone research.

Table 1 shows the most important methodological features of the three electrophysiological studies in this dissertation. Some methodological aspects did not change, while others were adjusted in subsequent studies. The first study was a pilot study and used only a single test person. Based on the results of this pilot study, a larger study was conducted to investigate whether the findings could be replicated and extended to other ECG 
components as dependent variables. Unfortunately, the available software did not reliably detect ECG waves in all test subjects. From that point, the focus was on brain activity. The reason ERP was not investigated in the second study was twofold; first, the study was initially set up to ultimately test EEG waves, and second, after no differences were found between the dialling and standby conditions, post-hoc ERP analyses did not seem justified since no adequate control condition was present.

\begin{tabular}{|c|c|c|c|c|c|c|c|}
\hline \multirow[t]{2}{*}{ Study } & \multirow[t]{2}{*}{$\mathrm{N}$} & \multirow{2}{*}{$\begin{array}{l}\text { Outcome } \\
\text { measure }\end{array}$} & \multirow{2}{*}{$\begin{array}{l}\text { Sessions \& } \\
\text { placement }\end{array}$} & \multicolumn{4}{|c|}{ Exposure } \\
\hline & & & & Phone & Duration & Phone & Duration \\
\hline $\begin{array}{l}\text { Pilot } \\
\text { study }\end{array}$ & $\begin{array}{l}1 \\
q\end{array}$ & $\begin{array}{l}\text { Heart rate } \\
\text { (macro- } \\
\text { and } \\
\text { microlevel) }\end{array}$ & $\begin{array}{l}4 \text { sessions, } \\
\text { phone on } \\
\text { chest }\end{array}$ & $\begin{array}{l}\text { 3G, } \\
\text { dialling }\end{array}$ & $\begin{array}{l}15 \text { minutes } \\
\text { per session }\end{array}$ & Dummy phone & $\begin{array}{l}2 \times 15 \text { minutes } \\
\text { per session }\end{array}$ \\
\hline Study 1 & $\begin{array}{l}31 \\
+9\end{array}$ & $\begin{array}{l}\text { EEG and } \\
\text { ERP }\end{array}$ & $\begin{array}{l}2 \text { sessions, } \\
\text { one chest } \\
\text { one ear }\end{array}$ & $\begin{array}{l}\text { 3G, } \\
\text { dialling }\end{array}$ & $\begin{array}{l}15 \text { minutes } \\
\text { per session }\end{array}$ & Dummy phone & $\begin{array}{l}2 \times 15 \text { minutes } \\
\text { per session }\end{array}$ \\
\hline Study 2 & $\begin{array}{l}30 \\
9 \\
+ \\
20 \\
0\end{array}$ & EEG & $\begin{array}{l}1 \text { session, } \\
\text { phone on } \\
\text { ear }\end{array}$ & $\begin{array}{l}\text { 3G, } \\
\text { dialling }\end{array}$ & $\begin{array}{l}\text { Approx. } \\
30 \mathrm{~min}\end{array}$ & 3G, standby & $\begin{array}{l}\text { Approx. } \\
30 \mathrm{~min}\end{array}$ \\
\hline
\end{tabular}

Table 1. Methodological parameters in the three electrophysiological studies. The pilot study is described in chapter 2 , study 1 in chapter 3 and 4 and study 2 in chapter 5 .

Table 1 provides a general overview of the studies. In addition to these key methodological decisions, there were several other methodological factors that need to be discussed.

- Mobile phone. A mobile phone was purposefully chosen to mimic real life as closely as possible. The limitation of this decision was that it was not possible to switch the radiation off entirely without entering the room. Another limitation was the presence of other electromechanical processes running in a mobile phone besides radiofrequency EMR, such as heat produced by the battery, programmes running in the background, and low frequency radiation. Therefore, it remains uncertain which part of mobile phone activity causes the 'macro' effects explained in chapter 2 . This is not the case for 'micro' effects, like the ERP in response to a radiation peak. The alternative would have been to use a device which simulated high frequency mobile phone radiation, an apparatus 
which is used in most existing studies. The undeniable advantage of such a device is the strict experimental control of radiation. Nevertheless, the fact that it was possible to mimic a real-life situation was the factor that led us to choose the current design.

- Network. A mobile phone which functioned on the $3 G$ network was used. Despite the fact that most research before the start of our experiments was conducted with a $2 \mathrm{G}$ network, we selected a $3 \mathrm{G}$ device, since most people are using the $3 \mathrm{G}$ network at that moment. In 2018, $3 G$ is still the standard, but $4 G$ is becoming popular. There seems to be a tendency of greater influence on brain activity by $2 \mathrm{G}$ compared to $3 \mathrm{G}$ networks (105).

- Mobile phone activity. In all three studies, we used a dialling phone as the exposure condition, meaning that a possible speech connection was established. This exposure method was chosen since dialling is the traditional way to use a mobile phone. Alternatives could have been to have an active connection to the Wi-Fi, GPS or Bluetooth. These functions were all switched off in the experiments. Most other studies have also chosen a dialling mobile phone as the exposure condition.

- Radiation detector. A radiation detector connected to a PC was used in all studies (radiation frequency was measured with $1000 \mathrm{~Hz}$ ). The detector served two goals: first, to keep track of the dose of radiation produced by the mobile phone and, second, to investigate effects on a micro level, that is, effects directly preceded by radiation outbursts. Unfortunately, the radiation detector could not specify the source of radiation. Most other research groups do not use radiation detectors.

- Within-subjects design. The choice of a within-subjects design was evident for our research team: first, fewer subjects are needed for this design compared to a betweensubjects design. Second, in a within-subjects design, large EEG differences between days are often observed. We tried to tackle these large EEG day effects by conducting the experiment in one session, alternating exposure and control conditions. Most other studies also used a within-subjects design. However, in the majority of these studies, the control condition was on a separate day or moment, thus leading to (unwanted) daily variation of brain activity.

- Correction for autocorrelation. Correction for autocorrelation was necessary since successive physiological data are highly correlated. It was interesting to note that most other studies computed averaged EEG values for the statistical models, at the cost of losing information.

The methodological parameters below were changed based on new insights or new research phases.

- Exposure duration. In the first two studies, a 15-minute exposure duration was chosen (compared to $2 \times 15$ minutes in the control condition). In the last study, we decided to use a more frequent alternation between exposure and control conditions to obtain stronger evidence of the replicability of the exposure effect. Each 30-second segment in one hour was individually, randomly appointed to exposure or control. The consequence of this 
decision was that the frequency of the exposure and control conditions was much higher compared to the first two studies. However, the average duration of the consecutive conditions was much shorter. In other studies, the exposure duration varied from 1 minute to 50 minutes.

- Control condition. With the shortening of the exposure duration, the control condition had to be changed from a dummy condition to a standby condition, since it was not possible to change the mobile phone from a dialling state to a completely switched off state from outside the testing room. The mobile phone state which resembles a dummy phone most closely is a phone in a standby state. This was considered an acceptable change, since there was less radiation present in the standby state compared to the dialling condition. The alternative would have been to use a radiation simulating device (see above) which could be remotely controlled.

- Amount of sessions and phone placement. In the first study, the participant was seen on four separate days. This was decided as there was only one participant, and an eventual effect could be replicated on different days. Regarding the second experiment, the reason for conducting the experiment on two separate days was to test two types of mobile phone placement: next to the ear and on the chest. In the second study, after demonstrating the effects in the ear placement condition, next to the ear placement was done only once. With respect to phone placement, most other studies have also chosen a placement next to the ear.

- Gender. The gender of the subjects was changed from only female in the first two studies to male and female in study 2 . In the first two studies, the sources of variability were kept small; therefore, only one gender was included. For generalizability, it was a logical next step to investigate both genders in study 2 .

- Electrically shielded electrodes. In the pilot study, standard electrodes were used to measure ECG (afterwards, we demonstrated that the ECG measurement was not influenced by radiation). In response to advice from technical colleagues, we decided to use electrically shielded electrodes instead of regular electrodes in subsequent studies, especially since the focus was on EEG measurement ${ }^{1}$.

- Statistical analyses. The pilot study used linear regression and ANOVA techniques to analyse the data, while the first and second study used multilevel regression analyses. Multilevel regression analysis was not used in the pilot because of the small dataset $(n=1)$. One strength of multilevel regression analyses compared to other statistical methods was that it allowed the option to distinguish multiple levels (or clusters) of information in a model to reduce estimation error (162).

1 In testing experiments it was demonstrated that regular electrodes are influenced by radiation when investigating EEG. This was not the case with shielded electrodes. 


\section{Electrophysiological results from a broader perspective}

The $n=1$ pilot study was valuable for developing a paradigm. The results provided hints of how heart rate might be influenced by the placement of a dialling mobile phone on the chest. However, the $n=1$ sample size was too small to make any generalizations. Other studies have also investigated heart rate. The overall conclusion, however, is still not clear. A recent double blind study investigating the effects of $3 \mathrm{G}$ mobile phone radiation on teenagers $(n=26)$ and adults $(n=26)$ showed no significant effects on heart rate, respiration rate, or heart rate variability (163). However, it should be mentioned that the statistical analyses used in the study could be criticized, since averages of the heart rate were analysed. Meanwhile, some studies have found significant effects of mobile phone radiation on heart rate, but they can also be criticized on methodological aspects $(55,79,80)$. The majority of studies that have investigated ECG have investigated heart rate and heart rate variability as dependent variables. It would be worthwhile to determine whether other important ECG measures such as intervals and wave areas are influenced by mobile phone radiation.

As discussed in chapter 3 , the first study $(n=31)$ revealed an increase of EEG power on the alpha, beta and gamma frequency bands under exposure of a dialling mobile phone compared to a dummy telephone. An increase of alpha activity is found in other studies regularly, but changes in other EEG frequency bands are seldom found. It is worthwhile to place the findings of the results of chapter 3 into perspective. Table 2 provides an overview of the current literature on mobile phone effects on resting EEG.

Regarding Table 2, there were 26 peer-reviewed experimental studies which investigated the effect of mobile phone radiation on resting EEG. To select these articles, no other in- or exclusion criteria were used. Eighteen studies found significant EEG effects for the exposure condition in comparison with the control condition. Of these studies, 15 detected effects on the alpha frequency band, 12 reported an increase of alpha activity during exposure, and three reported a decrease in the alpha frequency band. With respect to the other frequency bands, no clear overall conclusion could be drawn. The last column shows the sponsors/organizations that were involved. As already mentioned in the introduction, it has been statistically proven that sponsored studies are more likely to find no significant results (63). In this research field, this does not seem to be the case: $35 \%$ of the studies are related to the mobile phone industry or a comparable stakeholder. Of these, $89 \%$ found a significant outcome, while $59 \%$ of the 'independent' studies found a significant outcome. Further, an important observation was that most studies on this subject have investigated the effect of the $2 \mathrm{G}$ mobile phone network instead of the more frequently used $3 \mathrm{G}$ and $4 \mathrm{G}$ networks (2G: 91\%, 3G: 9\%). The studies in this thesis have investigated 3G. It is important to note that radiation is transmitted differently in a $3 G$ network than a $2 G$ network, which could result in different EEG effects. At the same time, both $2 \mathrm{G}$ and $3 \mathrm{G}$ are still in the RFEMF. It is remarkable that the two studies that researched the effects of $3 \mathrm{G}$ did not find any significant effects. 
In one study, low frequency fields did not seem to affect EEG, while both pulsed and continuous radiofrequency led to a change in the alpha frequency band (164). Therefore, the use of an actual mobile phone as an inductor of radiation in this thesis led to a change in EEG. This might not have been due to the low frequency waves which are also produced by an actual mobile phone.

Perhaps the most important difference in the study in chapter 3 compared to the majority of the studies in Table 2 is the method of statistical analysis. In chapter 3, multilevel regression analyses were used. Most studies use more conventional (i.e. t-tests, ANOVA) statistical tests in which conditions are compared with computed averages. In chapter 3 , it was demonstrated that an analysis of the mean condition difference yielded no significant effects, but when taking into account the clustering of the data (using multilevel regression analyses), significant effects could be demonstrated. It would be very interesting to reanalyse data on comparable studies with this type of modelling. In retrospect, statistical modelling is probably the most important explanatory factor for the discrepancy between the results of chapter 3 and the literature. In conclusion, the type of (statistical) analysis used in demonstrating small EEG effects due to mobile phone radiation is a crucial factor and needs to be considered carefully in future research.

In chapter 4, radiation peaks were considered as events and were analysed using the ERP method. Treating radiation peaks as events is an unconventional technique, since a radiation peak is not consciously experienced by the subject. The results showed that a subliminal ERP was detected in response to radiation peaks. This finding can be compared to Carrubba et al. (51), which is the only other study, to our knowledge, which used a comparable design. Carrubba et al. found similar results. Treating radiation outbursts as 'events' is a promising technique, since it is almost certain that the radiation used for making connections to the network leads to the observed EEG change. This is not the case in other EEG frequency band studies, where other processes could, in theory, cause the effect (e.g. the active battery of the mobile phone).

In addition to comparing the results of this thesis to the results of the existing literature, it was necessary to explore the meaning of the results in a clinical context. As mentioned in the introduction to the discussion section, no statements about health can be made on the basis of the present results. It is, however, possible to outline the meaning of a change in EEG and, more specifically, a change in alpha and beta frequency band activity.

EEG is a noninvasive registration method of electrical brain activity. In a clinical context, it is mainly used for diagnosing epilepsy and sleep disorder. In the research field, EEG is used in the fields of neuroscience, cognitive science, neurolinguistics and psychophysiology. It is important to note that the spatial resolution of an EEG measurement, based on 12 leads, is low. This means that it is not capable of indicating the source of activity in the brain. At the same time, EEG is a valuable tool because it has a high temporal sensitivity that is superior to that of magnetic resonance imaging or positron-emission tomography (MRI or PET). 
The EEG frequency range, which is often found to be affected by mobile phone exposure, is the alpha frequency band $(8-13 \mathrm{~Hz})$. Alpha is best registered in the posterior regions of the head, and it is generally related to a state of relaxation. The significance of an experimentally induced increase of the alpha frequency band (due to the activity of a mobile), however, is unclear. Briefly, it is very likely that radiation results in a change in EEG and, especially, in alpha activity. Future research is needed to gain more insight into the meaning of this increase.

\section{Conflicting results between the first and second studies}

The second study (chapter 5 ) of this thesis unexpectedly did not show a significant increase in EEG frequency bands due to the exposure condition, as was the case in the first study (chapter 3). In this paragraph, a final evaluation about this discrepancy will be made.

The most important difference between the two studies is the control condition. Standby cannot be considered as an optimal contrast for a dialling mobile phone since radiation is still present. The standby mode is active during periodic location updates, at a frequency set by the network operator. Furthermore, it is considered a passive radio receiver without microwave emission. In other words, a standby mobile phone might also cause EEG effects. This issue needs to be further investigated, since only one EEG study partly reported on this subject (165) H .

As mentioned before, in the second study, the number of both exposure and control segments was increased, while the duration of these segments were shortened. This resulted in an alternating dialling/standby scheme which lasted for one hour. It is not clear what the implications of these changes were. Afterwards, it was hypothesized that to obtain clear and statistically significant EEG effects, longer, uninterrupted exposure durations are necessary.

In addition, there are two other critical aspects of EEG. First, EEG as a measure of brain activity represents the ultimate product of a host of rapidly changing processes and aspects, such as thoughts and changing sensory input. Beyond this complexity of electrophysiological activity, we were interested in distilling the presumed additional (small) effect of radiation emitted by a mobile phone. Therefore, it was worthwhile to a) have a sufficient sample size, b) try and keep many influential factors as constant as possible and c) have a frequent alternation of the exposure and control conditions. The second critical aspect was that of confounding factors. When EEG is measured, every electrical activity is measured instead of only the insinuated encephalic activity. The measured signal will, also include a certain amount of activity of the head and neck muscles. That is why, in a standard EEG measurement, electro-ocular activity (EOG) is measured. EOG is used to correct the confounded EEG for eye movement by means of data rejection and correction. Despite this convention, EOG was taken out of the statistical models in the post-hoc analyses of the second study. More significant effects in line with the first study could be demonstrated, as described in chapter 5 . This means that EOG acted as a confounder for the condition effect, 
since an obvious trend towards enlarged EEG activity in the dialling condition was observed without EOG in the models.

Based on this observation, the data of the first study were reanalysed (these results were not published in a peer reviewed article). EOG was removed as a covariate in the statistical models. This adjustment did not change the results. Why EOG acted as a confounder in the second study, but not in the first study, is not entirely clear. It can be hypothesized that in the second study, EOG itself was influenced by mobile phone radiation. This might have occurred because of a longer-lasting exposure to radiation than in the first study, since the 70 minutes of exposure time (the standby periods cannot be considered as radiation free) in that study were much longer than the 15 minutes in the first study. This post-hoc hypothesis was rooted in the literature $(166,167)$, as mentioned in chapter 5.

The purpose of the studies in this thesis was to measure the possible effects of a mobile phone on brain activity. If muscle activity is influenced by using a mobile phone, as hypothesized above, it is debatable whether EOG, a radiation-influenced variable, can be incorporated as a covariate. Figure 1 depicts this dilemma. The relation of interest is the one between mobile phone radiation and brain activity. The method to measure brain activity is EEG, including both brain as well as muscle activity. To compensate for this mix-up of information, EOG is also measured. However, EOG is also a mix-up, since it partly contains brain activity. After conducting the second study, it was realized that muscle activity itself might be influenced by mobile phone radiation.

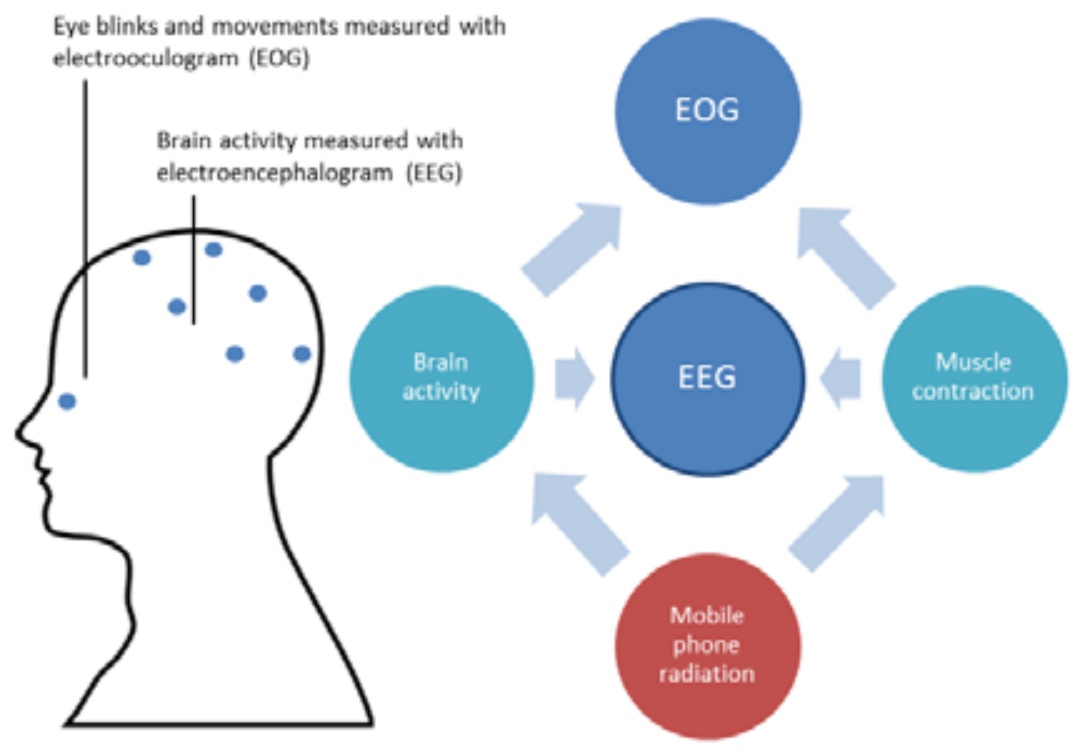

Figure 1. Mix-up of brain and muscle activity in measurements. 
To conclude, it is not clear why the second study did not find increased EEG power like the first study, but the two main changes in methodology, namely the standby instead of the dummy as the control condition as well as the different exposure durations, probably played a role in this discrepancy. Furthermore, radiation might be able to influence EOG, which makes EOG a disputable covariate. Finally, the reader might ask himself or herself whether the results of chapter 3 , chapter 5 , or even both are flawed. Based on the discussion in this section, the most plausible answer is that the results of both studies are true. The final conclusion is that the subsequent attempt to compare the methodologies (and results) of both studies was not realistic.

\section{Mobile phone usage and psychological outcome measures}

The addition of a sixth chapter to this thesis, in which emotions and behaviour (as measured with ESM) are linked to mobile phone usage, might seem surprising after the electrophysiological studies. However, there are two more or less logical explanations for this choice. First, emotions and behaviour cannot be treated separately from brain activity. In other words, emotions and behaviour cannot exist without a brain. Although the bodymind dualism as explained by René Descartes still has a considerable influence in science today, the mind-body distinction is debatable. For example, an anxious (mind) person can get bowel problems (body) and high stress levels, which can be measured simultaneously (cortisol, body). The more medical knowledge is gathered, the more likely a mind-body connection is established. The ESM study provides a link between an external influencing factor (mobile phone usage) and the final outcome (emotions/behaviour) of a complex brain process. The second argument for incorporating an ESM study in this thesis is that it also maps out the subtle short-term psychological effects of mobile phone use. The primary goal of chapter six was to set up a pilot study to generate hypotheses (by means of demonstrating correlations).

The experience-sampling method has a repeated-measure design (in contrast to crosssectional questionnaire data), which allows for modelling behavioural and affective dynamic patterns during the day and offers the possibility of linking environmental phenomena to these patterns. It was therefore considered suitable for testing the relation between mobile phone usage during the day and affect. Although the pilot study in chapter 6 had only two subjects, a substantial amount of data over a course of three months was collected. Significant relationships between mobile phone usage and affect were found. It appeared that the amount of mobile phone usage corresponded with the emotional state of the user. It would be very interesting to investigate on a larger scale whether the influence of mobile phone use on affect can be linked with certain personality traits, as has been proposed in the literature (57). A possible limitation of the methodology is that the Psymate application on which the participants rated their emotions and phone usage was also installed on their mobile phones and influenced their phone usage. 
Other studies have found a relationship between mobile phone usage and psychological outcome measures. Significant relationships with mental disorder constructs like depression, anxiety and stress have been reported repeatedly $(59,168)$. An interesting study was conducted by Saeb et al. (169), in which the so called 'Purple Robot' phone app was used for two weeks and a short depression survey was conducted before and after the two weeks. This app collects phone sensors, such as GPS location and phone usage data, from participants. This passively collected data contained factors which could be related to depression symptom severity, such as circadian movement and location variance.

\section{Conclusions}

This thesis has clarified that the research on the effects of mobile phone usage on human functioning can be very complex. A large amount of confounding and or interacting variables is present. The following conclusions can be drawn:

- Exposure to a dialling $3 G$ mobile phone for 15 minutes next to the ear compared to a dummy phone leads to an increase of the EEG frequency bands of alpha, beta and gamma.

- Exposure to radiation peaks caused by a dialling $3 \mathrm{G}$ mobile phone next to the ear leads to a subconscious event-related potential.

- A frequently alternating dialling/standby 36 mobile phone, over the course of one hour, does not lead to significant changes in EEG frequency bands between the dialling and standby conditions.

- There are indications that an increase in mobile phone usage is accompanied by an increase in negative affect, a decrease in positive affect and a decrease in concentration.

\section{Recommendations for future research}

\section{Electrophysiology}

In future research investigating the relationship of mobile phone radiation on electrophysiological outcome measurements, close collaboration with technical and physics departments is recommended for the administration of radiation. Full control over the amount of administered radiation is key. Therefore, an apparatus which can mimic a mobile phone in detail, including low frequency radiation, would be ideal. This apparatus should be able to mimic different networks (2G, 3G, 4G, 5G) through remote control in dialling and standby states and also mimic other features like Wi-Fi and Bluetooth.

In addition to this 'perfect' radiation-administering device, a different set of test subjects should be obtained if there are unlimited resources. As is the case for almost all mobile phone radiation research, there is no reference group of people who never use a mobile phone. Ideally, a large research group would be gathered, and some of the participants are not exposed to mobile phone radiation for a substantial amount of time while others are. 
During this time, several parameters of electrophysiological data (EEG, ECG, EOG, EMG), and perhaps other outcome parameters such as MRI, blood and semen samples, should be measured repeatedly throughout the study to investigate the long-term effects of mobile phone usage on basic human functioning. In this design, in addition to long-term effects, short-term effects can be investigated using the radiation device discussed above at $\mathrm{t}=0$ and at the end of the experiment. To achieve the perfect research population, it is strongly recommended that children be included. It is generally acknowledged that the brain of children is more susceptible to electromagnetic fields (because of their thinner skulls) (170) (Schonborn, Burkhardt, \& Kuster, 1998) (170) (170) compared to adults. Although few studies have investigated the effect of mobile phones and electromagnetic fields in general on children, it cannot be denied that many children are exposed to mobile phones, $\mathrm{Wi}-\mathrm{Fi}$ and other sources of RF-EMF on a daily basis. Therefore, it is very important to gain insight into the effects of these new phenomena on future generations.

It would be worthwhile to reanalyse existing datasets with multilevel regression analysis. Future research should apply multilevel regression analyses in case of repeated-measure designs.

EEG (including frequency bands and ERP) is an adequate measure to objectify radiation effects. However, as long as the clinical meaning of a short-term change in EEG is not completely clear, the value of significant EEG outcomes should not be overestimated.

\section{ESM}

The ESM pilot study needs to be replicated with a larger population to be able to draw definite conclusions. An objective measure of phone usage should be incorporated in addition to subjective measures. A combination of phone sensor data, as described above, would fulfil the need for objective phone usage measurement and would also provide extra information on, for example, location variance. Furthermore, personality traits could be linked to different responses to mobile phone use. 


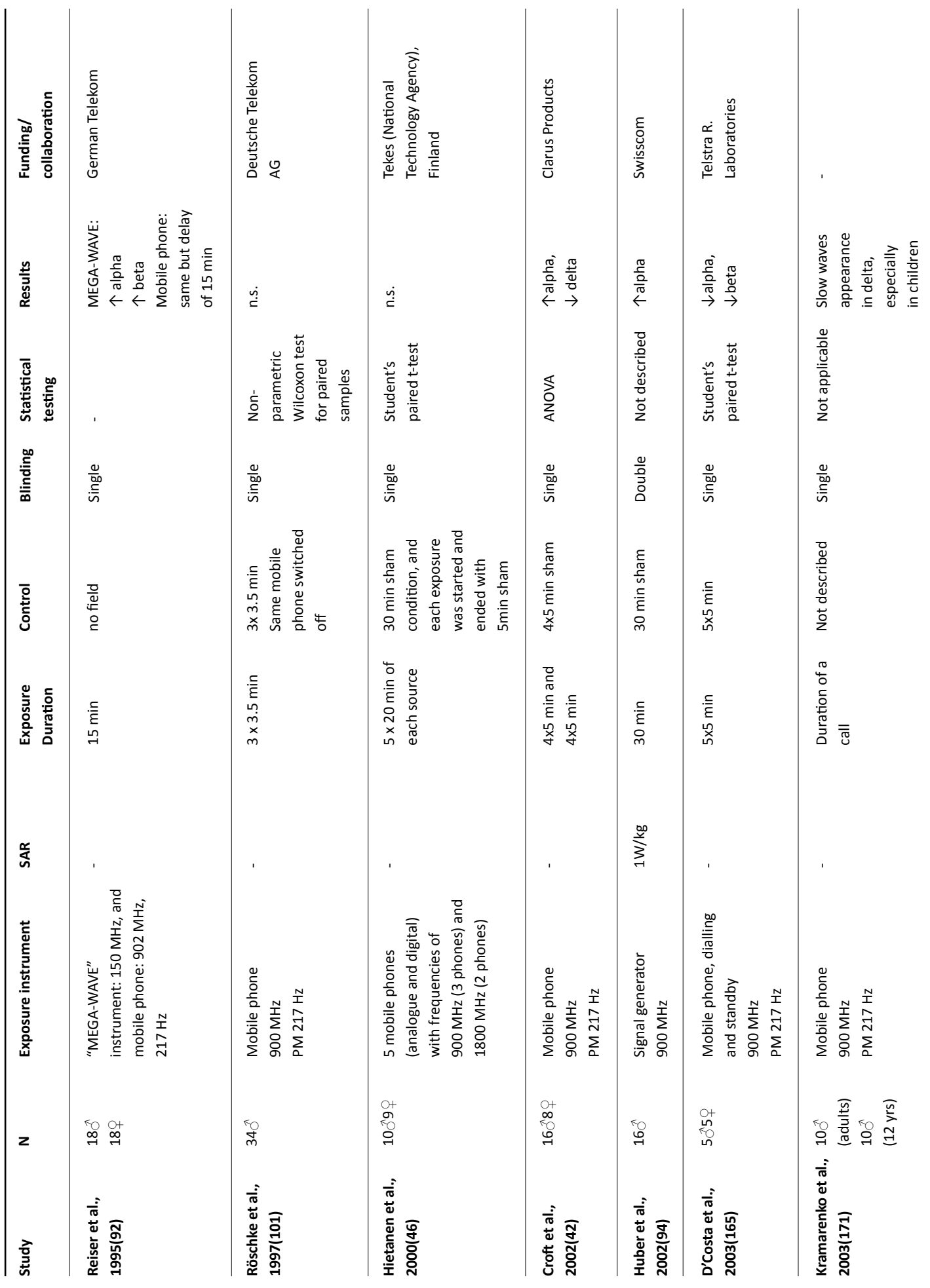




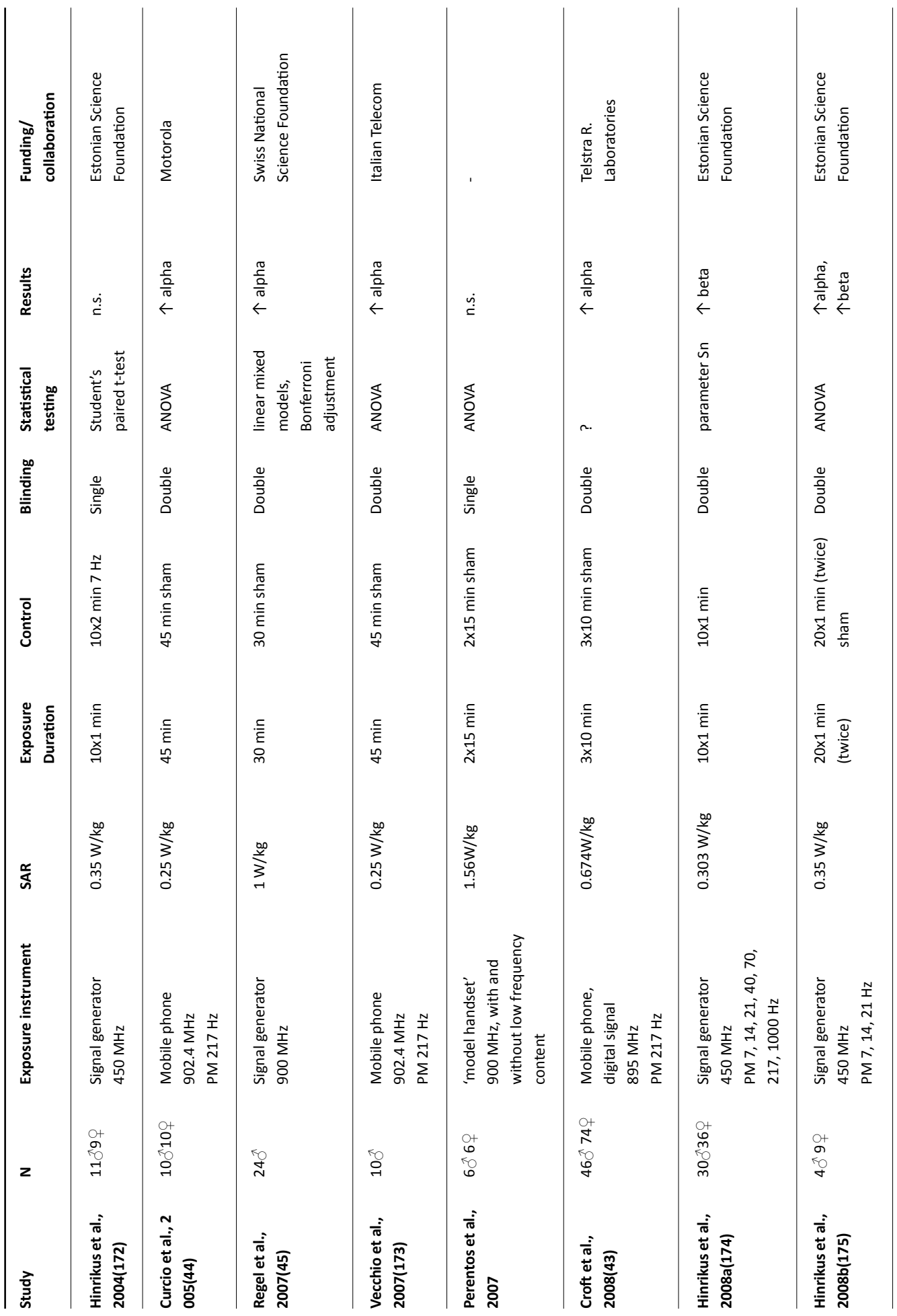




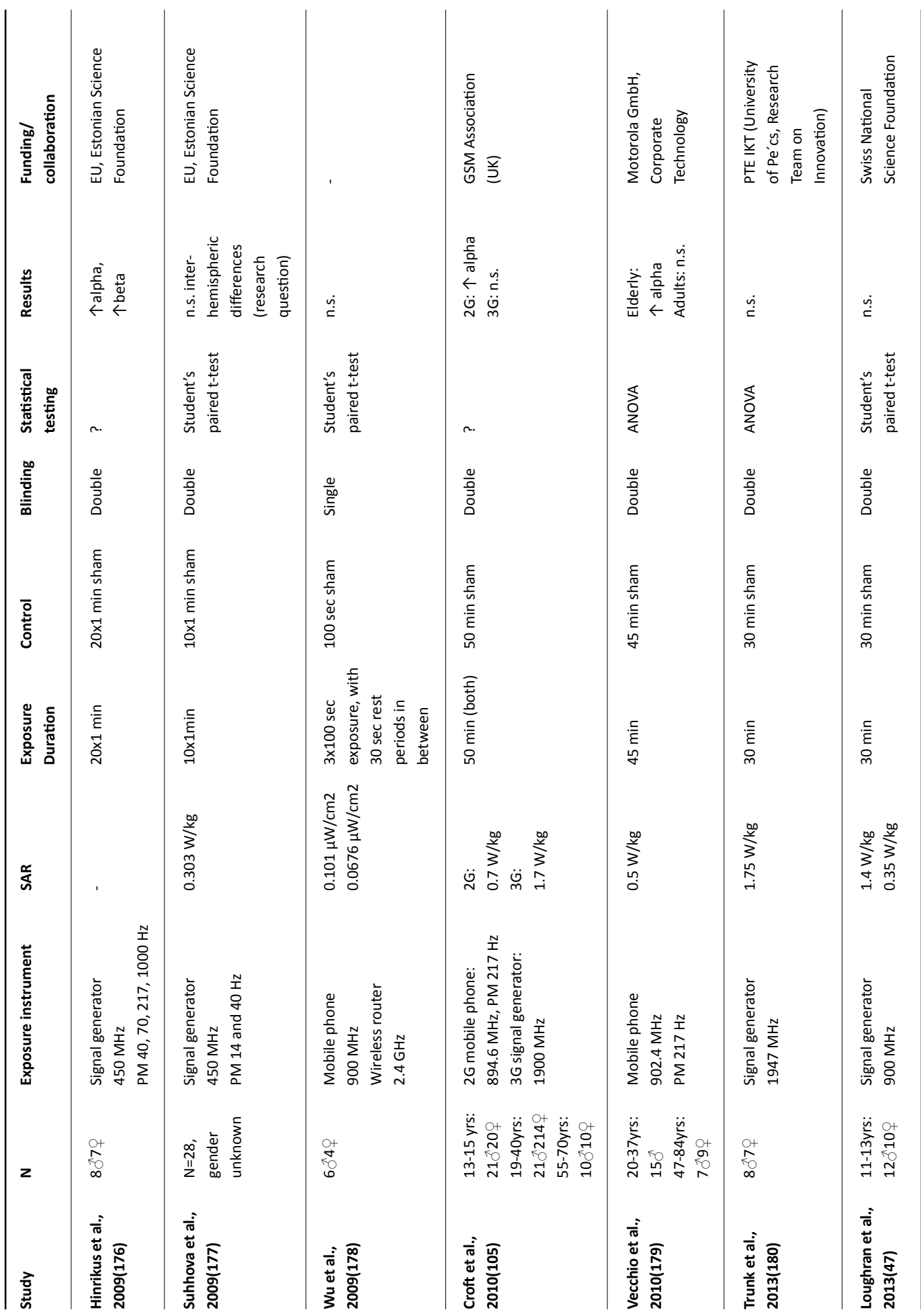




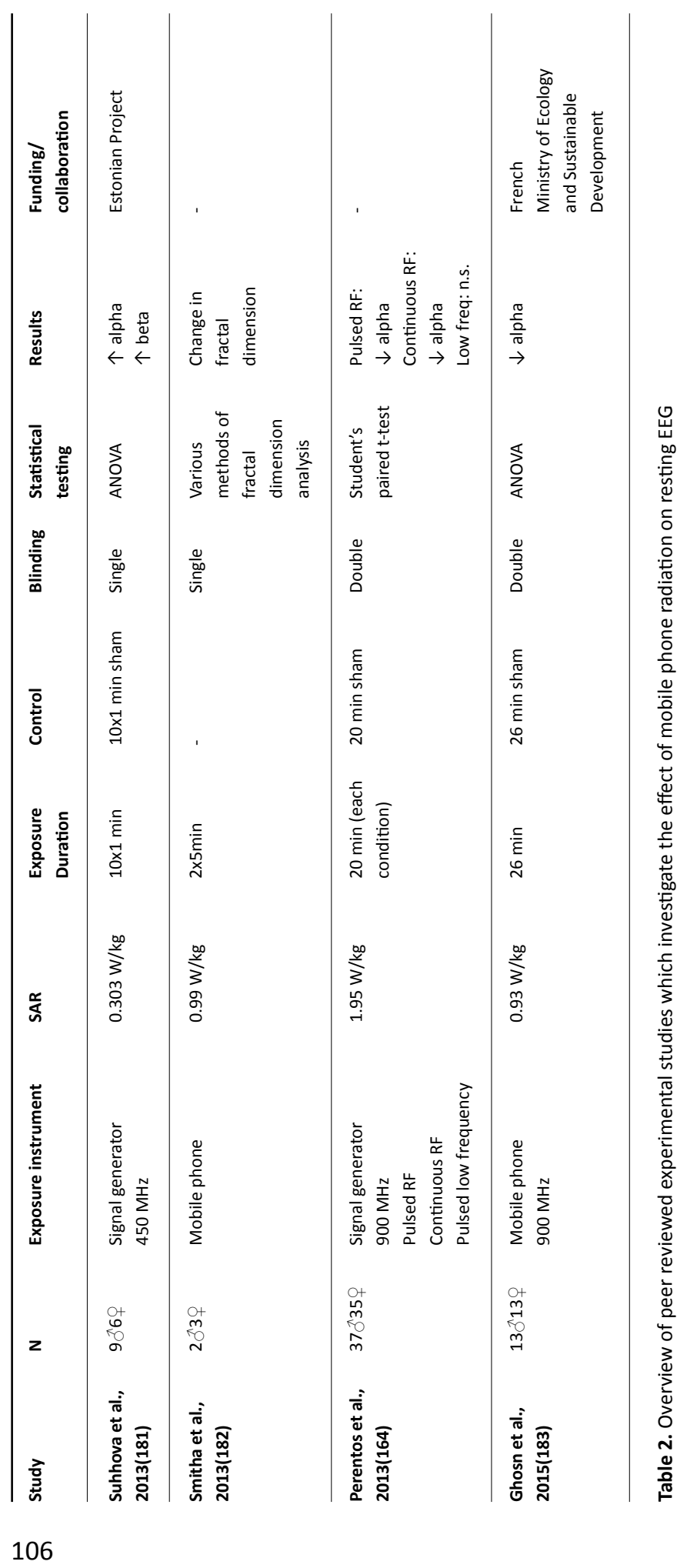




\section{Summary}

\section{Samenvatting}





\section{SUMMARY}

For many people, mobile phones are increasingly becoming an integral part of life. Although the mobile phone is a very efficient communication device with many possibilities, it is unclear whether this relatively new ecological phenomenon has an impact on human health. Its potential impact in several domains is still being investigated. Until now in 2018 there were conflicting findings in the literature. The most important obstacles to finding a definite answer were the following: i) the relatively limited presence of mobile phones and ii) the difficulty of finding a control group for longitudinal research, because almost everybody uses a mobile phone. This thesis focuses on the short-term effects of mobile phones. These short-term effects are being researched, because the obstacle of limited presence does not exist for short-term effects and to provide a basis for future long-term research. Several methods have been used to study how electrophysiological (brain) activity is influenced by the presence of $3 \mathrm{G}$ mobile phone radiation and how a mobile phone interferes with the affect of its user.

Chapter 1 contains the introduction of this thesis. The functioning of a mobile phone is roughly described and the position of mobile phone radiation within the electromagnetic spectrum is presented. Next, it is discussed in what way concerns about possible health effects of mobile phones arose. A short overview of the different lines of investigation of health effects due to mobile phone use in the existing literature is given. Afterwards, the realization of the studies in the subsequent chapters is discussed. A leading theme throughout this thesis is short-term effect research. The presence of a radiation detector, which was connected to the computer; the ERFIA method; and the experience of the department with the experience-sampling method made the research presented in this thesis possible.

Chapter 2 presents the first pilot study, in which the influence of mobile phone radiation on heart frequency is investigated. Heart frequency is not often investigated as a dependent variable (15 studies were encountered in literature at that moment) and setting up this pilot was relatively easy to realize. A mobile phone was placed on the chest of a healthy female participant on four separate days. An ABA-design was applied blinded, in which 15 minutes of exposure to a dialling mobile phone was preceded and followed by 15 minutes of a dummy mobile phone. During the entire experiment, a radiation detector was present, which registered radiation information with a frequency of $1000 \mathrm{~Hz}$ along with electrophysiological heart activity. The obtained data was analysed on two levels: on the so-called macro- and microlevel. Macrolevel encompasses the comparison between heart frequency in the dialling and dummy conditions. Microlevel denotes the direct effect of heart frequency after radiation peaks, as observed with the radiation detector, in comparison with radiation-free moments in the dummy conditions. At the macrolevel, a heart rate decrease of approximately one heartbeat per minute was observed compared 
to the previous 15-minute dummy condition. After the 15-minute exposure, the heart rate increased again by one heart beat per minute. At the microlevel, a decrease directly following a radiation peak was observed, which was a significant finding. A possible explanation for the decrease in heart rate was the activation of the autonomous nervous system due to the mobile phone radiation. Although the heart rate decrease was significant, a decrease of one beat per minute is clinically speaking, irrelevant. Because this was a pilot study with only one participant, no conclusions can be drawn, but the study did provide an impetus for the continuation of research in this field.

Chapter 3 describes the second study. After the significant results of the pilot study, another study with a larger research population was conducted for more evidential value. A total of 31 healthy female participants were included in this study. For each participant, the experiment was conducted on two separate days within a period of four days. On one of the two days, the mobile phone was attached to the ear and on the other day to the chest (at approximately heart height). EEG was included in addition to ECG as an effect parameter. When the data was collected, it became clear that with the existing software, it was not possible to detect ECG peaks reliably for all participants. Therefore, only EEG was used as an effect parameter. The data of this study, like the data of the pilot study, were analysed on two levels: the macro- and microlevel. This led to two articles. The microlevel article is described in chapter 4, and the macrolevel article is described in this chapter. This study again consisted of an ABA design in which the participants were exposed to a dialling $3 G$ mobile phone for 15 minutes. Before and after the exposure condition, they were exposed to a 15-minute dummy mobile phone (the control condition). The EEG was measured using 12 electrodes which were placed on the skull. The different frequency bands that can be distinguished in an EEG measurement ('delta', 'thèta', 'alpha', 'slowbèta', 'fastbèta', and 'gamma') were then calculated. At macrolevel, the difference in EEG frequency bands between the exposure condition in comparison to the control conditions before and after were analysed. Multilevel regression analyses were applied for statistical testing. With this type of statistical testing, it was possible to correct for clustering within the data on the following levels: participant, measurement (first or second), condition (three conditions per measurement), and segment (each condition was divided in 27 segments). Per segment, the average value of the power for the respective EEG frequency band per electrode was calculated. In the analyses, it was necessary to correct for the mutual dependency of these successive segments, since they were highly correlated. This correction was obtained by using an 'autoregressive' (called AR1) covariance structure in the statistical analyses. The use of multilevel regression analyses, which can correct for clustering in the data, was not applied in most of the prior research on EEG effects due to mobile phone radiation. The outcome of this study was a significant increase of the power of the EEG frequency bands of alpha, beta and gamma during the radiation exposed condition compared to the dummy conditions. When only the measurements in which the phone was placed next to the ear 
were analysed, the difference between the exposure and control condition was more obvious and the power of the theta frequency band was significantly increased.

Chapter 4 contains the coverage of the effects on the brain at the microlevel of the study which was described in chapter 3. Like in the pilot study, the radiation detector detected radiation peaks during the dialling exposure conditions and radiation data was measured from millisecond to millisecond. The research question was if these radiation peaks cause a direct brain activity response. To be able to answer this question, the ERFIA technique, derived from the event-related potential (ERP) technique, was used. With this technique, the brain activity directly after a radiation peak (the 'event') is investigated in a time segment (fixed interval). Normally, this technique is used to investigate the electrophysiological processing of stimuli, such as the processing of light or noise stimuli. In this study, it was investigated whether unconsciously observed stimuli of radiation peaks, as measured by the radiation detector, were processed by the brain. This method of research did show a significant brain response compared to randomly chosen fragments from the control conditions. This response was seen most clearly in the frontal region of the brain in the time segment of 240-500 ms after the radiation peak; an increase of electrical activity was observed. On almost all electrodes, but especially in the occipital brain area, a later response in the 500-1000 ms post stimulus was observed. It is important to note that the observed brain response is less prominent in comparison to consciously observed stimuli such as light stimuli. In conclusion, $3 \mathrm{G}$ radiation peaks are observed as a short-lived increase of cortical activity, peaks are thus subconsciously detected by the brain.

Chapter 5 presents the findings of a second multiperson study which investigated the effects of a dialling $3 \mathrm{G}$ mobile phone. A number of methodological adjustments compared to the previous study were made. First, the research population was increased from 31 to 50 participants. Both men and women were included in this study ( 30 females, 20 males). Second, the exposure and control conditions were varied more frequently to obtain more powerful evidence. Every measurement started with a 10-minute baseline condition, followed by a one-hour dialling schedule. In this schedule, dialling was varied with the standby condition. Each participant was assigned an individual dialling schedule: the hour was divided into 30-second segments, and each segment was randomly assigned to either dialling or standby. Third, to avoid entering the investigation room between conditions for a condition switch, the phone conditions were switched from a distance. This was, according to the knowledge available at the time, only feasible when using the standby mode as the control condition instead of a dummy phone as in the previous study. It was believed that the standby condition would offer a good contrast to the dialling phone, since tests conducted before the experiment showed a significantly lower level of radiation for the standby condition compared to the dialling condition. Fourth, it was agreed that each participant would be seen once instead of twice and that the mobile phone would only be placed against the ear. This placement was chosen because the previous study showed that 
this placement had the most influence on brain activity. The data analyses (using multilevel regression analyses) did not show any significant changes between the two conditions. Because this was against the a priori hypothesis, we looked for post-hoc explanations. The main post-hoc explanation was that the standby condition is not a radiation-free condition and therefore not an optimal control condition. In the literature, there is little data on the electrophysiological effects of a standby mobile phone. A second post-hoc explanation is the possible influence of the longer period of radiation exposure on the eyes. This could have influenced the outcomes, because electro-oculogram (EOG) data were used in the statistical models as a covariate. In post-hoc analyses, the removal of the EOG data from the models led to more significant outcomes in line with the previous study.

Chapter 6 covers the pilot study, in which two healthy female participants were offered a short questionnaire according to the ESM during a period of three months, 10 times a day at random moments. The questionnaire was presented to the participants on their smartphone, using a 'beep' sent by the so-called Psymate application. If the participants were not in a position to fill out the questionnaire, the beep was skipped. The beep represented a questionnaire which contained a constant set of questions on the participants' phone usage between the previous and the current beep, on their current emotions and complaints (pain, tiredness, level of concentration), and on the context at that moment (place, people in the surrounding area, activities). ESM makes it possible to link dynamic behavioural and affective patterns during the day to environmental factors like phone usage. This study was designed to investigate whether it is possible to show an association between emotions and phone usage using the ESM method. In this pilot study, a significant relation between mobile phone usage and emotions was found. An increase of phone usage was followed by an increase in negative affect and decrease in positive affect and concentration level. To gain more certainty about these outcomes, the study needs to be replicated with a larger research population.

Chapter 7 contains a general discussion on the contents of this thesis. The contents are integrated and placed within the context of the existing literature on the topic of the thesis. The significance of the outcomes is discussed, discrepancies are outlined and recommendations for future research are given. 


\section{SAMENVATTING}

Mobiele telefoons vormen voor velen, in toenemende mate, een integraal onderdeel van het leven. Hoewel de mobiele telefoon een zeer efficiënt communicatiemiddel is en vele mogelijkheden bevat, bestaat ook de vraag wat de potentiële impact van dit relatief nieuwe, ecologische fenomeen op de gezondheid van de mens is. Om hier achter te komen, wordt op verschillende domeinen onderzocht wat deze impact inhoudt. Tot op heden in 2018, bestaan conflicterende resultaten in de literatuur. De voornaamste obstakels om een eenduidig antwoord te kunnen verkrijgen op de vraag of mobiele telefoons invloed op gezondheid hebben, zijn: i) de relatief korte aanwezigheid van mobiele telefoons en ii) het vinden van een geschikte controlegroep in longitudinaal onderzoek, aangezien vrijwel iedereen tegenwoordig intensief een mobiele telefoon gebruikt. Dit proefschrift richt zich op de effecten van een mobiele telefoon op de korte termijn. Kortetermijneffecten worden onderzocht, omdat het obstakel van de korte aanwezigheid van de mobiele telefoon vervalt en om een basis te kunnen bieden voor toekomstig langetermijnonderzoek. $\mathrm{Er}$ is op verschillende wijzen onderzocht hoe de elektrofysiologische (hersen)activiteit wordt beïnvloed door de aanwezigheid van $3 \mathrm{G}$ mobiele telefoonstraling en daarnaast is onderzocht hoe een mobiele telefoon in het dagelijks leven interfereert met de emoties van de gebruiker.

Hoofdstuk 1 omvat de introductie van dit proefschrift. Er wordt weergegeven hoe een mobiele telefoon grofweg functioneert en welke plaats mobiele telefoonstraling binnen het elektromagnetische spectrum inneemt. Vervolgens wordt besproken op welke wijze de zorgen over gezondheidseffecten als gevolg van mobiel telefoongebruik zijn ontstaan. Er wordt een kort overzicht gegeven van de verschillende onderzoeksrichtingen waarin onderzoek gedaan wordt naar gezondheidseffecten van mobiele telefoons en de tot dusver bekende bevindingen in de literatuur. Daarna wordt ingegaan op de totstandkoming van de studies die in de volgende hoofdstukken worden besproken. Een rode draad door het proefschrift is het onderzoek naar directe kortetermijneffecten. Dit onderzoek was mogelijk door de aanwezigheid van een op de computer aangesloten stralingsmeter, de beschikking over de ERFIA-methode en de ervaring van de vakgroep met de experience sampling methode.

Hoofdstuk 2 presenteert de eerste pilotstudie, waarin wordt onderzocht in hoeverre de hartfrequentie door mobiele telefoonstraling wordt beïnvloed. Hartslag als afhankelijke variabele was destijds nog niet veelvuldig onderzocht (15 studies in de literatuur gevonden op moment van initiatie) en als pilot was het meten van hartslag relatief eenvoudig te realiseren. Een mobiele telefoon werd gedurende vier dagen op de borstkas van een gezonde, vrouwelijke proefpersoon gelegd. Een ABA-design werd geblindeerd toegepast, waarbij een kwartier blootstelling aan een bellende mobiele telefoon werd voorafgegaan en werd gevolgd door een kwartier dummy telefoon. Tijdens het gehele experiment was 
een stralingsmeter aanwezig die gelijktijdig met de elektrofysiologische hartactiviteit iedere milliseconde stralingsinformatie registreerde. De aldus verkregen data werd op twee niveaus onderzocht: op macro- en microniveau. Met macroniveau wordt gedoeld op de vergelijking van hartfrequentie tussen het kwartier dat de mobiele telefoon belt met de dummycondities. Het microniveau duidt op het directe effect van hartfrequentie na stralingspieken, zoals waargenomen met behulp van de stralingsmeter in vergelijking met stralingsvrije momenten uit de dummycondities. Op macroniveau werd een hartslagdaling gevonden van ongeveer een slag per minuut ten opzichte van het voorgaande kwartier in dummyconditie. Na het belaste kwartier steeg de hartslag weer met een slag per minuut. Op microniveau werd gevonden dat de hartslag direct na een stralingspiek daalt, tevens een significante bevinding. Een mogelijke verklaring voor de daling in hartslag is de activatie van het autonome zenuwstelsel door de mobiele telefoonstraling. Hoewel de hartslagdaling significant was, is een daling van een slag per minuut klinisch gezien irrelevant. Op basis van een pilotstudie waarin slechts op één persoon onderzoek is uitgevoerd, mogen geen conclusies worden getrokken. Echter, het onderzoek vormde wel de stimulus om verder onderzoek te doen.

Hoofdstuk 3 beschrijft de tweede studie. Na de significante uitkomsten in het pilotonderzoek werd besloten om meer bewijskracht te verkrijgen door deze volgende studie op een grotere onderzoekspopulatie uit te voeren. In dit onderzoek werden 31 gezonde, vrouwelijke proefpersonen geïncludeerd. Per proefpersoon werd het experiment op twee verschillende dagen, binnen een periode van vier dagen, uitgevoerd. De ene dag werden de mobiele telefoon en de dummytelefoon aan het oor bevestigd en de andere dag op de borst ter hoogte van het hart. Er werd besloten om naast ECG tevens EEG op te nemen als effectparameter. Toen de data verzameld waren, bleek het met de bestaande software niet mogelijk om de ECG-toppen voor alle proefpersonen betrouwbaar te detecteren. Daarom werd besloten uitsluitend EEG als effectparameter te hanteren. Er werd besloten om de data van deze studie, evenals de pilotstudie, opnieuw op macro- en microniveau te bestuderen. Dit leidde tot twee artikelen, waarvan het macroniveau in dit hoofdstuk wordt beschreven en het microniveau in hoofdstuk vier. In deze studie was opnieuw sprake van een ABA-design waarbij de proefpersonen geblindeerd werden blootgesteld aan een 3G-telefoon die gedurende vijftien minuten belde. Voorafgaand aan de bellende telefoon en nadien werden de proefpersonen gedurende vijftien minuten aan een dummytelefoon blootgesteld. Het EEG werd gemeten door 12 elektroden op de schedel te bevestigen. De verschillende frequentiebanden die in een EEG meting zijn te onderscheiden ('delta', 'thèta', 'alfa', 'slowbèta', 'fastbèta', and 'gamma') werden vervolgens berekend. Op macroniveau werd onderzocht wat het effect van de bellende telefoon op deze EEGfrequentiebanden was door de belconditie te vergelijken met de dummycondities. In de analyses werd met behulp van multilevel-regressieanalyses rekening gehouden met de volgende 'clusters': 'proefpersoon', 'meting' (eerste of tweede), 'conditie' (drie condities 
per meting) en 'segment' (iedere conditie was opgedeeld in 27 segmenten). Per segment werd een gemiddelde waarde van de power van de desbetreffende EEG-frequentieband per electrode berekend. In de analyses moest rekening worden gehouden met de onderlinge afhankelijkheid van deze opeenvolgende segmenten, aangezien deze logischerwijs sterk met elkaar gecorreleerd zijn. Dit werd bereikt door een 'autoregressive' (AR1 genoemd) covariantiestructuur te gebruiken in de statistische analyses. Deze methode van analyse (multilevel regressieanalyse), die rekening kan houden met onderliggende clustering in data, is in het merendeel van het onderzoek naar de EEG-effecten van mobiele telefoonstraling, niet toegepast. De uitkomst van deze studie is dat de power van de EEG-frequentiebanden 'alfa', 'bèta' en 'gamma' significant toeneemt gedurende de mobiele telefoonconditie ten opzichte van de dummycondities. Wanneer alleen de metingen worden geanalyseerd waarbij de telefoon aan het oor geplaatst werd, is het verschil tussen bellende telefoon en de controle conditie nog eenduidiger en is tevens de thèta-frequentieband significant in power toegenomen.

Hoofdstuk 4 is de rapportage van de herseneffecten op microniveau van de studie die reeds in hoofdstuk drie werd beschreven. Net als in de pilotstudie werd de stralingsinformatie van milliseconde tot milliseconde geregistreerd gelijktijdig met EEG en werden stralingspieken tijdens het bellen waargenomen. De onderzoeksvraag was of de stralingspieken direct tot een veranderde hersenactiviteit leidden. Om dit te kunnen onderzoeken, werd de ERFIA-techniek toegepast, die is afgeleid van de ERP-techniek. Hierbij wordt gedurende een bepaald tijdssegment (fixed interval) de hersenactiviteit direct volgend op een stralingspiek (event) onderzocht. Normaliter wordt dit soort onderzoek gedaan om de verwerking van bewust waargenomen prikkels zoals lichtflitsen of geluid te kunnen onderzoeken. In deze studie werd onderzocht of de niet bewust waargenomen stralingspieken, gemeten met behulp van de stralingsmeter, ook worden verwerkt en worden opgepikt in de hersenen. Deze opzet leverde een hersenreactie op die significant plaatsvond ten opzichte van willekeurig gekozen fragmenten van hersenactiviteit uit de controle condities. Deze reactie is met name te zien in de frontale regio van de hersenen in het tijdsegment van $240-500$ ms na de prikkel, wanneer een toename aan elektrische activiteit optreedt. Over vrijwel alle electroden, maar met name occipitaal, wordt een latere respons van $500-1000$ ms poststimulus waargenomen. Het is hierbij van belang om op te merken dat de geobserveerde hersenrespons minder prominent is in vergelijking met bewust waargenomen prikkels. Concluderend worden 3G-stralingspieken onbewust door de hersenen waargenomen, wat tot uiting komt door een kortdurende toegenomen corticale activiteit.

Hoofdstuk 5 presenteert de bevindingen van de tweede en grotere studie waarbij opnieuw de effecten van een bellende 3G-telefoon werden onderzocht. Een aantal methodologische aanpassingen ten opzichte van de eerste studie werden doorgevoerd. Ten eerste werd de onderzoekspopulatie vergroot van 31 naar 50 proefpersonen (30 
vrouwen, 20 mannen). Ten tweede werden de bellende-mobiele-telefoonconditie en de controleconditie frequenter afgewisseld voor een sterkere bewijsvoering. ledere meting werd gestart met een tien minuten durende baselineconditie, gevolgd door een belschema van een uur. In dit belschema werd bellen afgewisseld met de stand-by-conditie. Per persoon werd een individueel belschema gemaakt door het uur op te delen in halve minuten en iedere halve minuut gerandomiseerd toe te wijzen aan ofwel bellen ofwel stand-bystand. Ten derde werd besloten om de telefooncondities op afstand te besturen, zodat de onderzoeksruimte niet meer tussentijds betreden hoefde te worden. Dit kon, volgens het inzicht op dat moment, alleen gerealiseerd worden door voor de controleconditie een stand-by-toestand te gebruiken in plaats van een dummytelefoon zoals in de eerdere studie. Enkele tests voorafgaand aan de studie toonden aan dat de straling in de standby-toestand lager was en daarom werd er aangenomen dat standby contrast voor de bellende conditie zou vormen. Ten vierde werd besloten om iedere proefpersoon eenmaal in plaats van tweemaal te zien, waarbij de mobiele telefoon aan het oor werd geplaatst. Deze opzet werd gekozen omdat in studie één was waargenomen dat deze plaatsing het meest teweegbracht op hersenniveau. De data-analyses (met multilevel-regressieanalyse) toonden geen significante verschillen tussen de twee condities. Aangezien deze uitkomst tegen de a-priori verwachting inging, is gezocht naar post-hoc verklaringen. De voornaamste post-hoc verklaring is dat stand-by geen stralingsvrije conditie is en dus geen optimale controleconditie is. In de literatuur is nog weinig onderzoek gedaan naar de effecten van een stand-by mobiele telefoon op hersenactiviteit. Een tweede post-hoc verklaring is dat de ogen onder deze relatief langdurende bestraling ook beïnvloed werden. Hierdoor kunnen de uitkomsten een vertekend beeld hebben gekregen, doordat de data van het gemaakte elektro-oculogram (EOG) als covariaat in de statistische modellen werd opgenomen. In post-hoc analyses bleek dat het verwijderen van EOG uit de modellen tot meer significante uitkomsten leidde in de richting van de voorgaande studie.

Hoofdstuk 6 behandelt de pilotstudie waarin twee gezonde, vrouwelijke proefpersonen gedurende drie maanden dagelijks, tienmaal per dag, een korte vragenlijst volgens de experience sampling methode (ESM) kregen aangeboden. Dit gebeurde via de zogeheten Psymate-applicatie op hun smartphone, waarbij zij gewaarschuwd werden door middel van een 'beep' (een geluid door de mobiele telefoon). Deze vragenlijst werd ingevuld wanneer zij hiertoe in de gelegenheid waren. De beep vertegenwoordigt een vaste serie aan vragen, waarbij wordt gevraagd naar het telefoongebruik tussen de vorige beep en de huidige beep. Daarnaast worden emoties en klachten (pijn, vermoeidheid, mate van concentratie) op dat moment vastgelegd en wordt naar de context (plaats, personen in omgeving en activiteiten) gevraagd. De ESM-methode maakt het mogelijk om dynamische gedragspatronen en affectieve patronen gedurende de dag te linken aan omgevingsfactoren zoals mobiel telefoongebruik. Deze pilotstudie werd opgezet om te onderzoeken of er, middels ESM, een relatie bestaat tussen emoties en telefoongebruik. In deze pilot bleek 
een significante relatie te bestaan tussen telefoongebruik en emoties. Een toename aan telefoongebruik werd gevolgd door een toename van negatief affect en een afname van positief affect en concentratievermogen. Dit onderzoek dient op een grotere populatie te worden uitgevoerd om zekerheid over de gevonden relatie te krijgen.

Hoofdstuk 7 bestaat uit een algemene discussie over de inhoud van dit proefschrift. De inhoud wordt hier geïntegreerd en binnen de context van overig uitgevoerd onderzoek geplaatst. Daarnaast worden de betekenis van de bevindingen en discrepanties besproken en worden aanbevelingen voor de toekomst gedaan. 



\section{VALORIZATION}

The target audience of this thesis is the (potential) mobile phone using community. The societal relevance of this thesis, exploring health effects associated with mobile phone use, is therefore potentially large. The outcomes add knowledge to how mobile phones and the electrophysiology and emotions of human beings interact in the short term. It helps to build a more stable basis of knowledge about this interaction. This thesis explicitly did not aim to investigate whether mobile phone usage is harmful to human health. Ultimately, that would be the goal of mobile phone research but in order to investigate health consequences long term explorative research is required.

There are no specific products or activities in which the outcomes of this thesis are being used. There were product developers of for example radiation shield materials who contacted us to prove the effects of their material, however at this stage of research these issues were not relevant.

What can be called innovative is to have treated a $3 \mathrm{G}$ radiation peak as an 'event', to investigate directly the electrical cerebral response following a radiation peak. Further, statistical methods like multilevel regression analyses were used only very rarely in electrophysiological research. Finally, experience sampling technology has not been used before to investigate mobile phone use.

At the moment of publication of this thesis, the ESM article was under review and it is expected to be published soon. Especially this part of the research deserves a continuation, since it only has been piloted so far with two test subjects. It would be relevant to use more variables like GPS information, add pre and post questionnaires about for example depression and test the subject's personality traits. It has been proposed in the literature that mobile phone usage can become more or less problematic, depending on certain personality traits.

Today, mobile phones are being used very frequent and at an increasingly younger age. So far there is not much knowledge about the influence of mobile phones in the development of children. Therefore it is important to gain more knowledge on the effects of mobile phones on children. We therefore think it is instructive to also set up long term research including children. 


\section{CURRICULUM VITAE}

Suzanne Roggeveen was born on the $17^{\text {th }}$ of December, 1987 in IJmuiden. She grew up in Norg (Drenthe) and attended high school at the dr. Nassau College in Assen from 2000 to 2006. She started medical school at the Maastricht University in 2006. During the scientific participation in the last year of medical school she got involved in research, at first researching habituation on pain. A further research career was aspired and in 2012, she started her PhD training. Therefore she paused her curriculum of medicine during one year. After graduating in January 2014, she worked in the academic hospital of Maastricht and at PsyQ in Heerlen as a resident (ANIOS) psychiatry. In 2015 she started her training to become a general practitioner. 


\section{LIST OF PUBLICATIONS}

Roggeveen S, van Os J, Gielissen J, Mengelers R, Golombeck K, Lousberg R. (2014) Effects of mobile phone radiation on heart rate: a radiation-detector controlled pilot study. PeerJ PrePrints

Roggeveen S, van Os J, Viechtbauer W, Lousberg R. EEG changes due to experimentally induced 3G mobile phone radiation. PLoS One. 2015

Roggeveen S, van Os J, Lousberg R. Does the brain detect $3 \mathrm{G}$ mobile phone radiation peaks? An explorative in-depth analysis of an experimental study. PLoS One. 2015

Roggeveen S, van Os J, Viechtbauer W, van Alphen A, Luijcks R, and Lousberg R. The brain exposed to remote controlled alternating mobile phone conditions: what happens to $E E G$ ? Submitted.

Roggeveen S, van Os J, Viechtbauer W, Bemelmans K, van Poll M, and Lousberg R. Does mobile phone use impact mental state? A pilot study using the experience sampling method. Submitted.

Not related to the content of this thesis:

Vossen CJ, Roggeveen S, Lousberg R. Ik moet geopereerd worden, wat een catastrofe! Bookchapter. Balthasar A.J.R. (Ed.), Probleemgeoriënteerd denken in de pijngeneeskunde Een praktijkboek voor de opleiding en de kliniek. Uitgeverij de Tijdstroom. 2017.

Luijcks R, Vossen CJ, van Os J, Roggeveen S, Hermens HJ and Lousberg R. Impact of childhood trauma on EMG stress reactivity of the trapezius muscle. Medicine (Baltimore). 2016 


\section{DANKWOORD}

Richel, aan jou het eerste woord van dank. Ik zie dit boekje als een product van onze samenwerking en het voelt eigenlijk vreemd dat alleen mijn naam op de titelpagina staat. Wat hebben we intensief samengewerkt: wat hebben we samen veel brainstorms doorlopen, wandelingen gemaakt, analyses gerund en schrijfsessies beleefd. Tijdens deze intensieve samenwerking leerden we elkaar goed kennen. Dank voor jouw (ongevraagde) feedback en voor jouw vriendschap. Ook dank aan jouw familie voor de altijd hartelijke ontvangst en belangstelling.

$\mathrm{Jim}$, het is een eer om jou als promotor te hebben. Ik heb je ervaren als een zeer scherpe, doortastende en, ondanks jouw waanzinnig drukke bestaan, toegankelijke professor. Tijdens ons eerste gesprek zat jij relaxed achterover en kon ik niet anders dan je spontaan tutoyeren! Je bent een inspirator voor collegae en voor patiënten. Veel geluk op jouw nieuwe werkplek in Utrecht.

Op Vijverdal heb ik met een aantal mensen met enige regelmaat samengewerkt. Vanaf het begin, vanaf mijn WESP, leerde ik Carine kennen. Carine, dank voor jouw altijd kritische blik en warme belangstelling. Met Rosan was het eigenlijk vooral gezellig, waarvoor veel dank! Lekker samen lachen deed altijd goed, jammer dat we elkaar tegenwoordig minder vaak zien. Lonneke, veel dank voor onze gezellige avondjes eten en Spaanse lessen, ik hoop dat de bakken tegenslag die je hebt doorgemaakt nu voor bakken geluk zijn verwisseld. Lieve Marga, je bent een grote steun voor het 'lab' op Vijverdal, dank voor de altijd liefdevolle belangstelling en pas een beetje op Richel! Ron, dank voor het altijd mogen binnenlopen: gedurende de afgelopen jaren heb ik je ad hoc de gekste technische/ICT vragen gesteld.

Klaus Golombeck, Wolfgang Viechtbauer, Anne Marsman, Truda Driessen, Deborah Op 't Eijnde, Karel Borkelmans, Frenk Peeters, Philippe Delespaul, Jacqueline Strik, Elaine Scheepers, Mikal van Poll, Kelly Bemelmans, Anouk van Alphen, Trees Soute, Marjan Drukker, Peter, Johan Giellissen, Ron Hellenbrand, Jacco Ronner, Huub Hamers, Kevin van Schaijk, Jenna Arts en natuurlijk alle proefpersonen: dank voor jullie hulp en samenwerking.

Tevens wil ik de leescommissie bedanken voor hun tijd en interesse in mijn proefschrift.

Een groot deel van de promotietijd heb ik niet in Maastricht maar op andere werkplekken doorgebracht: PsyQ Persoonlijkheid Heerlen, TKD groep op de VOHA, Huisartsenpraktijk de ZuiderEs, SEH Tjongerschans en Huisartsenpraktijk Hartvelt: alle collegae dank voor de samenwerking en de belangstelling voor de vordering van mijn wetenschappelijke bezigheden.

Veel dank gaat uit naar mijn familie en vrienden. Hoewel ik besef dat ik niet altijd even attent ben als ver weg wonende, door het land crossende vriendin, is een taak zoals een promotie afronden onmogelijk zonder veel goede afleiding en ik wil jullie bij deze danken voor de bijdrage daaraan! Ik prijs me gelukkig met de mensen die ik lief heb en met wie het direct goed aanvoelt als we dan toch samen zijn. Soes, naast deze afleiding, heb je mij 
ook vaak onderdak geboden en hierdoor de promotie mede mogelijk gemaakt, dank dat je tijdens de verdediging naast mij wilt staan. In augustus zal ik naast jou staan! En Karlijn, carrière technisch gaan we altijd nek aan nek, het is nog de vraag wie het eerst in de verdedigende en wie in de paranimf rol zal staan!

Een bijzondere plaats neemt Jos in: dank voor jouw geweldige steun en hulp de afgelopen tijd en voor onze gezellige Lumière avonden in Maastricht, door jou voel ik me altijd gesteund en heb ik me extra thuis gevoeld toen ik van het hoge noorden naar het zuiden vertrok op mijn $18^{\mathrm{e}}$.

Lieve papa en mama, na jarenlang vrijwel onbezorgd leven hebben wij het de afgelopen jaren niet altijd gemakkelijk gehad. De ziekte van Parkinson is destructief en heeft jullie laatste tijd samen op zijn kop gezet, dit maakt me verdrietig omdat ik jullie graag samen gelukkig oud had zien worden. Dank jullie wel voor de onvoorwaardelijke liefde en zorg voor mij, ik zou niet weten hoe ik hier zonder jullie gekomen zou zijn. Me too from you! ${ }^{2}$

Tot slot: lieve Menno, zondagochtend (verbrand) croissant, poezen onderdompelen, 'in het midden', Jonen, lekker samen koken: niks zo fijn als de gewone dingen samen met jou! Dank voor jouw liefde, grappen en lust voor avontuur, zullen we dit nog een poosje samen voortzetten?

2 Hoewel Kees op het moment van publicatie niet meer leeft, heb ik de tekst ongewijzigd gelaten, omdat hij deze woorden zo heeft gelezen. 


\section{REFERENCES}

1. Heeks R. "Meet Marty Cooper - the inventor of the mobile phone".2010.

2. Worldbank. http://data.worldbank.org/indicator/IT.CEL.SETS.

3. InternationalCommunicationUnion. ICT Facts and Figures. 2015.

4. Maxwell JC. A Dynamical Theory of the Electromagnetic Field. Philosophical Transactions of the Royal Society of London. 1864;155:459-512.

5. Schüz J, Ahlbom A. Exposure to electromagnetic fields and the risk of childhood leukaemia: a review. Radiation protection dosimetry. 2008.

6. ICNIRP. Guidelines for limiting exposure to time-varying electric, magnetic, and electromagnetic fields (up to $300 \mathrm{GHz}$ ). Health Physics. 1998;74(4):494-522.

7. Reuters T. Analysis: A month on, Japan nuclear crisis still scarring2011.

8. Moysich KB, Menezes RJ, Michalek AM. Chernobyl-related ionising radiation exposure and cancer risk: an epidemiological review. The Lancet Oncology. 2002;3(5):269-79.

9. Hall EJ, Brenner DJ. Cancer risks from diagnostic radiology. $\mathrm{Br} J$ Radiol. 2008;81(965):362-78.

10. Fischer SM, Lo HH, Gordon GB, Seibert K, Kelloff G, Lubet RA, et al. Chemopreventive activity of celecoxib, a specific cyclooxygenase- 2 inhibitor, and indomethacin against ultraviolet light-induced skin carcinogenesis. Molecular carcinogenesis. 1999; 25(4):231-40.

11. Ng KH. Non-Ionizing Radiations - Sources, Biological Effects, Emissions and Exposures. Proceedings of the International Conference on Non-lonizing Radiation at UNITEN (ICNIR)2003.

12. Gaestel M. Biological monitoring of non-thermal effects of mobile phone radiation: recent approaches and challenges. Biol Rev Camb Philos Soc. 2010;85(3):489-500.

13. Adair ER, Black DR. Thermoregulatory responses to RF energy absorption. Bioelectromagnetics. 2003;Suppl 6:S17-38.

14. Guy A, Lin J, Kramar P, Emery A. Effect of 2450-MHz radiation on the rabbit eye. Microwave Theory and Techniques, IEEE Transactions on. 1975;23(6):492-8.

15. Brocklehurst B. Free radical mechanism for the effects of environmental electromagnetic fields on biological systems. International journal of radiation biology. 1996;69(1):3-24.

16. Nylund R. Proteomics analysis of human endothelial cells after short-term exposure to mobile phone radiation: Säteilyturvakeskus; 2011.

17. French PW, Penny R, Laurence JA, McKenzie DR. Mobile phones, heat shock proteins and cancer. Differentiation. 2002;67(4-5):93-7.

18. Leszczynski D, Joenväärä $S$, Reivinen J, Kuokka R. Non-thermal activation of the hsp27/p38MAPK stress pathway by mobile phone radiation in human endothelial cells: Molecular mechanism for cancer-and blood-brain barrier-related effects. Differentiation. 2002;70(2-3):120-9. 
19. Desai NR, Kesari KK, Agarwal A. Pathophysiology of cell phone radiation: oxidative stress and carcinogenesis with focus on male reproductive system. Reprod Biol Endocrinol. 2009;7:114.

20. Agarwal A, Singh A, Hamada A, Kesari K. Cell phones and male infertility: a review of recent innovations in technology and consequences. International braz $\mathrm{j}$ urol. 2011;37(4):432-54

21. Sage C, Carpenter DO. Public health implications of wireless technologies. Pathophysiology. 2009;16(2):233-46.

22. Havas M. When theory and observation collide: Can non-ionizing radiation cause cancer? Environmental Pollution. 2017;221:501-5.

23. Yakymenko I, Tsybulin O, Sidorik E, Henshel D, Kyrylenko O, Kyrylenko S. Oxidative mechanisms of biological activity of low-intensity radiofrequency radiation. Electromagn Biol Med. 2016;35(2):186-202.

24. Brain tumour risk in relation to mobile telephone use: results of the INTERPHONE international case-control study. Int J Epidemiol. 2010;39(3):675-94.

25. Acoustic neuroma risk in relation to mobile telephone use: results of the INTERPHONE international case-control study. Cancer Epidemiol. 2011;35(5):453-64.

26. Lönn S, Ahlbom A, Hall P, Feychting M. Long-term mobile phone use and brain tumor risk. American journal of epidemiology. 2005;161(6):526-35.

27. Schoemaker M, Swerdlow A, Ahlbom A, Auvinen A, Blaasaas K, Cardis E, et al. Mobile phone use and risk of acoustic neuroma: results of the Interphone casecontrol study in five North European countries. British Journal of Cancer. 2005;93 (7):842-8.

28. Schüz J, Jacobsen R, Olsen JH, Boice Jr JD, McLaughlin JK, Johansen C. Cellular telephone use and cancer risk: update of a nationwide Danish cohort. Journal of the National Cancer Institute. 2006;98(23):1707-13.

29. Lahkola A, Auvinen A, Raitanen J, Schoemaker MJ, Christensen HC, Feychting M, et al. Mobile phone use and risk of glioma in 5 North European countries. International Journal of Cancer. 2007;120(8):1769-75.

30. Hardell L, Carlberg M, Söderqvist F, Mild KH, Morgan LL. Long-term use of cellular phones and brain tumours: increased risk associated with use for $\geq 10$ years. Occupational and environmental medicine. 2007;64(9):626-32.

31. Hardell L, Carlberg M, Hansson Mild K. Epidemiological evidence for an association between use of wireless phones and tumor diseases. Pathophysiology. 2009;16(23):113-22.

32. Tillmann T. Indication of cocarcinogenic potential of chronic UMTS-modulated radiofrequency exposure in an ethylnitrosourea mouse model. International journal of radiation biology. 2010;86(7):529-41.

33. Coureau G, Bouvier G, Lebailly P, Fabbro-Peray P, Gruber A, Leffondre K, et al. Mobile 
phone use and brain tumours in the CERENAT case-control study. Occupational and environmental medicine. 2014;71(7):514-22.

34. Lönn S, Ahlbom A, Hall P, Feychting M. Mobile phone use and the risk of acoustic neuroma. Epidemiology. 2004;15(6):653.

35. Claman P. Men at risk: occupation and male infertility. Sexuality, Reproduction and Menopause. 2004;2(1):19-26.

36. Vignera S, Condorelli RA, Vicari E, D'Agata R, Calogero AE. Effects of the exposure to mobile phones on male reproduction: a review of the literature. Journal of andrology. 2012;33(3):350-6.

37. Falzone N, Huyser C, Becker P, Leszczynski D, Franken DR. The effect of pulsed 900$\mathrm{MHz}$ GSM mobile phone radiation on the acrosome reaction, head morphometry and zona binding of human spermatozoa. International journal of andrology. 2011;34(1):20-6.

38. Otitoloju A, Obe I, Adewale O, Otubanjo O, Osunkalu V. Preliminary study on the induction of sperm head abnormalities in mice, Mus musculus, exposed to radiofrequency radiations from global system for mobile communication base stations. Bulletin of environmental contamination and toxicology. 2010;84(1):51-4.

39. Kesari KK, Kumar S, Nirala J, Siddiqui MH, Behari J. Biophysical evaluation of radiofrequency electromagnetic field effects on male reproductive pattern. Cell Biochem Biophys. 2013;65(2):85-96.

40. Fakhri Y, Khoei HH, Sistanian F, Moloudizargari M, Adel M, Keramati H, et al. Effects of Electromagnetic Wave from Mobile Phones on Human Sperm Motility and Viability: A Systematic Review and Meta-Analysis. INTERNATIONAL JOURNAL OF MEDICAL RESEARCH \& HEALTH SCIENCES. 2016;5(6):172-82.

41. Divan HA, Kheifets L, Obel C, Olsen J. Prenatal and postnatal exposure to cell phone use and behavioral problems in children. Epidemiology. 2008;19(4):523-9.

42. Croft RJ, Chandler JS, Burgess AP, Barry RJ, Williams JD, Clarke AR. Acute mobile phone operation affects neural function in humans. Clinical Neurophysiology. 2002;113(10):1623-32.

43. Croft R, Hamblin D, Spong J, Wood A, McKenzie R, Stough C. The effect of mobile phone electromagnetic fields on the alpha rhythm of human electroencephalogram. Bioelectromagnetics. 2008;29(1):1-10.

44. Curcio G, Ferrara M, Moroni F, D'inzeo G, Bertini M, De Gennaro L. Is the brain influenced by a phone call?: An EEG study of resting wakefulness. Neuroscience research. 2005;53(3):265-70.

45. Regel SJ, Gottselig JM, Schuderer J, Tinguely G, Rétey JV, Kuster N, et al. Pulsed radio frequency radiation affects cognitive performance and the waking electroencephalogram. Neuroreport. 2007;18(8):803-7.

46. Hietanen $M$, Kovala $T$, Hämäläinen A-M. Human brain activity during exposure to 
radiofrequency fields emitted by cellular phones. Scandinavian journal of work, environment \& health. 2000:87-92.

47. Loughran S, Benz D, Schmid M, Murbach M, Kuster N, Achermann P. No increased sensitivity in brain activity of adolescents exposed to mobile phone-like emissions. Clinical Neurophysiology. 2013;124(7):1303-8.

48. Kleinlogel H, Dierks T, Koenig T, Lehmann H, Minder A, Berz R. Effects of weak mobile phone-Electromagnetic fields (GSM, UMTS) on event related potentials and cognitive functions. Bioelectromagnetics. 2008;29(6):488-97.

49. Kwon MS, Huotilainen M, Shestakova A, Kujala T, Näätänen R, Hämäläinen H. No effects of mobile phone use on cortical auditory change-detection in children: An ERP study. Bioelectromagnetics. 2010;31(3):191-9.

50. Hamblin D, Croft R, Wood A, Stough C, Spong J. The sensitivity of human eventrelated potentials and reaction time to mobile phone emitted electromagnetic fields. Bioelectromagnetics. 2006;27(4):265-73.

51. Carrubba S, Frilot C, Chesson AL, Marino AA. Mobile-phone pulse triggers evoked potentials. Neuroscience letters. 2010;469(1):164-8.

52. Volkow ND, Tomasi D, Wang G-J, Vaska P, Fowler JS, Telang F, et al. Effects of cell phone radiofrequency signal exposure on brain glucose metabolism. JAMA: the journal of the American Medical Association. 2011;305(8):808-13.

53. Persson BR, Eberhardt J, Malmgren L, Persson B, Brun A, Salford G. Effects of microwaves from GSM mobile phones on the blood-brain barrier and neurons in rat brain. PIERS Online. 2005;1(6):638-41.

54. Eberhardt JL, Persson BR, Brun AE, Salford LG, Malmgren LO. Blood-brain barrier permeability and nerve cell damage in rat brain 14 and 28 days after exposure to microwaves from GSM mobile phones. Electromagn Biol Med. 2008;27(3):215-29.

55. Augner C, Gnambs T, Winker R, Barth A. Acute effects of electromagnetic fields emitted by GSM mobile phones on subjective well-being and physiological reactions: A meta-analysis. Science of the total environment. 2012;424:11-5.

56. PÉREZ EJP, RODRÍGUEZ MT. Adicción o abuso del teléfono móvil. Revisión de la literatura. Mobile phone abuse or addiction. A review of the literature. Adicciones. 2012;24(2):139-52.

57. De-Sola Gutiérrez J, Rodríguez de Fonseca F, Rubio G. Cell-Phone Addiction: A Review. Frontiers in Psychiatry. 2016;7:175.

58. Elhai JD, Dvorak RD, Levine JC, Hall BJ. Problematic smartphone use: A conceptual overview and systematic review of relations with anxiety and depression psychopathology. Journal of Affective Disorders.207:251-9.

59. Thomée S, Härenstam A, Hagberg M. Mobile phone use and stress, sleep disturbances, and symptoms of depression among young adults-a prospective cohort study. BMC public health. 2011;11(1):66. 
60. Van den Bulck J. Adolescent use of mobile phones for calling and for sending text messages after lights out: results from a prospective cohort study with a one-year follow-up. Sleep. 2007;30(9):1220.

61. Feychting M. Mobile phones, radiofrequency fields, and health effects in children-epidemiological studies. Prog Biophys Mol Biol. 2011;107(3):343-8.

62. Sadetzki S, Langer CE, Bruchim R, Kundi M, Merletti F, Vermeulen R, et al. The MOBIKids study protocol: challenges in assessing childhood and adolescent exposure to electromagnetic fields from wireless telecommunication technologies and possible association with brain tumor risk. Frontiers in public health. 2014;2.

63. Huss A, Egger M, Hug K, Huwiler-Müntener K, Röösli M. Source of Funding and Results of Studies of Health Effects of Mobile Phone Use: Systematic Review of Experimental Studies. Environmental Health Perspectives. 2006;115(1):1-4.

64. InternationalCommunicationUnion. ICT Facts and Figures. 2011.

65. Ahamed VT, Karthick N, Joseph PK. Effect of mobile phone radiation on heart rate variability. Computers in Biology and Medicine. 2008;38(6):709-12.

66. Andrzejak R, Poreba R, Poreba M, Derkacz A, Skalik R, Gac P, et al. The influence of the call with a mobile phone on heart rate variability parameters in healthy volunteers. Industrial health. 2008;46(4):409-17.

67. Bortkiewicz A, Gadzicka E, Zmyślony M, Szymczak W. Neurovegetative disturbances in workers exposed to $50 \mathrm{~Hz}$ electromagnetic fields. International journal of occupational medicine and environmental health. 2006;19(1):53-60.

68. Kwon MK, Choi JY, Kim SK, Yoo TK, Kim DW. Effects of radiation emitted by WCDMA mobile phones on electromagnetic hypersensitive. 2012.

69. Parazzini M, Ravazzani P, Tognola G, Thuróczy G, Molnar FB, Sacchettini A, et al. Electromagnetic fields produced by GSM cellular phones and heart rate variability. Bioelectromagnetics. 2007;28(2):122-9.

70. Atlasz T, Kellényi L, Kovács P, Babai N, Thuróczy G, Hejjel L, et al. The application of surface plethysmography for heart rate variability analysis after GSM radiofrequency exposure. Journal of biochemical and biophysical methods. 2006;69(1):233-6.

71. Barutcu I, Esen AM, Kaya D, Turkmen M, Karakaya O, Saglam M, et al. Do mobile phones pose a potential risk to autonomic modulation of the heart? Pacing and Clinical Electrophysiology. 2011;34(11):1511-4.

72. Braune S, Riedel A, Schulte-Mönting J, Raczek J. Influence of a Radiofrequency Electromagnetic Field on Cardiovascular and Hormonal Parameters of the Autonomic Nervous System in Healthy Individuals. Radiation Research. 2002;158(3):352-6.

73. Huber R, Schuderer J, Graf T, Jütz K, Borbely AA, Kuster N, et al. Radio frequency electromagnetic field exposure in humans: Estimation of SAR distribution in the brain, effects on sleep and heart rate. Bioelectromagnetics. 2003;24(4):262-76.

74. Nam KC, Lee JH, Noh HW, Cha EJ, Kim NH, Kim DW. Hypersensitivity to RF fields 
emitted from CDMA cellular phones: a provocation study. Bioelectromagnetics. 2009;30(8):641-50.

75. Oftedal G, Straume A, Johnsson A, Stovner LJ. Mobile phone headache: a double blind, sham-controlled provocation study. Cephalalgia. 2007;27(5):447-55.

76. Tahvanainen K, Nino J, Halonen P, Kuusela T, Laitinen T, Laensimies E, et al. Cellular phone use does not acutely affect blood pressure or heart rate of humans. Bioelectromagnetics. 2004;25(2):73-83.

77. Tamer A, Gündüz $\mathrm{H}$, Ozyildirim S. The cardiac effects of a mobile phone positioned closest to the heart. Anadolu Kardiyol Derg. 2009;9(5):380-4.

78. Wilén J, Johansson A, Kalezic N, Lyskov E, Sandström M. Psychophysiological tests and provocation of subjects with mobile phone related symptoms. Bioelectromagnetics. 2006;27(3):204-14.

79. Colak C, Parlakpinar H, Ermis N, Tagluk ME, Colak C, Sarihan E, et al. Effects of electromagnetic radiation from $3 \mathrm{G}$ mobile phone on heart rate, blood pressure and ECG parameters in rats. Toxicology and industrial health. 2012;28(7):629-38.

80. Hietanen $M$, Hämäläinen $A M$, Husman T. Hypersensitivity symptoms associated with exposure to cellular telephones: no causal link. Bioelectromagnetics. 2002;23(4):264-70.

81. http://www.sardatabase.com/.

82. Cardiology TFotESo. Heart rate variability standards of measurement, physiological interpretation, and clinical use. Eur Heart J. 1996;17:354-81.

83. Bergqvist U, Vogel E, Aringer L, Cunningham J, Gobba F, Leitgeb N, et al. Possible health implications of subjective symptoms and electromagnetic fields. A report prepared by a European group of experts for the European Commission, DG V. ARBETE OCH HALSA VETENSKAPLIG SKRIFTSERIE. 1997.

84. InternationalCommunicationUnion. ICT facts and figures 2013.

85. Baan R, Grosse Y, Lauby-Secretan B, El Ghissassi F, Bouvard V, Benbrahim-Tallaa L, et al. Carcinogenicity of radiofrequency electromagnetic fields. The Lancet Oncology. 2011;12(7):624-6.

86. ICNIRP. Exposure to high frequency electromagnetic fields, biological effects and health consequences (100 kHz-300 GHz). ICNIRP. 2009;16.

87. Marino AA, Carrubba $S$. The effects of mobile-phone electromagnetic fields on brain electrical activity: a critical analysis of the literature. Electromagn Biol Med. 2009;28(3):250-74.

88. Kwon MS, Hamalainen $\mathrm{H}$. Effects of mobile phone electromagnetic fields: critical evaluation of behavioral and neurophysiological studies. Bioelectromagnetics. 2011;32(4):253-72.

89. Regel SJ, Achermann P. Cognitive performance measures in bioelectromagnetic research--critical evaluation and recommendations. Environmental health : a global access science source. 2011;10(1):10. 
90. Coggon D. Mobile Telecommunications and Health Research Programme, Report 2012. 2012.

91. van Deventer $E$, van Rongen $E$, Saunders R. WHO research agenda for radiofrequency fields. Bioelectromagnetics. 2011;32(5):417-21.

92. Reiser H, Dimpfel W, Schober F. The influence of electromagnetic fields on human brain activity. European journal of medical research. 1995;1(1):27-32.

93. Valentini E, Curcio G, Moroni F, Ferrara M, De Gennaro L, Bertini M. Neurophysiological effects of mobile phone electromagnetic fields on humans: a comprehensive review. Bioelectromagnetics. 2007;28(6):415-32.

94. Huber R, Treyer V, Borbely A, Schuderer J, Gottselig J, Landolt HP, et al. Electromagnetic fields, such as those from mobile phones, alter regional cerebral blood flow and sleep and waking EEG. Journal of sleep research. 2002;11(4):289-95.

95. Regel SJ, Tinguely G, Schuderer J, Adam M, Kuster N, LANDOLT HP, et al. Pulsed radiofrequency electromagnetic fields: dose-dependent effects on sleep, the sleep EEG and cognitive performance. Journal of sleep research. 2007;16(3):253-8.

96. Hall JE. Guyton and Hall Textbook of Medical Physiology: Enhanced E-book: Elsevier Health Sciences; 2010.

97. Kleinlogel $H$, Dierks $T$, Koenig $T$, Lehmann $H$, Minder A, Berz R. Effects of weak mobile Phone-Electromagnetic fields (GSM, UMTS) on well-being and resting EEG. Bioelectromagnetics. 2008;29(6):479-87.

98. Cacot P, Tesolin B, Sebban C. Diurnal variations of EEG power in healthy adults. Electroencephalography and clinical neurophysiology. 1995;94(5):305-12.

99. Jasper $\mathrm{H}$. Report of the committee on methods of clinical examination in electroencephalography. Electroencephalogr Clin Neurophysiol. 1958;10:370-5.

100. Carrubba S, Frilot li C, Chesson Jr AL, Marino AA. Evidence of a nonlinear human magnetic sense. Neuroscience. 2007;144(1):356-67.

101. Roeschke J, Mann K. No short-term effects of digital mobile radio telephone on the awake human electroencephalogram. Bioelectromagnetics. 1997;18(2):172-6.

102. Perentos N, Croft RJ, McKenzie RJ, Cvetkovic D, Cosic I. Comparison of the effects of continuous and pulsed mobile phone like RF exposure on the human EEG. Australas Phys Eng Sci Med. 2007;30(4):274-80.

103. Trunk A, Stefanics G, Zentai N, Kovács-Bálint Z, Thuróczy G, Hernádi I. No effects of a single 3G UMTS mobile phone exposure on spontaneous EEG activity, ERP correlates, and automatic deviance detection. Bioelectromagnetics. 2013;34(1):31-42.

104. Loughran S, Benz D, Schmid M, Murbach M, Kuster N, Achermann P. No increased sensitivity in brain activity of adolescents exposed to mobile phone-like emissions. Clinical Neurophysiology. 2013.

105. Croft R, Leung S, McKenzie R, Loughran S, Iskra S, Hamblin D, et al. Effects of $2 G$ and $3 G$ mobile phones on human alpha rhythms: Resting EEG in adolescents, young 
adults, and the elderly. Bioelectromagnetics. 2010;31(6):434-44.

106. Bland JM, Altman DG. Multiple significance tests: the Bonferroni method. Bmj. 1995;310(6973):170.

107. Bollimunta A, Mo J, Schroeder CE, Ding M. Neuronal mechanisms and attentional modulation of corticothalamic alpha oscillations. The Journal of Neuroscience. 2011;31(13):4935-43.

108. Lopes da Silva F. Neural mechanisms underlying brain waves: from neural membranes to networks. Electroencephalography and clinical neurophysiology. 1991;79(2):8193.

109. Gultekin DH, Moeller L. NMR imaging of cell phone radiation absorption in brain tissue. Proceedings of the National Academy of Sciences of the United States of America. 2013;110(1):58-63.

110. Borbely AA, Huber R, Graf T, Fuchs B, Gallmann E, Achermann P. Pulsed high-frequency electromagnetic field affects human sleep and sleep electroencephalogram. Neurosci Lett. 1999;275(3):207-10.

111. Loughran SP, McKenzie RJ, Jackson ML, Howard ME, Croft RJ. Individual differences in the effects of mobile phone exposure on human sleep: rethinking the problem. Bioelectromagnetics. 2012;33(1):86-93.

112. Lowden A, Åkerstedt T, Ingre M, Wiholm C, Hillert L, Kuster N, et al. Sleep after mobile phone exposure in subjects with mobile phone-related symptoms. Bioelectromagnetics. 2011;32(1):4-14.

113. Valentini E, Curcio G, Moroni F, Ferrara M, De Gennaro L, Bertini M. Neurophysiological effects of mobile phone electromagnetic fields on humans: a comprehensive review. Bioelectromagnetics. 2007;28(6):415-32.

114. Parazzini M, Tognola G, Franzoni C, Grandori F, Ravazzani P. Modeling of the internal fields distribution in human inner hearing system exposed to 900 and $1800 \mathrm{MHz}$. IEEE Trans Biomed Eng. 2007;54(1):39-48.

115. Carrubba S, Frilot II C, Chesson Jr AL, Marino AA. Mobile-phone pulse triggers evoked potentials. Neuroscience letters. 2010;469(1):164-8.

116. Shevrin H. Event-related markers of unconscious processes. Int J Psychophysiol. 2001;42(2):209-18

117. Roggeveen S, van Os J, Viechtbauer W, Lousberg R. EEG changes due to experimentally induced $3 \mathrm{G}$ mobile phone radiation. submitted. 2014.

118. Vossen CJ, Vossen HG, Marcus MA, van Os J, Lousberg R. Introducing the Event Related Fixed Interval Area (ERFIA) Multilevel Technique: a Method to Analyze the Complete Epoch of Event-Related Potentials at Single Trial Level. PloS one. 2013;8(11):e79905.

119. Dobbs R, Manyika J, (2015) WJ. No ordinary disruption: The four global forces breaking all the trends. First edition ed. New York: PublicAffairs; 2015.

120. Union IT. International Mobile Telecommunications 2000 (IMT-2000) Project. 
121. Marino AA, Carrubba $S$. The effects of mobile-phone electromagnetic fields on brain electrical activity: a critical analysis of the literature. Electromagn Biol Med. 2009;28(3):250-74

122. Green AC, Kheifets L, Savitz DA. ICNIRPSCIREVIEW. Environ Health Perspect. 2011;119(11):1534-8.

123. Roggeveen S, van Os J, Viechtbauer W, Lousberg R. EEG changes due to experimentally induced 36 mobile phone radiation. PLOS One. 2015.

124. Roggeveen S, van Os J, Lousberg R. Does the brain detect $3 \mathrm{G}$ mobile phone radiation peaks? An explorative in-depth analysis of an experimental study PLOS One. 2015.

125. H J. Report of the committee on methods of clinical examination in electroencephalography: 1957. Electroencephalography and Clinical Neurophysiology. 1958;10(2):3705.

126. Weaver and company TC, Neurodiagnostic Electrode Paste.

127. Roggeveen S, van Os J, Viechtbauer W, Lousberg R. EEG Changes Due to Experimentally Induced 3G Mobile Phone Radiation. PloS one. 2015;10(6):e0129496.

128. Ni S, Yu Y, Zhang Y, Wu W, Lai K, Yao K. Study of oxidative stress in human lens epithelial cells exposed to $1.8 \mathrm{GHz}$ radiofrequency fields. 2013.

129. Hancock $P$, Lesch $M$, Simmons $L$. The distraction effects of phone use during a crucial driving maneuver. Accident Analysis \& Prevention. 2003;35(4):501-14.

130. Wang J, lannotti RJ, Nansel TR. School bullying among adolescents in the United States: Physical, verbal, relational, and cyber. Journal of Adolescent health. 2009;45(4):368-75.

131. Bianchi A, Phillips JG. Psychological predictors of problem mobile phone use. CyberPsychology \& Behavior. 2005;8(1):39-51.

132. Toda M, Monden K, Kubo K, Morimoto K. [Cellular phone dependence tendency of female university students]. Nihon eiseigaku zasshi Japanese journal of hygiene. 2004;59(4):383-6.

133. Billieux J, Van der Linden M, Rochat L. The role of impulsivity in actual and problematic use of the mobile phone. Applied Cognitive Psychology. 2008;22(9):1195-210.

134. Igarashi T, Motoyoshi T, Takai J, Yoshida T. No mobile, no life: Self-perception and textmessage dependency among Japanese high school students. Computers in Human Behavior. 2008;24(5):2311-24.

135. Jenaro C, Flores N, Gómez-Vela M, González-Gil F, Caballo C. Problematic internet and cell-phone use: Psychological, behavioral, and health correlates. Addiction research \& theory. 2007;15(3):309-20.

136. Chóliz M. Mobile-phone addiction in adolescence: the test of mobile phone dependence (TMD). Prog Health Sci. 2012;2(1):33-44.

137. Rutland JB, Sheets T, Young T. Development of a scale to measure problem use of short message service: the SMS problem use diagnostic questionnaire. CyberPsychology \& Behavior. 2007;10(6):841-4. 
138. Walsh SP, White KM, McD Young R. Needing to connect: The effect of self and others on young people's involvement with their mobile phones. Australian Journal of Psychology. 2010;62(4):194-203.

139. Yen C-F, Tang T-C, Yen J-Y, Lin H-C, Huang C-F, Liu S-C, et al. Symptoms of problematic cellular phone use, functional impairment and its association with depression among adolescents in Southern Taiwan. Journal of Adolescence. 2009;32(4):863-73.

140. Martinotti G, Villella C, Di Thiene D, Di Nicola M, Bria P, Conte G, et al. Problematic mobile phone use in adolescence: a cross-sectional study. Journal of Public Health. 2011;19(6):545-51.

141. Kwon M, Kim D-J, Cho H, Yang S. The smartphone addiction scale: development and validation of a short version for adolescents. PloS one. 2013;8(12):e83558.

142. Billieux J. Problematic use of the mobile phone: a literature review and a pathways model. Current Psychiatry Reviews. 2012;8(4):299-307.

143. Bragazzi NL, Del Puente G. A proposal for including nomophobia in the new DsM-V. Psychology research and behavior management. 2014;7:155.

144. Przybylski AK, Murayama K, DeHaan CR, Gladwell V. Motivational, emotional, and behavioral correlates of fear of missing out. Computers in Human Behavior. 2013;29(4):1841-8.

145. Ha JH, Chin B, Park D-H, Ryu S-H, Yu J. Characteristics of excessive cellular phone use in Korean adolescents. CyberPsychology \& Behavior. 2008;11(6):783-4.

146. Sánchez-Martínez M, Otero A. Factors associated with cell phone use in adolescents in the community of Madrid (Spain). CyberPsychology \& Behavior. 2009;12(2):131-7.

147. Al-Khlaiwi T, Meo SA. Association of mobile phone radiation with fatigue, headache, dizziness, tension and sleep disturbance in Saudi population. Saudi medical journal. 2004;25(6):732-6.

148. Eduardo PP, Teresa M, Monje R, María J, Sanchez R, León D. Mobile Phone Abuse Or Addiction. A Review Of The Literature. Adicciones. 2012;24(2).

149. Walsh SP, White KM, Young RM. Over-connected? A qualitative exploration of the relationship between Australian youth and their mobile phones. Journal of Adolescence. 2008;31(1):77-92.

150. Ehrenberg A, Juckes S, White KM, Walsh SP. Personality and self-esteem as predictors of young people's technology use. CyberPsychology \& Behavior. 2008;11(6):739-41.

151. Butt S, Phillips JG. Personality and self reported mobile phone use. Computers in Human Behavior. 2008;24(2):346-60.

152. Hassan E. Recall bias can be a threat to retrospective and prospective research designs. The Internet Journal of Epidemiology. 2006;3(2):339-412.

153. Larson R, Csikszentmihalyi M. "The experience sampling method". New Directions for Methodology of Social and Behavioral Science. 1983;15:41-56.

154. Van Os J, Verhagen S, Marsman A, Peeters F, Bak M, Marcelis M, et al. The Experience 
Sampling Method as an mHealth Tool to Support Self-monitoring, Self-Insight and Personalised Health Care in Clinical Practice. Depress Anxiety. 2017; in press.

155. Oftedal G, Wilen J, Sandström M, Mild KH. Symptoms experienced in connection with mobile phone use. Occupational medicine. 2000;50(4):237-45.

156. Delespaul P. Assessing Schizophrenia in Daily Life: The Experience Sampling Method. Maastricht: Maastricht University Medical Centre; 1995.

157. Corp. I. IBM SPSS Statistics for Windows. 22.0 ed. Armonk, NY: IBM Corp.2013.

158. Delespaul P. Assessing schizophrenia in daily life: The experience sampling method. 1995.

159. Billieux J, Maurage P, Lopez-Fernandez O, Kuss DJ, Griffiths MD. Can disordered mobile phone use be considered a behavioral addiction? An update on current evidence and a comprehensive model for future research. Current Addiction Reports. 2015;2(2):156-62.

160. Myin-Germeys I, Oorschot M, Collip D, Lataster J, Delespaul P, van Os J. Experience sampling research in psychopathology: opening the black box of daily life. Psychological medicine. 2009;39(09):1533-47.

161. www.psymate.eu.

162. Greenland S. Principles of multilevel modelling. Int J Epidemiol. 2000;29(1):158-67.

163. Choi SB, Kwon MK, Chung JW, Park JS, Chung K, Kim DW. Effects of short-term radiation emitted by WCDMA mobile phones on teenagers and adults. BMC public health. 2014;14(1):438.

164. Perentos N, Croft RJ, McKenzie RJ, Cosic I. The alpha band of the resting electroencephalogram under pulsed and continuous radio frequency exposures. Biomedical Engineering, IEEE Transactions on. 2013;60(6):1702-10.

165. D'Costa H, Trueman G, Tang L, Abdel-Rahman U, Abdel-Rahman W, Ong K, et al. Human brain wave activity during exposure to radiofrequency field emissions from mobile phones. Australasian Physics \& Engineering Sciences in Medicine. 2003;26(4):162-7.

166. Balik HH, Turgut-Balik D, Balikci K, Ozcan IC. Some ocular symptoms and sensations experienced by long term users of mobile phones. Pathologie-biologie. 2005;53(2):8891.

167. Elder J. Ocular effects of radiofrequency energy. Bioelectromagnetics. 2003;24(S6).

168. Lee $\mathrm{Y}-\mathrm{K}$, Chang $\mathrm{C}-\mathrm{T}$, Lin $\mathrm{Y}, \mathrm{Cheng} \mathrm{Z}-\mathrm{H}$. The dark side of smartphone usage: Psychological traits, compulsive behavior and technostress. Computers in Human Behavior. 2014;31:373-83.

169. Saeb S, Zhang M, Karr CJ, Schueller SM, Corden ME, Kording KP, et al. Mobile phone sensor correlates of depressive symptom severity in daily-life behavior: an exploratory study. Journal of medical Internet research. 2015;17(7):e175.

170. Schonborn F, Burkhardt M, Kuster N. Differences in energy absorption between heads of adults and children in the near field of sources. Health Physics. 1998;74(2):160-8. 
171. Kramarenko AV, Tan U. Effects of high-frequency electromagnetic fields on human EEG: a brain mapping study. International Journal of Neuroscience. 2003;113(7):100719.

172. Hinrikus $H$, Parts $M$, Lass J, Tuulik V. Changes in human EEG caused by low level modulated microwave stimulation. Bioelectromagnetics. 2004;25(6):431-40.

173. Vecchio F, Babiloni C, Ferreri F, Curcio G, Fini R, Del Percio C, et al. Mobile phone emission modulates interhemispheric functional coupling of EEG alpha rhythms. The European journal of neuroscience. 2007;25(6):1908-13.

174. Hinrikus H, Bachmann M, Lass J, Karai D, Tuulik V. Effect of low frequency modulated microwave exposure on human EEG: individual sensitivity. Bioelectromagnetics. 2008;29(7):527-38.

175. Hinrikus H, Bachmann M, Lass J, Tomson R, Tuulik V. Effect of 7, 14 and $21 \mathrm{~Hz}$ modulated $450 \mathrm{MHz}$ microwave radiation on human electroencephalographic rhythms. International journal of radiation biology. 2008;84(1):69-79.

176. Hinrikus $H$, Bachmann M, Lass J, Tuulik V. Effect of modulated at different low frequencies microwave radiation on human EEG. The Environmentalist. 2009;29(2):215-9.

177. Suhhova A, Bachmann M, Lass J, Karai D, Hinrikus H. Effect of modulated microwave radiation on human EEG asymmetry. The Environmentalist. 2009;29(2):210-4.

178. Wu K, Sajad A, Omar S. The effect of high frequency radio waves on human brain activity: an EEG study. University of Toronto Journal of Undergraduate Life Sciences. 2009;3(1).

179. Vecchio F, Babiloni C, Ferreri F, Buffo P, Cibelli G, Curcio G, et al. Mobile phone emission modulates inter-hemispheric functional coupling of EEG alpha rhythms in elderly compared to young subjects. Clinical Neurophysiology. 2010;121(2):163-71.

180. Trunk A, Stefanics G, Zentai N, Kovács-Bálint Z, Thuróczy G, Hernádi I. No effects of a single 3G UMTS mobile phone exposure on spontaneous EEG activity, ERP correlates, and automatic deviance detection. Bioelectromagnetics. 2013;34(1):31-42.

181. Suhhova A, Bachmann M, Karai D, Lass J, Hinrikus H. Effect of microwave radiation on human EEG at two different levels of exposure. Bioelectromagnetics. 2013;34(4):26474.

182. Smitha C, Narayanan N, editors. Study of brain dynamics under mobile phone radiation using various fractal dimension methods. Signal Processing Image Processing \& Pattern Recognition (ICSIPR), 2013 International Conference on; 2013: IEEE.

183. Ghosn R, Yahia-Cherif L, Hugueville L, Ducorps A, Lemarechal J-D, Thuróczy G, et al. Radiofrequency signal affects alpha band in resting electroencephalogram. Journal of neurophysiology. 2015;113(7):2753-9. 
